


\section{Propositions}

1. Auditors have explicit and implicit values that inform their practices, and without understanding those values, one cannot understand what happens during an audit.

(this thesis)

2. Informational governance as a concept requires a much broader and deeper empirical body before it can be actionable.

(this thesis)

3. Dramaturgy is a valuable framework for organizational studies, particularly in times of organizational crisis.

4. The fields of conservation science and development studies do not currently consider the values that underpin their methods of evaluating impacts but would benefit from doing so.

5. Society has yet to meaningfully reckon with the tension between the consumerist nature of ecolabels and the principles of those labels.

6. Eco-labels are in danger of becoming business-as-usual rather than tools to change the behaviour of society.

Propositions belonging to the thesis, entitled

The role of auditing at the nexus between global certification standards and local forest practices

William Cook

Wageningen, 28 October 2021 
The role of auditing at the nexus between global certification standards and local forest practices

William C. Cook 


\section{Thesis Committee}

\section{Promotor}

Prof. Dr E. Turnhout

Personal chair at Forest and Nature Conservation Policy

Wageningen University \& Research

\section{Co-promotor}

Dr S. van Bommel

Senior Lecturer, Rural Development \& Agriculture

The University of Queensland, Australia

\section{Other members}

Dr A. Esguerra, University of Bielefeld, Germany

Prof. Dr A. Gupta, Wageningen University \& Research

Dr T.A.P. Metze, Wageningen University \& Research

Prof. Dr D. Sheil, Wageningen University \& Research

This research was conducted under the auspices of the Wageningen School of Social Sciences 


\title{
The role of auditing at the nexus between global certification standards and local forest practices
}

\author{
William C. Cook
}

\section{Thesis}

submitted in fulfilment of the requirements for the degree of doctor at Wageningen University

by the authority of the Rector Magnificus,

Prof. Dr A.P.J. Mol,

in the presence of the

Thesis Committee appointed by the Academic Board

to be defended in public

on Thursday 28 October 2021

at 11 a.m. in the Aula. 
William C. Cook

The role of auditing at the nexus between global certification standards and local forest practices 123 pages.

PhD thesis, Wageningen University, Wageningen, the Netherlands (2021)

With references, with summary in English

ISBN 978-94-6395-894-3

DOI https://www.doi.org/10.18174/549944 


\section{Acknowledgements}

There are several (groups of) people without whom I would have never been able to complete this thesis. I would like to extend my heartfelt gratitude to them.

First to my supervisors, Esther Turnhout and Séverine van Bommel. Thank you from the bottom of my heart. You are without a doubt two of the most keen-minded, helpful, and, above all, patient people I have ever have the pleasure of knowing. I am forever indebted to you for your near infinite well of tolerance for my delays and difficulties. You two make an absolutely stellar team, each complimenting and bolstering the other's strengths. I sincerely hope that, though on the other side of the world from each other now, you will continue to collaborate and produce the insightful contributions to academia that I have had the pleasure of seeing.

Next to my wife, Mona. Thank you for your actually infinite well of patience. We married when I had just started my PhD work, and it took me nearly a decade to complete it. You have been an enormous source of support for me, both practically and emotionally. I doubt you knew what you were getting yourself into when all this started, and so I want to thank you. For everything.

To my boys: Maybe you will read this someday. Then we can laugh at what a pedant your dad was, or probably still is. You two bring happiness into my life. Thank you.

To round out the personal acknowledgements, I would like to thank my parents and my brother. Without you, I would not have pursued the life I did. I am grateful for my upbringing and the values you instilled in me. Without that, I would not have gotten this far.

For fear of missing out on specific acknowledgements, I would like to also extend my appreciation to everyone at Wageningen University, the Forest and Nature Conservation Policy chairgroup, and FSC for their contributions to completing this thesis.

And finally, I would like to thank all the people around the world who let me observe them as they brought the FSC normative documents to vivid life. Truly, without you, this thesis would not have happened. 


\section{Table of Contents}

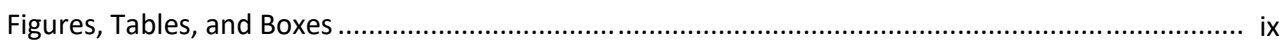

Chapter 1. Introduction ………………................................................................................. 1

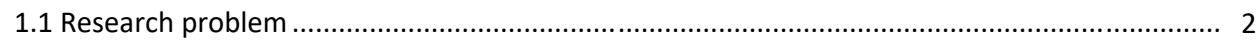

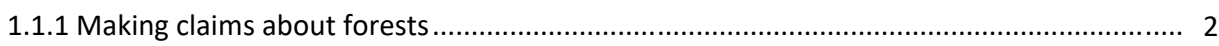

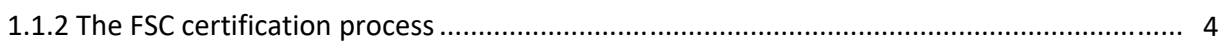

1.1.3 Auditing: the nexus between global standards and local forest practices ......................... 5

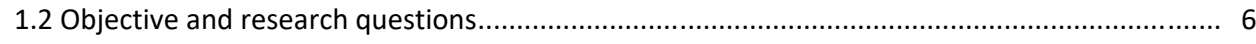

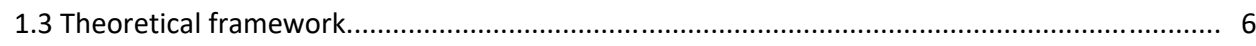

1.3.1 Certification as informational governance …................................................................ 7

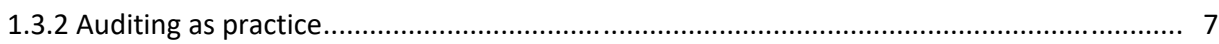

1.3.3 Critical transparency and auditing studies................................................................. 8

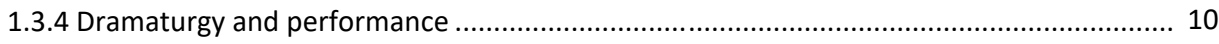

1.3.5 Friction and alignment at the global-local nexus......................................................... 11

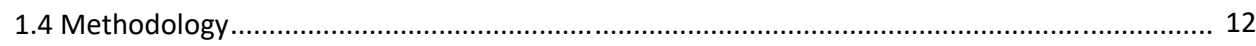

1.4.1 Conceptualization: Constructivism, interpretivism, and qualitative research ................... 12

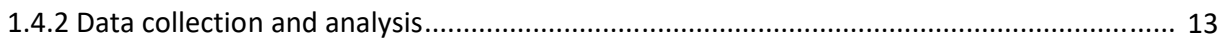

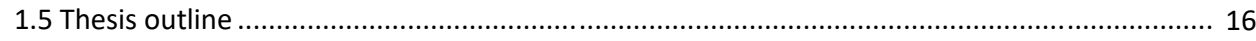

Chapter 2. Inside Environmental Auditing: Effectiveness, Objectivity, and Transparency.................. 19

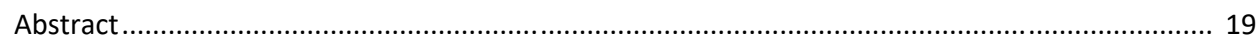

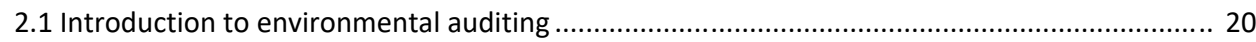

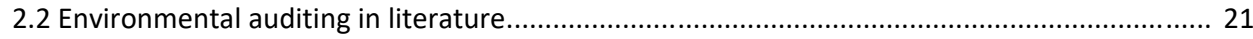

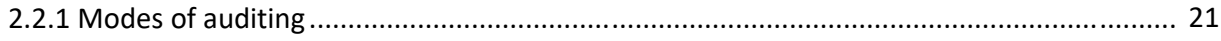

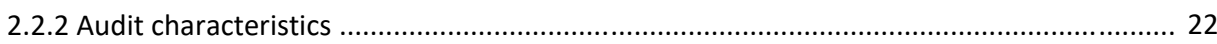

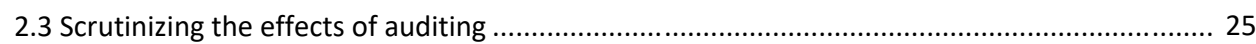

Chapter 3. Learning to Become an FSC Auditor: Objectivity, Interpretation, and Mastery ................. 29

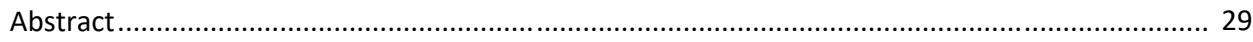

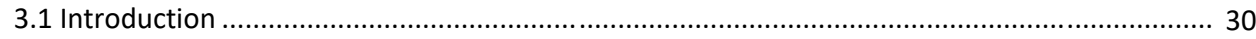

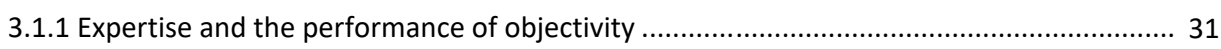

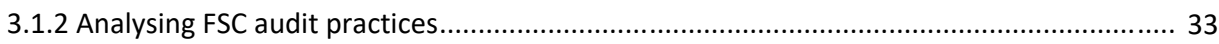

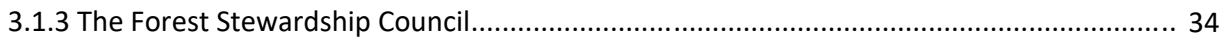

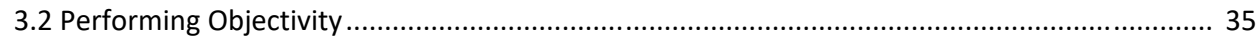

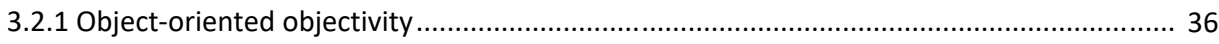

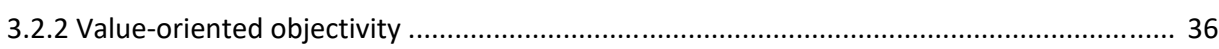

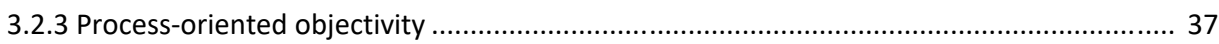

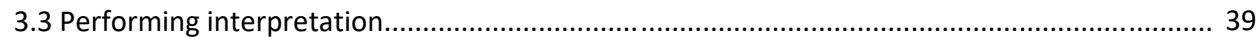




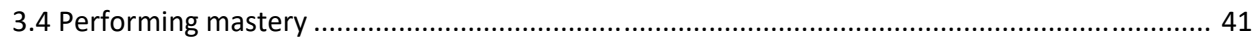

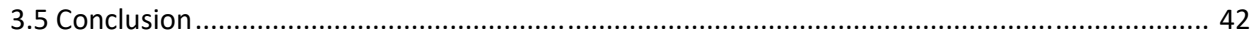

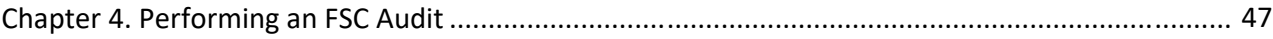

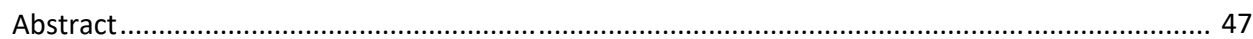

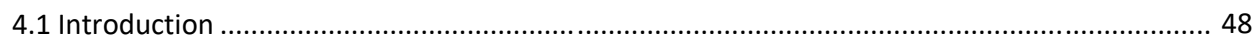

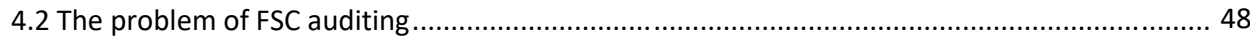

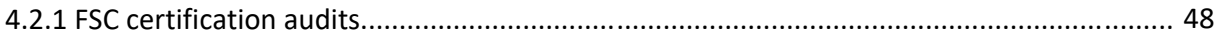

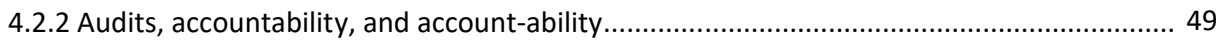

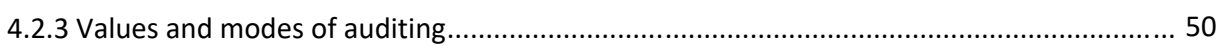

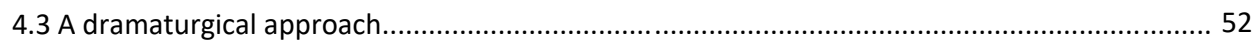

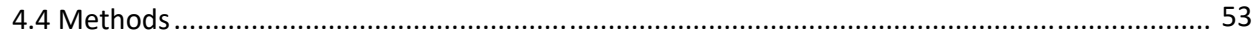

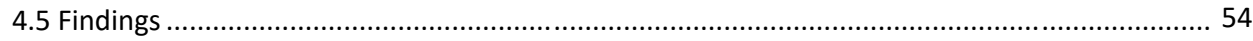

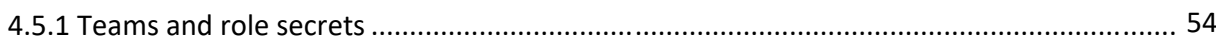

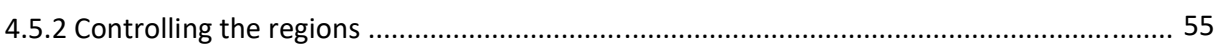

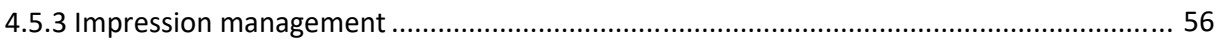

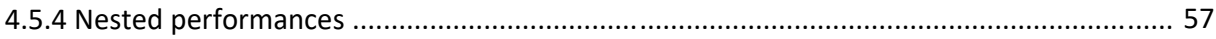

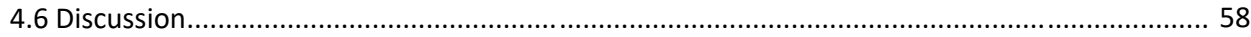

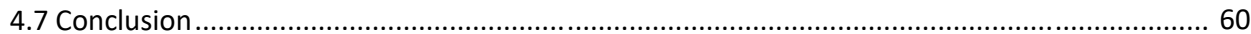

Chapter 5. How Do Policy Ideas Travel? Enactment, Friction and Alignment in Forest Stewardship

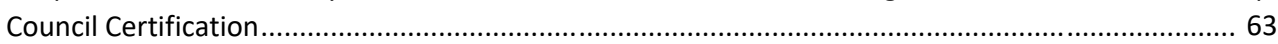

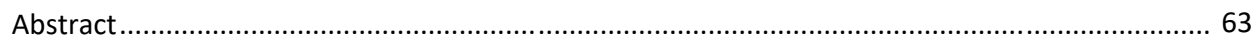

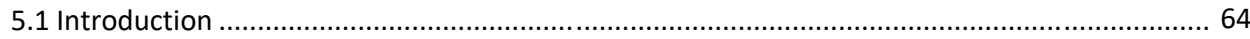

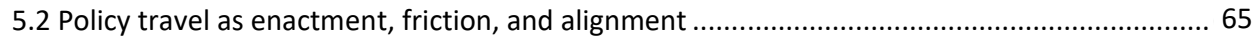

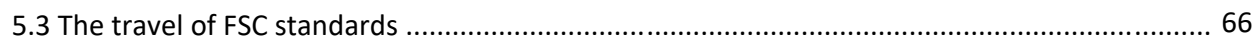

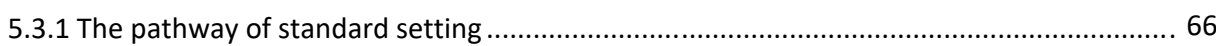

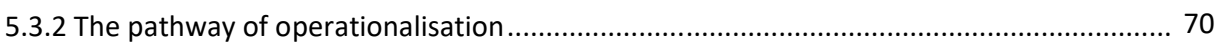

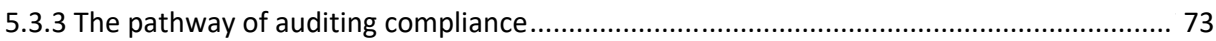

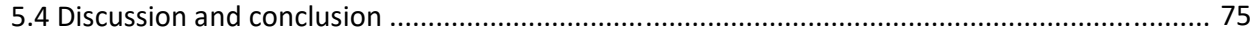

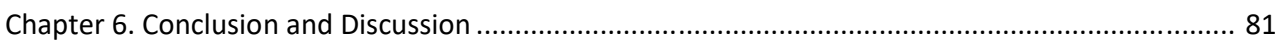

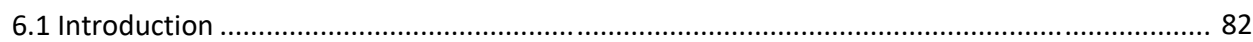

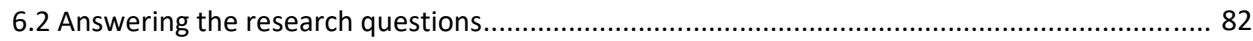

6.2.1 Q1: How is $3^{\text {rd }}$ party auditing of the environment conceptualized in literature?................ 82

6.2.2 Q2: How are FSC auditing practices and values performed by auditors? .......................... 83

6.2.3 Q3: How does FSC auditing connect global standards and local practices?....................... 84

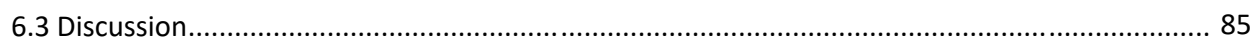

6.3.1 Informational governance: A foundation from which to build........................................ 85 
6.3.2 Whither auditing?

6.3.3 Dramaturgy: Practicing performative performances.............................................. 91

6.4 Reflection on data collection and analytical approaches .................................................. 93

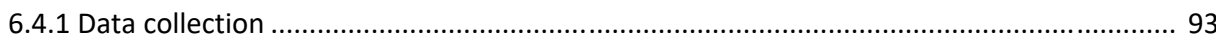

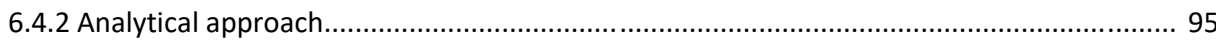

6.4.3 Which came first: The research methodology or the analytical approach? .................... 96

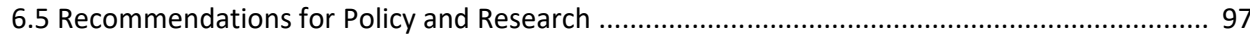

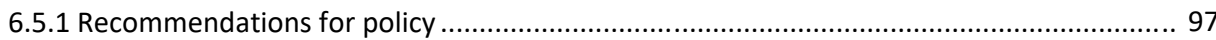

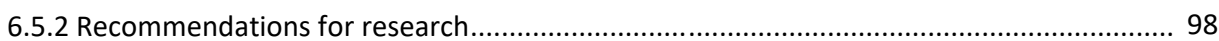

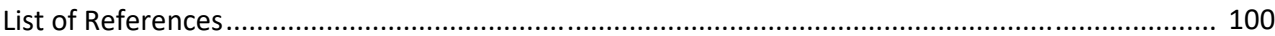

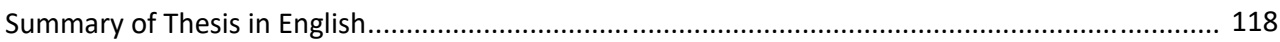

Completed Training and Supervision Plan .................................................................... 122 


\section{Figures, Tables, and Boxes}

Figure A. The FSC 'tick-tree' logo

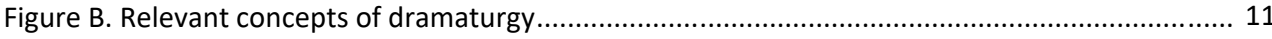

Figure $\mathrm{C}$. The iterative loops between data gathering and analysis ............................................. 16

Figure D. Summary of the types of internal and external audits .................................................. 20

Figure E. Example of conceptualisation of transparency as the base aspect of the "auditability" of a

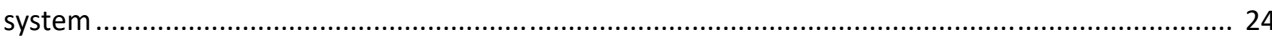

Figure F. Linking modes of auditing with audit characteristics.............................................. 26

Figure G. Proving something as objectively true involves triangulation, as reproduced above .......... 36

Figure $\mathrm{H}$. The inevitable link between openness and cooperation, and criticism and closure, as presented in the training

Figure I. The only official use of the term "interpretation", presented in the training in a highly simplified communication model .......................................................................................... 39

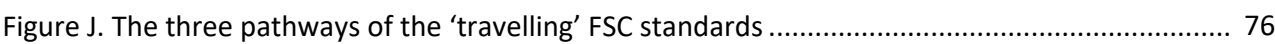

Figure K. How environmental auditing is conceptualized in literature ......................................... 83

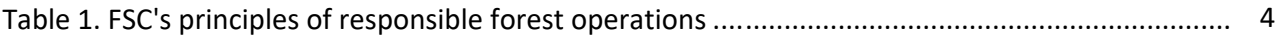

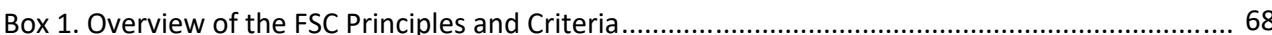




\section{"And these are your reasons, my lord?"}

"Do you think I have others?" said Lord Vetinari. "My motives, as ever, are entirely transparent."

Hughnon reflected that 'entirely transparent' meant either that you could see right through them or that you couldn't see them at all.

-- Terry Pratchett, The Truth 


\section{Chapter 1}

Introduction 


\section{Chapter 1. Introduction}

\subsection{Research problem}

\subsubsection{Making claims about forests}

By the 1980s, the world was becoming increasingly aware of the growing global threat to forests. Forest management practices of the previous centuries had led to increasing rates of harm to forest quantity and quality (Bass, 1997). In response, efforts to stem the haemorrhaging of forests ranged from national policy changes to civil movements to international initiatives. The failure of one such international initiative, the 1992 United Nations Conference on Environment and Development (UN CED) in Rio de Janeiro, catalysed the pioneering of market-based solutions to the problems (FSC, 2020d; ISO, 2020b). Forest management and chain of custody certification was born, with the Forest Stewardship Council (FSC) as a pioneer in this domain.

Certification in its modern sense is a system by which an entity can claim compliance with a predetermined set of norms or criteria (henceforth standards) that were developed by another entity. In many cases, such compliance is checked by a third party (ISO, 2020a). The standard-setters are removed from both the entity seeking compliance (henceforth organization) and the entities checking compliance (henceforth certification body). The role of the standard setter is not to dictate implementation, but to grant certificates in cases of proven compliance. The certified entity is then allowed to display their compliance through documentation or a mark.

In this system, a party other than the producer, buyer, or standard setter is accredited to check the entity's compliance with the standards and render their opinion on whether the entity complies or not. In the modern understanding of certification, this third party can be generally referred to as an auditor. Certification is done by the auditors who gather evidence of instances of compliance as well as non-compliance. At the end of the process, if the auditors find the organization in compliance with the standard, the auditing organization issues a certificate and the organization is typically granted access to some sort of stamp, seal, or other kind of statement can be placed on their documentation stating their compliance. Such a stamp or seal can in turn assure consumers that they were purchasing goods of expected quality and producers could be protected from competition from bad actors making claims to goods they were not really producing. In marking their goods as certified against a standard, companies are signalling to consumers that they can rest assured that the products they are paying for have been carefully accounted for, and that their actions meet the requirements of the standard, whether they be technical, social, environmental, or economic in nature. In principle, the company should gain preference with the discerning consumer and be able to earn a price premium (Auld, 2010; Marx \& Cuypers, 2010). Over time, common macroeconomic wisdom goes, the floor for all such goods will be raised as more and more companies want to "get in on the action", until the demand for such certified goods and services is met entirely. At this point no more companies will seek to become certified.

While certification is relatively new, the underlying concept of marking a good to identify something of its origin or qualities is ancient. Makers marks, origin names, and other such identifying information appeared on goods of the Roman Empire and earlier (Rogers, 1910; Millard, 2005). This likely served to influence buyers' behaviours in order to favour particular marks (Prior, 2007). By the medieval period in Europe, the issue of good's identification had become even more important. At this point, the guilds of Europe were on the rise. The exact purpose of these organizations was varied and likely misinterpreted in modern times (Swanson, 1988; Epstein, 1998; Richardson, 2001), but one of their purposes was to ensure that all members produced goods to a given quality or specification and by 
providing am identifiable characteristic that was very hard or costly to counterfeit in order to ensure their goods would be associated only with their guild (Richardson, 2008). This ensured the guild could trade on their name both domestically and abroad.

Aside from producers, the resellers of goods were also subject to the implications of (mis)identifying the origins of goods. One anecdote from the Holy Roman Empire relates how an innkeeper was sentenced to be hanged for selling generic wine as a Rudensheimer wine (Rogers, 1910). Such actions undermined the assurance of the buyer that they were receiving goods that bore the claimed characteristics, and this was a transgression worthy of death. One of the earliest modern examples of certification of goods is the l'Appellation d'origine contrôlée (Bass, 1997), created in 1935 by French governmental decree (INAO, 2020). This label of origin was to certify that wine and spirits came from the regions bearing their namesakes. By extension, it assured buyers that the goods were made according to the expected processes that would give the good its signature characteristics. High-value, region-specific food goods thus had a strong history of certification by the late $20^{\text {th }}$ century, but this was not the case for natural resources such as timber which were mostly regulated by governments or not at all. Yet, since the $19^{\text {th }}$ century, we have seen a move away from centralized and hierarchical conceptions of government to the recognition of the role of non-state actors such as civil society organisations, landowners, citizens, and businesses. This also implied a move away from commandand-control types of regulation towards voluntary forms of governance.

Thus, with the practice of marking goods to make a claim about origin or creation processes so well established, the limited success of UN processes to control deforestation and forest degradation, and the trend towards non-state actors and voluntary governance, the precipitation of the FSC certification scheme seems inevitable in retrospect. In 1994, two years after the failed attempt by the UN to produce a legally binding agreement between states on deforestation, a group of "environmental NGOs, timber traders, indigenous people' groups, forest workers organizations, and other stakeholders" (Auld, et al., 2008) formed the Forest Stewardship Council as a legal entity in Oaxaca, Mexico.

Since the 1990s, certification as a form of governance has risen in several high-profile industries including not just forests and timber but also fisheries, cotton, and coffee (Auld, 2014; Kuit \& Waarts, 2014). In most places, one only needs to browse the shelves of local stores to see various stamps and logos on paper goods, chocolates, fish, meat, etc. This prevalence of certified goods indicates the economic importance of certification schemes. Furthermore, many certification schemes make claims to improve social or environmental aspects of their producers, regardless of market importance (Fairtrade, 2020; UTZ, 2020). In many cases, governmental public procurement policies require or strongly recommend independent certification schemes for goods, further elevating the importance of this style of governance (Mechel, et al., 2006; EPA, 2020). Such voluntary governance is aimed at encouraging the behaviour of actors (Gupta \& Mason, 2014). In the case of FSC, three groups are being steered: 1) Consumers are being steered to prefer goods bearing the FSC logo, which indicates the goods' materials are from well-managed forests, over those that do not bear the logo; 2) Companies are being steered to sell goods that capture the portion of the market willing to pay more for certified goods; 3) Forest managers are being steered to become certified to supply those companies. All of this relies on the credibility of the claims that FSC makes about forests and how this credibility is ensured in the process of FSC certification. 


\subsubsection{The FSC certification process}

The aim of FSC is to create a label that allows for the identification products made from well- or sustainably-managed timber (FSC, 2020d). As discussed above, the central underlying idea was that consumers want to know if their timber was contributing to deforestation and could 'vote' with their wallets for reducing deforestation. FSC was the first to introduce a global standard for forest management. Originally this standard consisted of 9 high-level requirements, called the FSC Principles and Criteria (FSC, 2020d). In 1997, the FSC membership ratified the $10^{\text {th }}$ principle (Table 1).

\begin{tabular}{|l|l|}
\hline Principle \# & Principle Theme \\
\hline 1 & Compliance with laws \\
\hline 2 & Workers' rights and employment conditions \\
\hline 3 & Indigenous peoples' rights \\
\hline 4 & Community relations \\
\hline 5 & Benefits from the forest \\
\hline 6 & Environmental values and impact \\
\hline 7 & Management planning \\
\hline 8 & Monitoring and assessment \\
\hline 9 & High conservation values \\
\hline 10 & Implementation of management activities \\
\hline
\end{tabular}

Table 1. FSC's principles of responsible forest operations

Entities that are found in compliance with the FSC standards are granted access to the so-called 'ticktree' logo (Figure A) which can be placed on their sales documents, products, and promotional materials.

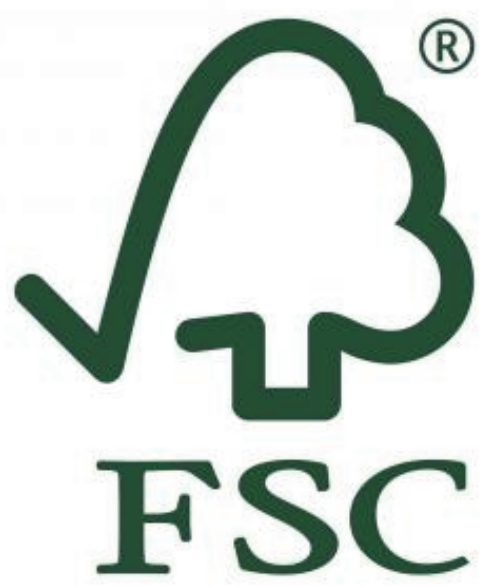

Figure A. The FSC 'tick-tree' logo.

FSC's certification system is a clear example of a third-party auditing system: FSC International sets the standard internationally, or nationally when there is a national office. These standards are developed by experts representing the environmental, economic, and social interests associated with forestry. Companies then hire an independent auditing firms (called "certification body" [CB] in the 
FSC system) to verify their compliance with the standard. The certification bodies are regulated not by FSC, but by an independent accreditation body (Assurance Services International, or ASI). This regulation is done through meeting minimum training requirements established by FSC and enforced by $\mathrm{ASI}$, and by occasional attendance of ASI representatives in certification audits.

The audits themselves fall into two categories: main evaluations and surveillance evaluations. After the first main evaluation, main evaluations happen every $5^{\text {th }}$ year a certificate is maintained. They are meant to be particularly rigorous, covering all the Principles and Criteria. Surveillance audits happen at least 4 times (once per year on average) between main evaluation audits. These audits are less rigorous, and in fact may not require actual site visits to forest management units (FSC AC, 2009a). All audits require the presence of an auditor (or possibly a team of auditors) to gather evidence that the forest management practices are conforming with the standard.

During the audit, any time the auditors observe something that may be in contravention of the standard, they are obliged to investigate it to discover if it is in fact not conforming with the standard. The outcome can be that no action is required, what is called an "observation", or a "corrective action request" (CAR). When no action is required, nothing is necessarily recorded, although some CBs do so. An "observation" is akin to a red flag. It is a concern, or a possible contravention of the rules, but not a clear, systematic breaking of the rules. This is recorded for follow-up in the future. When the rules are clearly broken, the auditors record a description of the circumstances of the violation and indicate whether is it is a major (severe or systematic) or minor (slight or isolated) non-conformity. At the end of the audit, the auditors send a report to their superiors describing any CARs, among other details, and they also inform the auditee about the outcome. The certification body can then issue a certificate of conformance if there are no major non-conformances and not many minor non-conformances. Some of the details of the audit are then made available to the public (FSC AC, 2009b). After successful conclusion of an audit and issuance of a certificate, the auditee can use the FSC label on its (certified) material to communicate that it is complying with the FSC standard. This certificate (generally) stays with that material until the final product is completed and sold to consumers with an on-product label.

\subsubsection{Auditing: the nexus between global standards and local forest practices}

As described above, FSC was formed in protest to ongoing deforestation and forest degradation with the aim to conserve forests and improve management. To borrow the language of Power (1991), protest values took centre stage in FSC's early days. This meant that FSC was primarily concerned with auditors identifying environmental harm and less with the details of auditing and evaluation. However, the crucial role of these audits in the credibility of the certificate meant that what Power (1991) has called professional values started to become more important. Environmental auditing started to adhere to auditing norms that were derived from the business and financial sectors and started to focus on procedures and standardization. This development kept pace with the general growth of FSC. The number of FSC chain of custody certificates issued and the number of hectares certified has grown consistently through time $(45,063$ certificates and more than 220 million hectares at the beginning of 2021), although certified area seems to have slowed down in recent years (FSC, 2021a). This is reflected in the more than 40 million USD revenue generated by FSC International in 2019 (FSC, 2020b). Altogether, this demonstrates the very real impact this certification scheme has in terms of reach and economic impact. The need for professionalization underscores the central importance of auditing in the entire FSC system. The standard can be the best-designed standard in the world, but if the auditors are ill-informed or not consistent, then the credibility of the system is in jeopardy. The forest management practices can be as good as imaginable, but if the auditors do not give care to their presentation, they will not be seen as such. It is the task of auditors to explain and characterize what 
is seen to play out in the forest and capture it in a report which serves as the artefact that connects local forest management to global standards.

Auditing is not a straightforward or self-evident activity. First, auditors must navigate between protest and professional values (Power, 1991), thus between the aim of FSC to improve forest management and conservation on one hand, and the professional standards of auditing to objectively check standardized criteria. Second, they are charged with the task to interpret the FSC standards, the forest management practices, and the relation between these two in terms of conformance and nonconformance. This is not an easy task since FSC is a global certification scheme; it creates international standards for forest management, which can be personalized to a specific country's situation within certain limits. The formulation of these standards, while as participatory and contextually appropriate as possible within FSC's rules, nevertheless happens far removed from the forests in which they will be applied. Interpretation and judgement are thus inevitably involved in auditing practices (Eden, 2008). These interpretations are shaped in the interactions between the forest managers who try to make their practices match the standard as best they can and who try to present this convincingly during the audit, and the auditors who are in charge of the final assessment.

Yet, in the final audit reports, these interpretations and interactions are not fully captured. This means that a vital element of the workings and practices of certification-in-action remains hidden from view. To improve understanding of certification, it is important to open up the black box of auditing, and to examine how auditing is done in practice, how it is guided by different values and norms, and how connections between global standards and local forest realities come about.

\subsection{Objective and research questions}

In view of the importance of certification, the central role of auditing, and the lack of understanding of the interactions and interpretations involved in auditing, there is value in carefully examining how auditing is meant to work in theory, how it works in practice, and how it connects broad, universal themes around certification to practical realities. The objective of this thesis, therefore, is to contribute on the practical level by filling a gap in the literature by providing descriptions of auditing and auditor training in strongly grounded terms. Furthermore, it aims to expand and deepen the concept of environmental informational governance by exploring auditing and certification and offer perspectives on what auditing is for and what it does.

To these ends, three questions guided the theoretical development and research of this thesis:

1. How is $3^{\text {rd }}$ party auditing of the environment conceptualized in literature?

2. How are FSC auditing practices and values performed by auditors?

3. How does FSC auditing connect global standards and local practices?

The following section describes the concepts important for understanding how the questions are pursued in the research and provides context for the final discussion chapter at the end of the thesis.

\subsection{Theoretical framework}

The following section shows the concepts that enable this thesis to address the research questions. Furthermore, they provide basic links between concepts that give a view of how certification and auditing are conceptualized throughout the thesis.

This thesis position certification and auditing within the concept of Informational Governance, in that $3^{\text {rd }}$ party certification requires and reinforces social organization around and for information 
production and use. The engine driving this is the audit itself, which is examined in light of the practices performed in the field. To analyse the auditing practices, the thesis draw on critical studies of transparency and auditing in order to examine the "value-laden" context of auditing and auditors while they go about their practices, and to critically examine role of interpretation plays in these processes. In the end, this highlights what remains invisible in the endeavour. Simultaneously, it utilizes concepts of dramaturgy, as characterized by Goffman (1959) to examine the interactions between auditors and auditees to explain observed behaviours. Finally, the concepts of friction and alignment are introduced to analyse how universal global standards connect to contextualized local forest management practices, and how they exist in both tension and support of each other in the context of auditing.

\subsubsection{Certification as informational governance}

Auditing and certification can be considered an example of what Mol (2008) called "informational governance". He characterised informational governance as "institutions and practices of [...] governance that are to a significant extent structured and 'ruled' by information, informational processes, informational technologies and struggles around access to, control over, and production and use of [...] information." (pp. 80-81). This description clearly echoes the description of certification schemes and auditing. Certification fundamentally relies on information about compliance which is produced in auditing. Also, the label itself can be seen as a type of information companies can show to consumers to demonstrate their good behaviour, and so steer consumers to their products. Certification also has strong links to another related concept: governance by disclosure. This notion is characterised by the relatively recent rise in both governmentally enforced and voluntary actions wherein entities' behaviour is steered by requiring certain facts and practices be made scrutable to outside observers. Governance by disclosure is often associated with corporate social reporting (Hess, 2008), but is equally applicable to various other activities in the domain of environmental governance (Gupta, 2008).The trend towards governance by disclosure is part of a wider development that is described by Gupta and Mason (2014) as a "transparency turn" in environmental governance. They argue that, while traditionally a governmental concept wherein governments disclose information to particular audiences, this concept has rapidly spread to other entities aiming to steer an audience's behaviour by showing or revealing otherwise obscured facts or processes. This form of governance is often associated with societal goods such as accountability, legitimacy, and effectivity.

FSC certification is all about revealing information. Auditors go into forest management organizations and examine private documents and practices, and then reveal some parts to different audiences in reports (public summaries or full reports to the accreditation body). The generation or harvesting of the information that goes into that report is aimed at increasing the accountability and legitimacy of the FSC claim (Gupta \& Mason, 2014). After all, without the report, there is nothing to back up the organization's claim of following the standard.

\subsubsection{Auditing as practice}

The objective of the thesis to contribute to understanding of how auditing is done reveals a focus on practice. Rather than institutional rules around auditing, a focus on practice prioritizes a grounded approach to analyse the contextual and situated nature of audits. The reason for this is well summarized by Arts et al. $(2012$, p. 6) when they say, "rules and institutions explain social behaviour inadequately or not at all: people improvise, are creative, and interpret and reshape rules and institutions in practice." 
Nicolini (2012) further illustrates this point by broadly characterising the unifying concepts underpinning taking a practice-based theoretical perspective: Behind rules and institutions are actors who do things. These things are practices. The practices that are enacted and how they are enacted shape the resultant outcome and how the outcome can be observed. Seemingly mundane aspects of what is and how something is done can have important implications on the observable outcome. Actors may strive to do things in different ways, and therefore the observable outcome is a result of that tension. The meaning of the outcome is constituted by the practices and may not be fully described by what is said about the practices by those performing the practices.

Taking this as starting point for understanding what it means to employ a practice-based theoretical perspective, this thesis conceives of auditing in a similar way. While auditing may have procedures and rules, what is done during an audit is the crucial point for consideration. Seemingly mundane actions and activities will inevitably shape who can participate, how they can participate, and how the interactions between the actors involved in the audit can interact. The particular configuration of practices, both physical elements and normative values that are enacted, will shape the outcome (Gomart \& Hajer, 2003; Hajer, 2005). Furthermore, the audit itself, constituted as it is through concrete practices, is only made meaningful when considered in the context of the meaning put forward by those practices. Its meaning is only explicable in terms of the practices.

Conceptualizing audits as a set of practices in this way means that the meanings of standards are not self-evident and that the standards that are used in the audit should not be considered as external yardsticks that fully determine outcomes. Instead, the standards acquire meaning and are only understandable through what is done in the audit itself. Enacting these standards shapes what the standard and the observed forest management come to mean (Eden, 2008). In short, focusing on the practices of auditing means "analytical focus is neither placed on the social system nor on individual agency, but rather on the entwinement of agency and structure in practice" (Behagel, et al., 2019). This leads to establishing the understanding that what is observed is the result of practices interacting with each other in real-world contexts.

This is particularly relevant when you consider the subject of this thesis. FSC's standard is a set of rules that exists only as a concept on paper. Likewise, principles of auditing are only ideas until they are manifested in the world. Only by focusing on the creative process of actually doing the audit, on the actions taken, can we explore the audit effectively. Therefore, it is critical to conceptualize audits not as arrangements of institutions, rules, or any other abstractions, but as practices that are performed. Without this conceptualization, all nuance of what is done in the field is lost. To describe the practices in the context of the rules auditors act within, this thesis looks to Goffman's concept of performance (Goffman, 1959), described in section 1.3.4 below, which allows simultaneous description of what is expected, and what is done.

\subsubsection{Critical transparency and auditing studies}

One of the primary outcomes of an audit is the production of information about the audit. But to what end? The commonly held purpose of the (publicly available) information produced in audits is to provide transparency to the audit process, revealing the contents of the audit, and thereby assuring the reader that the audit was performed properly (Dando \& Swift, 2003). But, as established in the preceding section, this information production is a practice enacted by actors during an audit. Taking a practice-lens to this activity results in a sensitivity to how the information is produced, and it demands an examination of the considerations and choices involved in deciding what is observed and what is reported. 
Strathern (2000) serves as a good starting point on this topic by pointing out that "making the invisible visible", as in the case of audit information production, is not a neutral process. That which is made visible, and how it is made visible, are outcomes of political processes which do not privilege all parties and perspectives equally. She also points out that by the same token, that which reveals may also obscure. While some criticize audits for "doing a poor job of really describing what goes on." (Strathern, 2000, p. 134) we need to recognize that audits are specific and groomed account that do not and cannot show everything. This is equally true if one focuses on the other end of the information production. Audit information is revealed for a particular audience, which involves someone making a judgement call about what the audience really needs to know, thereby highlighting one of the criteria by which some things may be safely concealed while still laying claim to increasing transparency and disclosure (Mason, 2008). Moreover, the contribution of increased transparency to achieve governance goals is itself questionable, regardless of the particular set of practices employed, as systems of disclosure by themselves do not necessarily "change existing power structures, or... accomplish much of anything." (Florini, 2008, p. 15). Empirical and modelling research on this topic also highlights the variable nature of outcomes of transparency efforts on governance (Islam, 2006; Florini, 2010; Kosack \& Fung, 2014).

When we recognize that audits both hide and conceal things, the question emerges what considerations guide what choices are made. As Gupta and Mason (2014) point out, transparency, and any system of governance based upon it, is by its nature situated in a socio-political and "value laden" context. These values guide what is disclosed, what remains concealed, how information is framed and how standards and forest management practices are interpreted. From this perspective, selfevident, rational ideals like objectivity become problematic, as how to do audit-related actions becomes a matter of interpretation depending on the values holding prominence.

Power (1991) highlighted how the values (or orientation) of an audit could influence how audits occur and the impacts that implied in the early days of the emerging industry of environmental auditing. As the trappings and tools of financial auditing were adapted to the environmental arena in the 1980s, there emerged a new type of expert: the environmental auditor. Their expertise, and associated position of authority, ran the risk of rendering any controversy into the terms of that expertise and authority. The result could be a depoliticization of controversy over the principle of accountability. Considering this possibility, Power proposed a spectrum of auditing between protest-driven auditing that actively seeks to problematise information and professionalised auditing that is more concerned with "[neutral] monitoring [of] pre-exiting information." (Power, 1991, p. 37). While a professional audit is one that is predictable, replicable, and efficient, all of which are noble goals unto themselves, the dominance of this value is not without risk. Important context may be ignored or stripped away, impoverishing the resultant understanding (Turnhout, et al., 2014), and weaknesses in the underlying principles being audited may be hidden from view (Power, 1996). Consequently, a dominant focus on professional values may distract attention from what is at stake: the sustainability of forest management. In other words, there is the risk that the auditability of forest management, that is how good forest managers are at being audited, takes precedent over real impact (Craig, et al., 2014), resulting in auditing becoming mere box-ticking (Watson \& Emery, 2004). In short, audits that valued professionalism over protest threatened to defang controversies.

FSC's certification system was conceived of to occupy the protest end of the value spectrum, in contrast to other then-new auditing models (Elad, 2001). This is consistent with the way in which FSC portrays itself as standing against the status quo, and coming up with an innovative model for reversing the negative trend in forest degradation (FSC, 2020). This runs counter, however, to the 
trend in how FSC presents itself as "impartial" either through direct actions or association with organizations such as ISEAL (McDermott, 2012; Lemeilleur \& Alliare, 2016), which does follow recent trends informational governance has been following. This implies that FSC itself struggles with placing itself in the value-laden context represented by the spectrum with protest on one end and professionalism on the other.

\subsubsection{Dramaturgy and performance}

The main perspective in this thesis to engage with the interactions between auditors and auditees is a return to one of the primary sources on applying the concepts of drama and theatrics to non-theatre topics: Dramaturgy as presented by Erving Goffman. Goffman (1959) considers everyday interactions between people, and frames them as a performance in the most literal sense. The goal of this is, most simply put, to explain why the interaction occurs in the way it does and to provide a coherent structure for others to do so as well. In doing this, Goffman puts the content of the performance itself on equal footing with "facts discrepant" (p. 65) with the performance. Thus, this conception of interactions acknowledges the idea that meaning is made in the interaction, even to the exclusion of other meanings that are already established elsewhere. To put this in practice-based terms, dramaturgy provides a way to interrogate the configuration of practices the actors put forward, and to help understand the meaning that is constructed through the practices.

However, Goffman does imply that what happens backstage, when a performer is out of the eye of its audience, is somehow more real than what happens on stage. In those spaces, the mask is dropped, and the actor may behave in a more genuine way. This thesis rejects this perspective, instead agreeing with Lippert (2013) that "reality does not consist of some objectively truer backstage, but just of multiple stages" (p. 38). But, like Lippert, this thesis find use in describing the elements of practices in terms of which region (backstage or frontstage) they happen in, especially when the actors actively and literally control others' access to certain spaces. When actors engage with the elements of dramaturgy, the most relevant of which are shown in Figure $B$, the best tool for engaging with them are dramaturgical in nature.

Exploring auditing with this perspective is useful in several ways. Firstly, it keeps the focus on what is done; it firmly roots any observations or analyses in terms of the practices. Simultaneously it does not imply that the contents of the audit is more or less real, instead it supports the idea that the actions themselves perform reality, thereby eluding the trap of "naïve empiricism" (Nicolini, 2012, p. 7). This thereby eliminates the temptation to conflate what happens in an audit to what should happen, or what would happen in an ideal world.

Secondly, the interactional and nested nature of dramaturgy places emphasis on actors participating in multiple performances at once, and even when preparing for the performance the actor is deliberately engaging in, they are still staging a performance. This then raises the possibility of auditors and auditees simultaneously staging their own performances for each other and staging a performance together for another audience at in an entirely different setting.

Thirdly, this conception of interaction allows for the possibility of non-human actors staging a performance (Hilgartner, 2000; Boje, et al., 2004). This opens the possibility of considering the artefacts of the audit as having their own impacts completely independent of the audit activities themselves, even while the audit serves as the backstage for the artefact's performance. 


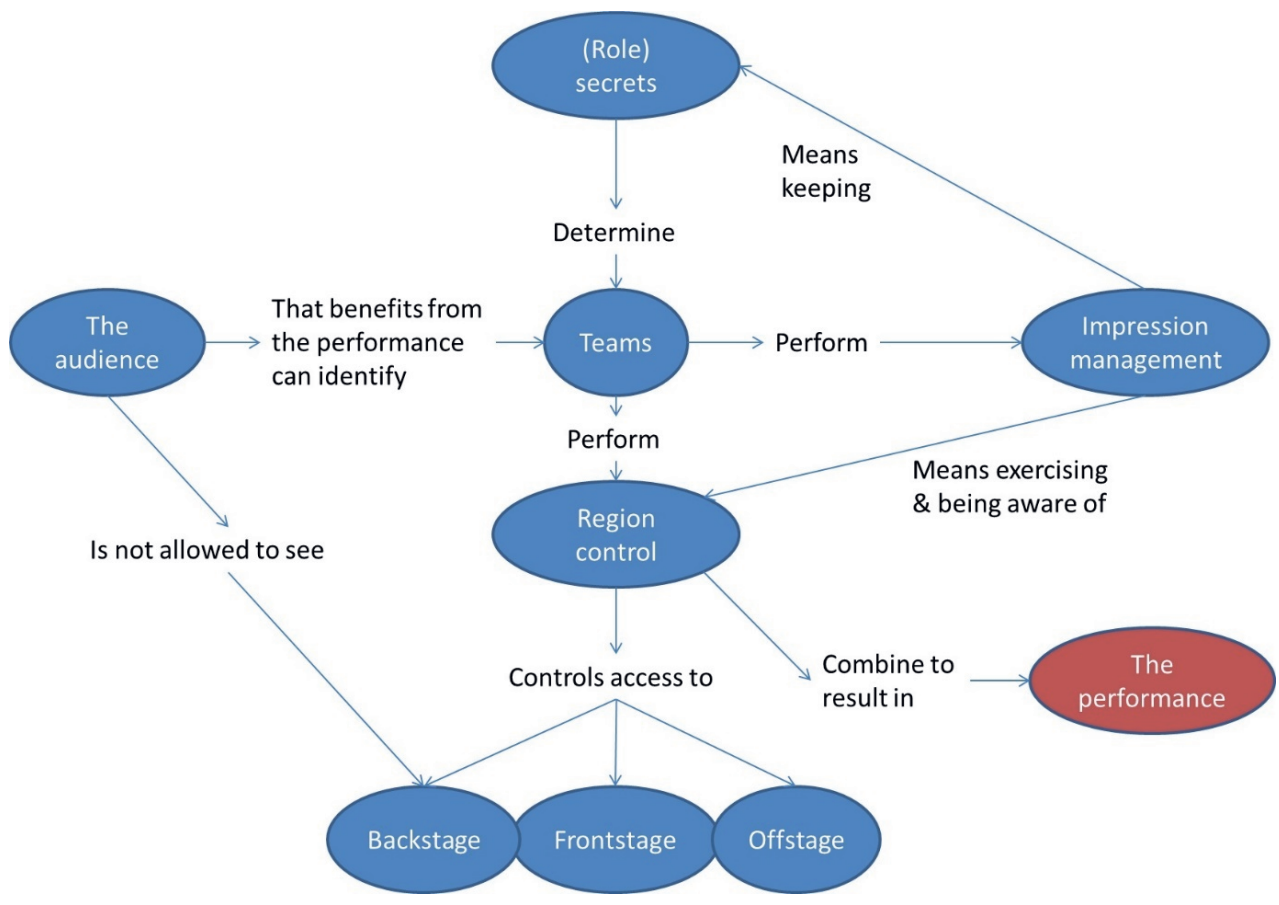

Figure B. Relevant concepts of dramaturgy. These terms recur prominently in chapters 3 and 4 .

\subsubsection{Friction and alignment at the global-local nexus}

FSC certification practices, and the governance-by-disclosure they utilize, are also prime examples of the liberal conception of governance at a distance (Rose \& Miller, 1992). In the most basic sense, those who are making the standards are spatially and temporally separated from those whose behaviour it is meant to impact directly and indirectly (forest managers and consumers). The audit and the information generated during the audit closes that distance between global standards and local forest management. The standard assumes presence and meaning through the proxy of auditors, while the forest managers are represented back to FSC in the audit information. This then, feeds back into revisions of the standards. Thus, again we see how the audit and its information hold a central position between global concepts and local realities.

Linking the local and global is no simple matter, however. While the principles of informational governance might suggest a smooth, unproblematic link so long as the information flows freely, forging these links takes work, and is not without tension. Tsing (2005) characterised this friction as occurring when something originally designed to be universally applicable becomes embedded in a context, and is thus forced into confrontation with practices that do not completely match. This friction must be navigated in some way to enable these universals to (do) work and produce effects. To avoid catastrophic break-down of the process, the universal and the contextual need to be aligned by arranging people, things, and practices so that the contextual is acknowledged and accounted for without defying the universal (Suchman, 2000). It follows that certification can be understood as involving processes of friction and alignment that result from encounters between global or national standards, auditing, and forest management practices. Auditors are placed in the position of 
confronting universal standards with local contexts and navigate their way to alignment, whether this be recommending or not recommending certification.

\subsection{Methodology}

\subsubsection{Conceptualization: Constructivism, interpretivism, and qualitative research}

The previous section on concepts represents the nuts-and-bolts used in this thesis to describe and analyse the topic of certification and of auditing. The research chapters and the discussion points of the thesis are couched in these terms. However, they all fall into a broader understanding of knowledge and of reality. Very broadly, this view is covered by two related topics: Constructivism and interpretivism. In this section I will briefly explain where I position myself about these two and present an explanation of why they are appropriate.

On the topic of constructivism, this thesis draws on Behagel's (2012) description of critical constructivism which establishes that social structures are historically and contextually contingent, making them not inevitable and not fully explanatory of the social reality that is being observed. This stands in opposition to the notion that there is an objective reality to be revealed by the research presented in this thesis. Instead, a critical constructivist perspective posits that facts or observations, no matter how self-evident, are inherently vehicles for underlying assumptions and meanings (Latour \& Wollgar, 1979; Fischer, 1998). Therefore, interrogating the social world requires interrogating the values and assumptions that are part-and-parcel of the observations. This requires the researcher, therefore, to interpret the observations in terms of those values and assumptions while simultaneously being critical of the values and assumptions themselves. As a result of this, very close attention must be paid to both the interpretations of reality presented during the research and the interpretations drawn during the analysis of the research observations.

This is particularly important when examining something like FSC certification which aims to provide a rational response to the problem of forest degradation and deforestation that did not challenge the prominent cultural paradigm of consumerism and capitalism. While this may seem as a natural or inevitable tool to achieve this end, it is in fact a choice that is made based on hidden or unquestioned assumptions and values. An interpretivist and constructivist approach enables meaningful engagement with the context that makes this policy tool an obvious choice. The same goes for the micro-level interactions during an audit. The standards that auditors and auditees follow are intended to represent an objective, immutable reference point, but individual interactions rarely make sense when taken out of context. Ultimately, to answer the question of how an audit is done, one needs to interpret why someone is doing it this way, and in such a dynamic situation, context is king.

Interpretivism also emphasizes the position of the researcher and how the researcher comes to know what is presented in this thesis. Yanow's (2015b) in-depth examination of the development and characterization of interpretative methods highlights the key element of interpretivism for this thesis: seeking meaning of social observations in context. The (social) world is inherently value-laden, and the researcher seeks to interpret those values in the context of the observations. But this activity is itself not value neutral. The interpreter has their own values and a-priori knowledge that must be reckoned with. Thus, the meaning of what is observed is both contextual to the original situation and contextual to the researcher's situation. Thus, what something means necessarily changes depending on who is doing the interpreting (Chowdhury, 2014). 
To summarize, the overarching conceptual position of this thesis rests on three pillars:

- The meaning of the world is constructed by the actors in the world and is therefore subject to the values and assumptions of those actors.

- Getting at those values and assumptions is an interpretive endeavour.

- Interpretation is itself constructivist in nature.

A consequence of these presuppositions is that while the work in this thesis is concerned with understanding the nature of the reality of FSC auditing, it is also concerned with "how that reality is arrived at" (Cooper \& White, 2012, p. 6). This is a typical characteristic of qualitative research, wherein the researcher becomes the primary data gathering and analytical instrument in the field and contextualized "reading" of the available data (Schwartz-Shea \& Yanow, 2011; Cooper \& White, 2012). Indeed, this type of research was the primary way data was gathered and analysed, as it seemed the only reasonable way to examine the research questions while remaining within the conceptualization described above. Combining the constructivist and interpretivist underpinnings and the qualitative nature of the research positions this thesis in what Schwartz-Shea and Yanow (2011) call the "qualitative-interpretive" family of methods. This is further reflected and characterised by the methods of data collection and analysis employed in this thesis.

\subsubsection{Data collection and analysis}

As is typical for research conducted using an interpretive-qualitative perspective (Schwartz-Shea \& Yanow, 2011), the empirical chapters of this thesis employ qualitative, interpretive research and analytical methods. Qualitative, interpretive research is as diverse of a topic as the researchers who employ it. In general terms, however, it is characterised by a focus on meanings, using the researchers themselves as the primary instrument for collection and analysis of data, and by in-depth descriptions and analyses of the situations observed (Merriam, 2002).

To prime their own mind, as the primary instrument of measurement, I engaged with those bodies of substantive and methodological literature that seem relevant to the topic of research. This resulted in a loose framework of concepts, articulated as a preliminary research question to be investigated. However, this framework rarely survived contact with the research topic. Invariably, the framework, informed by literature encountered what was observed in the field, leading to reflexive adjustments both in the analysis itself and in the conceptual focus applied to the findings (van Bommel \& van der Zouwen, 2012) It also sometimes resulted in abandoning the conceptual framework entirely and seeking out other explanatory concepts in other extant literature. Likewise, this required revisiting the originally proposed research question to better reflect the real question that was being investigated. As a knock-on effect, this then created expectations in my mind for the next excursion into the field. This loop is characterised further in the section below on iterative, interpretive analysis.

The tension between pre-existing expectation on my part and observations resulted in "a puzzle or surprise" (Schwartz-Shea \& Yanow, 2011, p. 28) that marked the starting point of developing the analysis (i.e. as presented in the research chapters of this thesis). As such, the methods of this research can generally be classified as abductive (Schwartz-Shea \& Yanow, 2011). This general approach underlies each set of methods that were used to generate the chapters of this thesis which are characterised below. 


\section{Modified snowball literature search}

To answer the question of how environmental auditing is conceptualized in literature, a "snowball" method was employed when searching the literature. Starting with a few foundational texts (Power, 1991; Power, 1997; Eden, 2008), I made a selection of sources that were included in the references. Then, using Google Scholar, I looked for sources that cited those foundational texts. Independently, based on keywords, searches of online databases were also performed. Selection was based on the contents of the abstract closely relating to the research questions. This search happened on an iterative bases between rounds of analysis. Once analysis was decided to present a coherent picture of environmental auditing, the search stopped.

\section{(Participant) ethnographic observation}

Answering the second research question involved attending events in the field for direct observation. I attended training courses as a participant, with the goal of both gaining insight into how auditors learned about auditing, and to learn the substantive contents of the course in order to pass the exam at the end of the course. This meant that attention was paid to the utterances of the trainers and trainees both for the content of what they were saying in a teaching/learning sense and in the sense of monitoring for clues about the issues that were of concern, challenging, or easy. I was free to ask questions about the course content at any time, but questions about perceptions and opinions were relegated to breaks and mealtimes. I spent 10-hour days with the trainers and participants, from the start of the training day, through breaks and meals, until I returned to my hotel in another city. During the time that I was present, notes were taken about what was said, how it was said, the physical behaviours of those present, and the location the training took place in. The principle of this approach was to maximise the amount of recorded observations based on my perception.

The situation was similar when observing audits. I spent whole days with the audit teams, often sharing breakfast with them, listening to their conversation, recap of the previous day, and planning for the coming day. Then, during the audit, I was obliged to stay with the auditor, as part of the formal agreement between auditor, auditee, and observer in the FSC system. Unlike in the training, I was not free to ask questions whenever they came up. As part of the observation agreement in FSC, observers must not interfere with the functioning of the audit, and so questions were held until a convenient or appropriate time presented itself. This had the deleterious effect that, despite the auditors prompting me to ask questions, I would sometimes be unable to follow up on particular lines of enquiry simply because the audit had moved on, or I would forget or reconsider the question.

In both situations, I was present for the entire duration of the events that were to be observed and had nearly unfettered access to the auditors during the hours in which they were working. As a result, the data collection was often in the form of rushed, hastily scribbled notes in a notebook as I struggled to keep pace with the action around me. Despite this difficulty, the resulting data was full of direct quotations, close paraphrasing, and detail-thick observations that served as the building blocks for their own analysis

Answering the final research question also relies on a particular breed of participant ethnographic observation: autoethnography. In this case, I was employed by FSC's standard-setting body. This meant that I was directly involved in many of the events described, having personal and professional stakes in their success or failure, but ultimately doing these things as a job. As a result of this, the normal method of recording observations did not happen, as these experiences were not intended to be published, and instead were only relevant in hindsight (Ellis, et al., 2011). Due to this, the instances explored are less based on the details of the occurrence but are appreciably more certain in my mind. 
There is no other actor to impart meaning, it is solely my lived experience that informs the observed actions and activities and serves to prime the data for analysis.

\section{Iterative, interpretive analysis}

The process of analysing the collected data is difficult to characterise in a coherent way. A place to begin is to borrow a phrase from Bryman and Burgess (1994, p. 217): "Analysis is not a distinct phase." The process of analysing the data that was gathered happened progressively, sometimes while making the observations themselves, sometimes in the hours between bouts of observation, and sometimes weeks, months, or years after the fact. In some cases, at the end of a day of observation, I would spend time digitally recreating their field notes while sorting between things that were seen and heard and things I had thought or felt during the occurrence. Simultaneously, I would add new notes about what was thought of in hindsight, away from the immediacy of the observations themselves. Furthermore, the data was not examined for analysis only once. The content of the field notes was examined repeatedly. Again, sometimes days, months, or even years would elapse between episodes of analysis, and each time might reveal slightly different or new details. As a result, the meanings and implications that were generated from the data would shift and change through time.

The goal of the analysis, as is common for qualitative, interpretive research (Glaser \& Strauss, 1967), was to abductively build towards a theoretically sound explanation of the situations observed. The primary method of trying to build a theoretically sound interpretation of the meanings and implications was very limited open coding of the data. This meant I would examine the observations and, using the content of those observations, develop a set of themes that were broadly applicable to any given set of observations. This not done in a rigid way, with each field note line or paragraph being assigned a code, but rather it was often done conceptually, in the process of drafting ideas for publication, apart from the field notes themselves (Goodall, 2000).

This was complicated by the fact that the conceptual coding was done iteratively. After coming to a particular conclusion about some set of observations, that conclusion would play a role in interpreting or re-interpreting other observations. This resulted in a snowballing effect of concepts that folded into each other, building outward. This building body of concepts would also inevitably lead to pre-existing analytical frameworks and tools, which previous authors had developed in response to similar data sources or similar data content. Some of these frameworks and tools were incorporated into the analysis of the data, becoming fundamental to the understanding of the data that had itself led me to finding it.

The resulting process of analysis was, therefore, quite messy in its iterative nature. While observations may have been recorded with an initial lens in mind, ultimately attempting to group and interpret the observations themselves led to the resultant interpretations of what was observed. Figure $C$ demonstrates the iterative nature of the research presented in this thesis. 


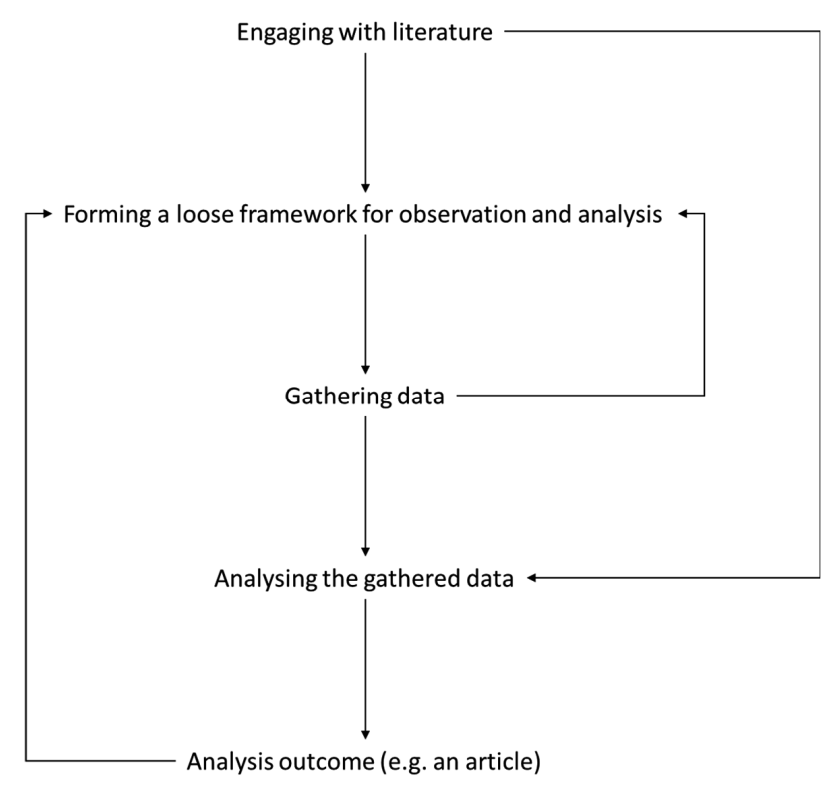

Figure C. The iterative loops between data gathering and analysis, adapted from Whiteley and Whiteley (2005).

\subsection{Thesis outline}

The following section briefly describes the remaining chapters of this thesis, with focus on the research questions, concepts, and methods used in their construction.

\section{Chapter 2 - Inside environmental auditing: effectiveness, objectivity, and transparency}

This chapter attempts to answer the first research question "How is $3^{\text {rd }}$ part auditing of the environment conceptualized in literature?". As such, it is a literature review on the topic of auditing environmental systems and management, often in the context of certification schemes. As a starting point, auditing is framed by a spectrum of modes of auditing, or ways in which audits can be done. The poles of this spectrum are "protest" and "professionalism". The literature is then analysed in terms of which audit values, or characteristics, were of primary concern. Three characteristics emerged: Effectiveness, objectivity/neutrality, and transparency. The article concludes by demonstrating how the modes of auditing and audit characteristics can be linked to better understand how any given audit functions, and the values that are being espoused. This chapter demonstrates how assessing an audit in principle is not possible, and only by considering the practices can conclusions of the nature of the audit be drawn. Furthermore, it also shows how an audit, traditionally considered an exercise in revealing truths, may place greater or lesser value on transparency, and thereby influence what is revealed or obscured. 


\section{Chapter 3 - Learning to become an FSC auditor}

Following on from the issue of which values are given prominence in an audit, this chapter contributes to answer the question, "How are FSC auditing practices and values performed by auditors?" by examining the values that are taught to auditors during training. Using experiences drawn from participant observation, the values of objectivity and interpretation are subjected to scrutiny. The ways in which auditors are taught to perform objectivity, and the constraints on being seen to perform interpretation are characterized, and the tension between objectivity and interpretation explored. The topic of performing mastery of being an auditor is introduced to ease an auditor into the values of objectivity and interpretation. The chapter concludes with a reflection on the tension between the objective and subjective values present in auditing, and how the former need not undermine the former when it is appropriately noted and considered.

\section{Chapter 4 - Performing an FSC audit}

This chapter also answers research question number 2: "How are FSC auditing practices and values performed by auditors?". The chapter examines how audit and auditor values are enacted in practice. This chapter relies on a dramaturgical framework to analyse the audit practices considering the protest-professionalism value spectrum from chapter 2. As a result, the chapter demonstrates how auditors perform begin a professional auditor, and how auditees perform being an auditable organization. A particularly important aspect of making this performance convincing and visible to outsiders (e.g. FSC itself or any member of the public) is the auditors and auditees tacitly participating in so-called nested performances, wherein the performance by auditors for auditees as audience (and vice versa) is actually the back stage of another performance with another audience. In conclusion, the chapter highlights how the global interest in a professional performance of schemes like FSC might ultimately undermine the value of FSC certification as an agent for change in the field of forestry practices.

\section{Chapter 5 - How do policy ideas travel? Enactment, friction and alignment in Forest Stewardship Council certification}

Having examined the particulars of FSC audit practices in close detail, this chapter reengages with broader considerations to answer the question "How does auditing connect global standards and local practices?" This chapter frames the issue in terms of "enactment, "friction"”, and "alignment" between the general, universal standards of FSC and the specific, contextual practices of forest management when they meet in an audit. The chapter examines three pathways through which FSC's policy ideas travel: the pathway of standard setting, the pathway of operationalization, and the pathway of auditing. Each of these pathways entail different spatial and temporal resolutions, but all can be considered in terms of the disciplining effects of the standards and the ability of actors to "act otherwise" through friction and alignment. The result of this demonstrates how FSC's normative requirements are simultaneously both boundary objects and sites of boundary work. As such, it shows how the enactment of the requirements occurs simultaneously with the processes they intervene in and control.

\section{Chapter 6 - Synthesis and Conclusion}

This chapter serves to connect the preceding chapters, and to directly answer the research questions posed in the introduction. It also presents additional observations and discussion on the topics of informational governance, auditing, and dramaturgy as well as recommendations for future policy and research. 


\begin{tabular}{|l|}
\hline $\begin{array}{l}\text { Today there is no black or white } \\
\text { Only shades of gray }\end{array}$ \\
-- The Monkees, Shades of Gray \\
\hline
\end{tabular}




\title{
Chapter 2
}

\section{Inside Environmental Auditing: Effectiveness, Objectivity, and Transparency}

\begin{abstract}
With the rise of non-traditional governance methods, the third party audit has become a critical part of governing through and with information. Third party audits are considered an integral part of the process of the generation and dissemination of credible information, and are subject to critique and praise. In this article, we take stock of the literature about auditing. In particular we will examine what modes of auditing are distinguished and how norms of transparency, objectivity, and effectiveness are attributed to auditing. Our review shows that the majority of the auditing literature evokes these norms in an uncritical fashion as characteristics of good audits or as things that audits fail to achieve. We conclude our article by advocating for a more grounded examination of transparency, objectivity and effectiveness, not as norms that can be used to separate good from bad audits, but as they are enacted during the audit process.
\end{abstract}

William Cook, Séverine van Bommel, Esther Turnhout

Published in Current Opinion in Environmental Sustainability in 2016 DOI: 10.1016/j.cosust.2015.07.016 


\subsection{Introduction to environmental auditing}

Auditing has become a ubiquitous phenomenon in many public and private institutions including government institutions, universities and businesses. The term auditing can refer to a process, a tool, or a policy instrument depending on the source. It has its roots in the financial domain, wherein an auditor would verify the financial account of an organisation or individual (Power, 1997). Following the "audit explosion" of the 1970s and 1980s (Power, 1997), auditing as a tool for management began to percolate into other fields. Within the environmental domain, auditing has risen as an important policy instrument to both assess and improve the performance of environmental policies and programs (Power, 1997). Ultimately, however, auditing refers to the process of assessing the performance of organisations or institutions, often by using certain criteria, such as effectiveness or efficiency, often against a specified standard (Tomlinson \& Atkinson, 1987).

With its focus on the generation of information for purposes of governance, auditing can be seen as part of what has been dubbed informational governance (Mol, 2008) or governance by disclosure (Gupta, 2008; Gupta \& Mason, 2014). The main idea of auditing in relation to governance is to increase possibilities for public oversight of all forms of governance including environmental governance. Increased transparency by means of the disclosure of information is assumed to make such oversight possible. This idea took on new meaning when business ideals of new public management were transposed to the public sector and effective- ness and efficiency became important standards to judge performance by (Turnhout, et al., 2014).

Currently, there is a wide diversity of auditing approaches and the products of these approaches may fulfil different needs and are aimed at different audiences (see Figure $D$ ). There are also debates as to what the best form of auditing is. Some authors argue that regardless of their audiences, purposes, and fields of application, audits are best (or should only be) performed by financial auditors as the principles of auditing remain the same regardless of the audit type or setting (Gray, 2000). This generally agrees with Power $(1991 ; 1997 ; 2003)$ who considers many forms of environmental auditing to be comparable when discussing principles. How- ever, on could argue that environmental auditing is a special case because it is often difficult to assess improvements in environmental quality in specific sites on the basis of generic standards and criteria and even more difficult to demonstrate that these improvements are the result of specific measures. Environmental auditing thus, poses specific challenges for auditors when they are faced with the task of interpreting and applying the standards (Robertson, 2006; Eden, 2008).

\begin{tabular}{|c|c|c|c|}
\hline \multirow{4}{*}{$\begin{array}{l}\text { Report } \\
\text { Audience }\end{array}$} & \multicolumn{3}{|c|}{ Report Compilers } \\
\hline & & Internal actors & External actors \\
\hline & $\begin{array}{l}\text { Internal } \\
\text { actors }\end{array}$ & $\begin{array}{l}\text { 1. } \\
\text { - Management audit } \\
\text { - Accounting } \\
\text { - Compliance audit } \\
\end{array}$ & $\begin{array}{l}\text { 2. } \\
\text { - Regulators' reports } \\
\text { - Environmental consult } \\
\text { - Stakeholder research }\end{array}$ \\
\hline & $\begin{array}{l}\text { External } \\
\text { actors }\end{array}$ & $\begin{array}{l}\text { 4. } \\
\text { - Annual disclosure } \\
\text { - Environmental reports } \\
\text { - NGO social audits }\end{array}$ & $\begin{array}{l}\text { 3. } \\
\text { - Certification audit } \\
\text { - Pressure group audits } \\
\text { - Trade union reports }\end{array}$ \\
\hline
\end{tabular}

Figure D. Summary of the types of internal and external audits. Quadrant 1 represents purely internal audits, while quadrant 3 represents purely external audits, such as certification audits. Adapted from Gray (2000). 
In this paper, we review the current state of the art literature about auditing in the environmental domain. We use a critical social science lens inspired amongst others by critical accounting studies, science and technology studies and political ecology to not only look at the quality of auditing system or their purported effects, but also examine how auditing practices work; how they produce information and align this with standards, and criteria in order to make assessment or evaluation possible. We have structured our review as follows: first we take stock of the mainstream literature about auditing both in the financial and in the environmental domain. This will help to clarify what the main focus is of academic debates on auditing. On the basis of that, we proceed by examining three main defining features of what is considered to be a good audit: objectivity, transparency and effectiveness. We end our article with a discussion of the main blind spots in current auditing research, arguing for the importance of critical social science enquiry into the practice of auditing.

\subsection{Environmental auditing in literature}

The literature surrounding environmental auditing is diverse and wide ranging, encompassing many different schools of thought, methods, and contexts. Here we first highlight a novel way to think about environmental auditing which we have termed "modes of auditing". It provides a way to discuss the contextual understanding between auditor and auditee about what audits are meant to achieve and how they are to be performed. While this is not new, we found that is has not been taken up in the larger academic discussion about auditing. Secondly, we demarcate three audit characteristics that are commonly discussed: transparency, objectivity and effectiveness. In contrast to modes of auditing, these are well established themes in the literature.

\subsubsection{Modes of auditing}

As auditing has become increasingly popular and used in the toolbox of environmental management, the prominent style, or mode, of auditing has been in a state of flux between two similar but distinct definitions:

(1) "concept of examination and assessment of performance" (Tomlinson \& Atkinson, 1987)

(2) "systematic, independent and documented process for obtaining audit evidence and evaluating it objectively to determine the extent to which the audit criteria are fulfilled" (Domingues, et al., 2011)

The first definition is general and lacks a number of details on the 'how' that are present in the second, namely that it should be 'systematic', 'independent', 'objective' and 'evidence-based'. Furthermore, the first definition leaves its key term entirely uncharacterised. What is meant by assessment or examination? Against what is it performance assessed? Nevertheless, it focuses on judging management performance without concern for mechanistic details of what an audit is or how it is performed. The second definition is, arguably, more complete. It certainly makes an effort to establish the details of what an audit is, as is evidenced by additional adjectives and adverbs. It also solves the issue of the previous definition by making it clear that performance is being assessed against "audit criteria". This additional specificity gives auditors and auditees more clear expectations of how audits should be performed, but it also burdens the process with being more rigid, and being linked, conceptually, to notions of evidence, objectivity and evaluation. This second definition has gained ground in the traditional understanding of auditing because of its specificity. This progress towards auditing becoming strictly defined activity, co-evolved with the emergence of different modes of auditing which differ in terms of the style in which an audit is done and the functions it fulfils. 
According to Power (1997) environmental auditing started as an activity in which outside groups wanted to gain more insight into the environmental effects of certain organisations such as industry and began questioning traditional accountability structures. As such, environmental auditing was not clearly specified in terms of standards and criteria or in terms of the kind of information that was needed. However, with time, principles of financial auditing, which had a much longer history, increasingly started to invade environmental auditing. Environmental auditing became more strictly defined along the lines of the second definition and it professionalized. We can now look at auditing as consisting of different modes that exist on a spectrum between "professionalisation", what we call professionalism, and "protest" (Power, 1991). "Professional" auditing is representative of a more strict view of auditing, as it arose from financial auditing. This view posits audits as the "neutral monitoring" of pre-existing information against stated criteria (Power, 1991). In contrast, "protest" auditing is not necessarily restricted to pre-existing information or to stated criteria. It can make use of a wider scope of normative yardsticks to evaluate environmental performance against, for example with the aim to raise aware- ness of specific environmental problems and their causes.

Thus, the difference between the poles of the protest- professionalism spectrum, and their associated definitions, is that they "[render] selectively visible" (Power, 1991) different types of evidence in accordance with different standards and criteria which may result different out- comes in terms of performance. Within a single audit process, these modes can lead to different expectations and tensions between the actors involved; the audit procedures prescribe audits to be "professional" while the expectations of stakeholder, and in some cases also auditors, are more "protest" oriented (Elad, 2001; Eden, 2008). Despite the importance of these differences, the different modes of auditing are often implicit. Not many authors actively engage with the mode of auditing to which their analysis subjects subscribe, nor do they reflexively consider what mode of auditing they themselves use. As we will argue in more detail later, by scrutinizing auditing practices we may gain insight into where an audit falls between protest and professionalism, and thereby better understand which audit characteristics are considered important and why.

\subsubsection{Audit characteristics}

While the modes of auditing discussed in the previous section are largely unexplored, there is a body of literature that discusses the characteristics of audits. Out of this literature, three main themes arise: effectiveness, objectivity/neutrality, and transparency. As we will show in this section, these characteristics are often simply posited as defining features of an audit, or used as criteria to evaluate the quality of an audit.

\section{Effectiveness}

We see a distinction between two types of effectiveness in the auditing literature. The first type focuses on how audits are performed. Studies relating to this internal effectiveness focus on questions such as "Are audits being performed in an effective manner?" This is an entirely self-contained or selfreferential topic as it is only concerned with the workings of an audit and how audits can be better performed, regardless of the outcome. Gray (2000) provides an example of how the internal processes of audits are judged as effective or ineffective. The author examines the individual skills and backgrounds of the auditors. Based on their background skills, the author then makes a judgement as to who would perform the better audit. Herbohn (2005) also devotes effort to describing the points in the auditing process where the outcome of the audit would be improved if the inner working were streamlined or enhanced. Thus, this part of the literature is mainly concerned with best practices in auditing. 
The second type of effectiveness focuses on the effects of auditing on the world outside the auditing unit and addresses questions such as "Are audits effecting the change their standards claim?" This is linked with the, sometimes implicit, problem audits are meant to solve in a field of management. If organisations are able to show that they contribute to solving these problems through audits, the audit is in that sense effective. By having these audits, these organisations receive the seal of approval for following some form of best practice in achieving environmental goals, and they are therefore either allowed to enter a market, or are more likely to increase their market share (Yakhou \& Dorweiler, 2004; Fischer, et al., 2005). This can be shown as a concern for specific outcomes, such as minimising environmental impacts of tourism (Diamantis, 1999), increasing stakeholder involvement in forest management (Nitkin \& Brooks, 1998), or more comprehensive improvements of overall performance (Markopoulos, 1998; Ebeling \& Yasué, 2008; Ling, 2010). Also authors that focus on the effectiveness of the larger certification system are, by extension, concerned with the effectiveness of audits (Tikina \& Innes, 2008).

Moore, Cubbage, and Eicheldinger (2012) provide a clear example of the uncritical focus on environmental ac- counting effectiveness. By performing an e-mail survey of forest managers, the authors quantify the changes in forest management practices, concluding that "all [111] firms changed many practices in forest management, environmental protection, community relations, public affairs, economic, and environmental management systems to receive [Forestry Stewardship Council or Sustainable Forestry Initiative] certification" (Moore, et al., 2012, p. 86). Without engaging with the normative values, the ac- counting is assessed in terms of how it results in managerial changes, and therefore in environmental changes.

\section{Objectivity/neutrality}

The second thematic topic that emerges in the literature deals with the idea of objectivity or neutrality. While according to Power (2003), it is "well established" that auditing is not neutral or objective, the majority of the literature is remarkably silent on this issue. Authors either do not engage with the issue at all, or simply assert that audits are objective. Shapiro (1987) noticed that auditors themselves often claim the position of "impartial guardians", and this was echoed in contemporary academic works such as Tomlinson and Atkinson (1987). Other recent authors accept the idea of neutrality as a defining feature of audits without meaningfully engaging with it (Rametsteiner \& Simula, 2003; Sugiura, et al., 2012; Ungureanu, 2012). Rau and Moser (1999) performed an experiment to test the effects of bias on auditor's ability to perform their ongoing audit activities. We infer that the authors indicate that un-biased (objective) auditor behaviour is the idealized behaviour. Auditors deviate from this ideal due to external influences. Thus, in most auditing studies, the idea of objectivity or neutrality has become a given; something that is propagated as a characteristic of auditing or as a norm for good audits.

A relatively small part of the social science literature about auditing, or about other forms of bureaucratic knowledge production, is concerned with how objectivity and neutrality are mobilized during auditing processes. This literature documents the more complex relationship between the auditors and the knowledge that they pro- duce. Robertson (2006) argues that the process of generating formal information for purposes of bureaucratic control (in his case wetland banking) involves various steps during which the indeterminacy of the field is erased and codified by means of principally unstable forms of knowledge, such as species identification. Similarly, ethnographic accounts of auditing show how auditors cannot remain removed from the situation in which they are placed, but at the same time must present their information as objective and neutral (Pentland, 1993; Eden, 2008; McDermott, 2012). Thus, while it is crucially important for auditing information to be seen 
as objective, these studies show that the production of objectivity is situated in the actual practices of auditing.

\section{Transparency}

The final theme we wish to highlight in the literature on the topic of environmental auditing is the issue of transparency. This topic is evoked primarily in terms of how it relates fundamentally to processes of openness, truth- telling and accountability. This particular way of placing transparency in the system of auditing is discussed by Lamberton (2005). Figure $E$ highlights that for Lamberton, transparency is seen as absolutely fundamental to the "auditability" of a system, in order for an audit to be effective, the system in which it resides, the certification standards and auditing procedures, must be transparent. This resonates well with the literature about information- al governance, which promotes transparency as something self-evident and benign (Mol, 2008; Gupta \& Mason, 2014).

However, in contrast to what Figure $E$ suggests, transparency is not always the starting point of audits. A number of authors argue that complex systems are inherently opaque, in that their development is not observable by outside actors, and that in order for audits to be effective, they make sense of this opacity. Pentland (1993) presents an example of auditing without transparency where auditors in show their work by constructing a set of terms as opaque as the management system they are auditing. Asdal (2008) demonstrates how transparency can be seen as the result of the auditing rather than its starting point. Eden (Eden, 2008) echoes this using ethnographic methods to highlight how auditors work with auditees to make environmental standards "fieldworthy", or actionable, in the field. In this work, auditees and auditors strive together and against each other to define key terms of the audit. One such example is the idea of what a "clump" of trees is. The author concludes that the auditors and auditees together define the meaning of the standards in a process that is impossible to observe outside the audit in action. This stands in opposition to the notion that audits are performed against pre-defined standards, which is a key aspect of auditing.

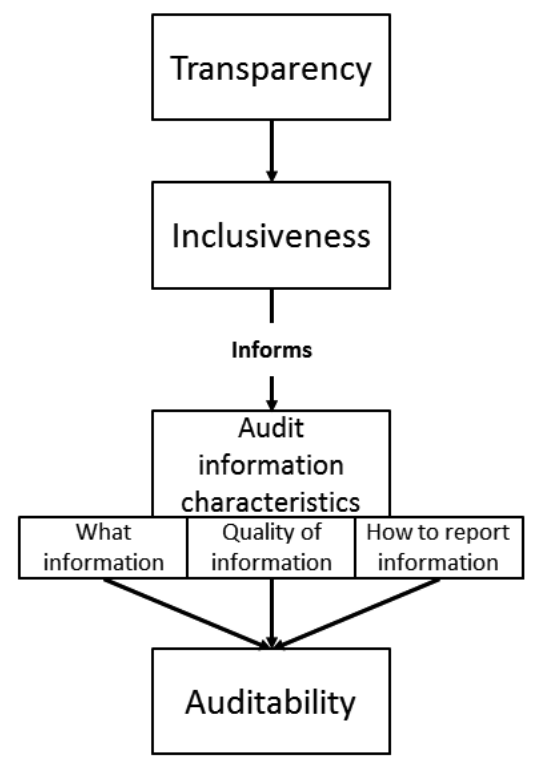

Figure E. Example of conceptualisation of transparency as the base aspect of the "auditability" of a system. Adapted from Lamberton (2005). 
Finally there are authors that interrogate the very idea of transparency and suggest that it is something that is constructed rather than a pre-existent characteristic of a system (Strathern, 2000), as well as others (Fox, 2007; Gupta, 2008; Etzioni, 2010; Turnhout, et al., 2014). This literature argues that while audits are effective only on transparent systems; it is the audits that make systems transparent. However, this transparency is never a fulfilled ideal but always partial and conditional. Neyland (2007) offers a succinct analysis of how this works. He argued that auditing involved the mobilization of "visibles" in order to support the claim of transparency, even if it does not improve an organization's functioning. In this way, transparency is actually more about overlaying a veneer of transparency over a body of working that remains otherwise opaque.

While many authors acknowledge how transparency is a construct of the auditing process, the presence of a recent, very clear, model with transparency as a starting point indicates there is still a notion that transparency is some- how external to the process, as a condition for auditing or as an objective that can be achieved. Moreover, a lack of examples examining transparency underlines a general trend in accepting it as a given part of the audit process (Ungureanu, 2012).

\subsection{Scrutinizing the effects of auditing}

The overall effect of the literature is a division between three general strands in the auditing literature. First, there is instrumental literature that tends to be descriptive in nature, and as such provides a tremendous amount of insights into how audits take place. However, it tends to avoid challenging the assumptions of more traditional views of auditing (Klooster, 2000; Nsekyiere \& Simula, 2000; Hansen, et al., 2006). It is often concerned with discussing whether audits are being performed effectively, whether an audit has effects on management practice, and whether audits are neutral, objective and transparent. Instrumentalist auditing studies may critique auditing for not having achieved objectivity or transparency in auditing, but generally consider those characteristics as things that are assumed to simply exist and can be assessed in a straightforward way. Thus, in this literature, the criteria of objectivity/neutrality and transparency go unchallenged, and in some cases, they act as the jumpingoff point for the whole system.

Second, there is critical literature, which asserts that auditing is not objective or neutral and that transparency is not conditional for audits to take place. This literature exposes audits as something else - opaque, subjective - than they portray themselves to be and argues that objectivity, neutrality and transparency are unattainable. We also note that despite these profound criticisms, the first camp continues without taking notice of the critical literature and without engaging fundamentally with the audit characteristics discussed in this paper. Indeed, it seems that the instrumentalist literature continues to expand at a rate that outstrips the critical literature.

While these two strands of literature differ in how they view a possible lack of objectivity and transparency - as a problem to be solved in the instrumental camp or as an inevitability in the critical camp - both are to some extent similar in their reification of objectivity and transparency. We suggest that by glazing over the question how auditors and auditees think, frame and enact audits as objective/neutral or transparent, both camps in the literature tend to discount the agencies of the auditors and the auditees. This is taken up explicitly in the third strand of auditing literature (Pentland, 1993; Maletz \& Tysiachniouk, 2009; Gupta, et al., 2014). These studies do not uncritically evoke objectivity, effectivity and transparency, nor do they dismiss them. Instead, they offer detailed analyses of how auditors and auditees go about constructing, negotiating, and reconstructing their representations of effectiveness, objectivity and transparency during an audit. Eden (Eden, 2008) once again provides an excellent example by carefully examining the utterances and actions during the 
audit process. In order to determine the "naturalness" of older forests, auditors and auditees engaged in considerable amounts of to ensure that dead- wood measurements (as an example) are presented as factually representative of "naturalness" in the audit report. Thus, the integrity of the audit is produced not necessarily through accurate reporting, but rather through practical negotiation and construction. In order to have a more grounded appreciation of what auditing does and how it produces its effects (which is not the same as asking about its effectiveness) more such studies of auditing practices in the environmental domain are necessary.

These studies would benefit from including what we have termed "modes of auditing". We assert that considering the mode of auditing provides valuable contextual information. It reveals how the way in which an audit is conceptualized by both the auditor and the auditee, alters the expectations of how an audit is performed and how its outcome is received. Examining the working definition of what an audit is provides insight into where along the spectrum an audit might fall. This means considering the spectrum of modes would be useful in fieldwork when considering auditor and auditee behaviour. The mode of auditing therefore interacts with the characteristics of the audit in largely unexplored ways, leaving a considerable blind spot in how we understand audits. Unfortunately, there seems to be a disconnect between those studies that wish to consider the "definition" of auditing and those studies that are concerned with actually performing an audit. Power (1997) argues that focus should be on the effects of auditing rather than the intentions behind it. While we agree with this point to a degree, the lack of critical concern for the assumed principles and definitions behind each audit leads analyses missing data that can calibrate the entire discussion. Specifically, we argue that bypassing discussions regarding more basic assumptions such as what does it mean to be effective, or how effectiveness is performed, limits exploration of the wherefores behind audit (in)effectiveness.

Figure $F$ demonstrates how these ideas can be linked. First, we can see how the two ends of the modes of auditing spectrum can be linked to concrete definitions of auditing, and how different modes are more closely related to different audit characteristics. We would expect to see correlation in investigations into auditing between the mode and the focus of how an audit is performed.

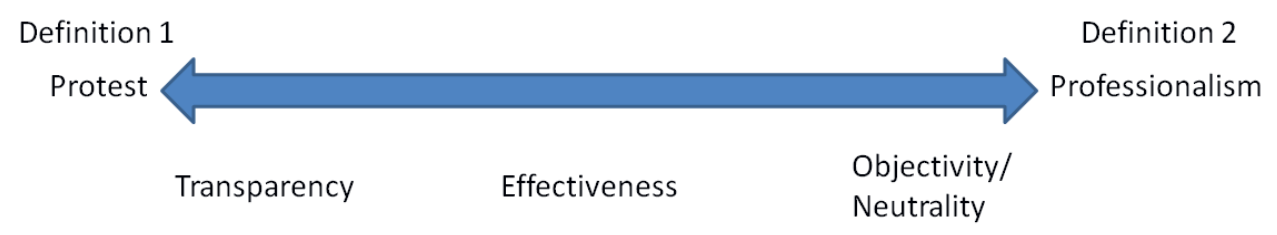

Figure F. Linking modes of auditing with audit characteristics.

Audits and auditors that are more concerned with professionalism, we would expect focus more on issues of objectivity/neutrality. McDermott's study (2012) shows how Forest Stewardship Council (FSC) "ISO-ized" (i.e. professionalized) their processes in order to "signal impartiality". The author goes on to describe how forestry industry representatives were against highly procedural, prescriptive audit processes. This implies that those entities more concerned with professionalism desire auditors to have more freedom to make perform audit procedures without having to show every step they take. Environmentalists, on the other hand, lobbied for "certifier proof" (McDermott, 2012, p. 8) standards. In this view, transparency is inextricably linked with the notion of protest. Elad (2001) also links protest and transparency particularly. In this example "unscrupulous forest managers strive to actively use corporate social disclosures to defend their company's enlightened self-interests, or to deflect undesirable stakeholder demands" (Elad, 2001, p. 649) by not thoroughly explaining key audit 
terms. We therefore see objectivity/neutrality linked to professionalism and transparency linked to protest. Effectiveness is the thread that runs through all modes of auditing literature. Regardless of the normative value placed on the auditing process, there is always concern for either the external or internal effectiveness, as was evident in the literature discussed.

We acknowledge, of course, that this model only deals with the extremes, and in reality, audits processes fall somewhere in between the two poles, but being the subject to which the concepts are applied, they do not appear on the diagram itself. Therefore, to make this conceptual model actionable, more empirical work would be necessary to qualify what exactly exists along the spectrum. As we have conceived it, the model can serve future research by offering multiple entry points to analysing the audit processes. Regardless of whether the research starts exploring the normative values of audits or the mechanical concerns, links can be made to the other audit elements. Having grounded, contextualised data is necessary for these ideas to serve as a useful conceptual framework for future studies about auditing practices that take seriously both the definitions of auditing at work, the practices of auditing, and the relationships between.

Following Li (2007) we assert that definitions of auditing and auditing practices are both equally real and both merit critical attention. Such a practice-based approach to the analysis of auditing (Arts, et al., 2014) along the lines set out in the third strand of literature discussed in this article takes seriously the simultaneous negotiation of the definition and characteristics of auditing, the social context in which auditing takes place, and the phenomenon (the environmental, management activities) that is being audited. Contrary to what the majority of the auditing literature contends, the meaning and importance of effectiveness, objectivity and transparency are not well established. Rather, these characteristics are supremely mutable, and as a matter of course must be made actionable. Insight into how this is done and how it relates to definitions, characteristics and modes of auditing is what is needed to get inside environmental auditing. 
A little learning is a dangerous thing;

Drink deep, or taste not the Pierian spring:

There shallow draughts intoxicate the brain,

And drinking largely sobers us again.

-- Alexander Pope, A Little Learning 


\title{
Chapter 3
}

\section{Learning to Become an FSC Auditor: Objectivity, Interpretation, and Mastery}

\begin{abstract}
This paper aims to open the black box of auditing for the Forest Stewardship Council (FSC) forest management standard. Specifically, we delve into the early steps of becoming an FSC auditor by examining two auditor training sessions in northern Europe.

Using a mix of participant observation and unstructured interviews, the paper subjects the trainings to a dramaturgical analysis that focuses on the ways in which objectivity was performed and on how it was taught to be performed.

Alongside being an exploratory piece on FSC auditor training, this article highlights how objectivity and subjectivity are co-supportive components. Instead of being something to shy away from, auditors are implicitly taught the values of auditing even if they compromise the objective claims of the auditing process. Furthermore, the paper establishes that both interpretive and objective aspects are necessary, and that to compromise either is to diminish the capacity of the audit process.
\end{abstract}

William Cook, Esther Turnhout, Séverine van Bommel

Published in Science \& Technology Studies in $2020^{1}$

DOI: $10.23987 /$ sts. 60766

\footnotetext{
${ }^{1}$ Minor typographical errors in the original text have been corrected in this thesis.
} 


\subsection{Introduction}

The first image of an auditor is that of an outsider, an interloper who swoops in to scrutinise and criticise. It is an image of ledgers, numbers, checklists, and cold, hard facts. It is also an image of faceless devotees busy ferreting away until the truth is finally revealed. These images are not so easily aligned with the daily practices of auditors as they try to make sense of the world; to reconcile what is observed empirically against the audit standards that they are required to apply. Faced with the interactions needed to compress the intricacies of life into easy-to-comprehend checklists for reporting in order to feed society's hunger for information, auditors face a daunting task.

An audit, according to Domingues et al. (2011, p. 1) is a "systematic, independent and documented process for obtaining... evidence and evaluating it objectively to determine the extent to which the audit criteria are fulfilled". This meaning of auditing is becoming increasingly important in a wide range of practices including business management, public policy development and environmental governance activities. The rise of auditing can be seen as part of a wider trend of what has been called informational governance (Gupta \& Mason, 2014; Mol, 2008). As captured by notions such as evidence-based policy or new public management, the legitimacy of policies, including certification schemes, is seen to depend on the systematic evaluation of effectiveness, which requires the systematic collection of standardized information (Turnhout, et al., 2014). Simultaneously, demand for information about how that information is produced has also risen, leading to the so-called 'tyranny of transparency' (Strathern, 2000).

In the environmental arena, this need for information has manifested in the form of third party certification audits, which have borrowed practices and language from financial accounting (Konefal \& Hatanaka, 2011; Power, 1997). The Forest Stewardship Council (FSC) is one of the most prominent examples. Its logo, the 'tick- tree', is near-ubiquitous and can be found on many paper or wood products. FSC has been studied extensively from multiple perspectives. Some authors have focused on the quantitative assessment of the impact of FSC (Auld, et al., 2008; Ebeling \& Yasué, 2008; Moore, et al., 2012), resulting in descriptive accounts of how FSC is effectuating change globally. Other literature has focused on critical examination of the principles behind FSC and FSC auditing (Auld \& Bull, 2003; Arts \& Buizer, 2009; McDermott, 2012). Finally, a small group has looked directly at the practical implementation of the FSC system in the field (Eden, 2008; Maletz \& Tysiachniouk, 2009).

This article draws inspiration from the final group in its focus on the contextualised practice of auditing. However, rather than auditing itself, our analysis addresses auditor training material and how auditors are trained. Analysing this aspect of auditing allows us not only to examine how underlying principles and standards are presented to new auditors, but also to better understand how prospective auditors are taught to apply these principles. As with all educational or training activities, examining underlying elements is an important part of understanding the process of becoming an expert. Particular attention is paid to the importance of objectivity in the repertoire of an auditor, and by extension, the role of what is considered subjective. In so doing, we follow along the lines of Power (2003) who, drawing on the work of Bourdieu, rejects the assertion that the seemingly well-formed concept of objectivity signifies anything at all. Instead, we conclude that while the explicitly trained and well-practiced aspects of auditing are important for the overt performance of objectivity, the illformed, ill-trained aspects of the FSC audit are equally important for creating meaningful audits and performing objectivity. It is important that this is recognized in view of the increasing significance attached to auditing as an indispensable part of legitimate and effective environmental governance. Furthermore, it is in the interest of improving audits for this to be recognized if the principles of audits and auditing are to be prioritized in society. 
Power (2000) questioned the prominence of auditing in society outside of the UK, but one only needs to look at the state of FSC's certificates to see that it is a global phenomena. In 2017 there were more than 1500 valid FSC forest management certificate and 33000 valid FSC chain of custody certificates globally (FSC, 2017b), each one representing a yearly surveillance audit and quinquennial recertification audit. These audits are performed by approximately 40 organizations (ASI, 2017) of varying sizes from a few individuals to major multi-national organizations. Considering the magnitude of FSC certification as an industry, and the importance of its values such as transparency, accountability, and objectivity in environmental governance (Power, 1997; Mol, 2008; Gupta \& Mason, 2014), it is crucial to examine the explicit and implicit aspects of auditing as auditors themselves learn them.

By presenting an analysis of two FSC auditor trainings in 2013 and 2014, this article contributes to the understanding of auditing as a practice. Before presenting our findings, we first provide an explanation of our methodological and conceptual approaches, followed by a more detailed introduction to the FSC auditing system.

\subsubsection{Expertise and the performance of objectivity}

The definition of auditing offered earlier emphasizes the term 'objectively'. Objectivity indicates a rigid system by which auditors gather and analyse data. These data are subsequently confronted with the standards in order to determine whether they are evidence of conformity or non-conformity. However, as in other processes of knowledge production, there is a social dimension to auditing. Porter (1995, p. 35) explains "strict rules are almost indispensable unless those gathering the numbers are themselves very well socialized in the craft." This suggests that following rules is important for novices, while those with more experience are apparently able to transcend the intellectual pursuit of 'objective thinking' to the point of being intuitively a master of a craft (Yanow, 2015a). Mastery of a craft means that expertise has reached a level where expert judgement no longer requires deliberation or justification. This is derived from Dreyfus and Dreyfus (2005, p. 779) who argue that "intuitive judgment is the hallmark of expertise". Applied to auditing, Pentland (1993) describes how seasoned financial auditors conclude their activities only after preforming the 'ritual' of becoming 'comfortable' with the numbers, which is far from an objective measure.

Collins and Evans (2007) characterise expertise, working their way through their 'periodic table of expertises' from those skills which all members of a group share (e.g. common language) to the highest level of expertise (e.g. competently doing the activity). In between these extremes is the production and acquisition of knowledge or facts without context or 'practical competence' (incidentally, this is precisely the outcome of the training we analyse, but this will become evident later). For this so-called interactional expertise, no amount of if-then statements can capture the knowledge necessary. It begins to transcend the common language, relying entirely on the language of the expert-group. Essentially, one can 'talk the talk' even if one cannot 'walk the walk'. These descriptions of expertise are subject to limitations when the knowledge is subjected to high-risk, low margin of error situations (Turner, 2010). Types of expertise that demand fast adjustments with little room (spatially or temporally) for error correction do not have the luxury to disguise the errors and must sometimes instead acknowledge their "interpretive flexibility" (Turner, 2010, p. 250). When there is a failure in the knowledge of the expertise, the expert is forced to improvise, drawing on the baser elements of Collins and Evans' periodic table. This includes non- deliberative, non-knowledge-based elements.

Kotzee's (2014) review of the literature of expertise criticized the 'fluency' narrative, which can be seen in the references to 'intuition' and baser skills in the texts above. The author's concern was that 
in-the-field experience is seen as the only real teacher of expertise. As such, teaching has become concerned with the performance of expertise rather than the outcome. The author also objected to the idea that the so-called tacit knowledge of expertise was tacit only because physical constraints prevent effective characterization of fast-paced or complex activities, and therefore no attempt is made to teach it. The author called for a 'social realism' perspective on expertise in which academics, educators, and experts themselves "see expertise as a real and objective ability to accomplish something in the world that enables the expert of give advice to others..." (Kotzee, 2014, p. 176). As such, it is important to keep in mind the "matter of how the expert... acts or... their own interpretations of their work." (Kotzee, 2014, p. 176). Kotzee (2014)) goes on to critique the training of experts resulting in a preoccupation with the appearance of being an expert, avoiding valuing "real and objective" abilities. Our article follows this line of reasoning to a point but draws on the understanding of expertise as both entirely socially constructed and also absolutely real it its effects (also see Eyal and Buchholz, 2010). This point is made in our concluding remarks.

Bal et al. (2002) offer further insight into how expertise, despite its constructedness, can assume authority and produce effects. They have outlined a central tension in the authority of science; science presents itself as authoritative and objective; however, it can only be so because behind the scenes the actors are able to effectively navigate and negotiate what it means to be authoritative and objective. Gilbert and Mulkay's (1984) analysis of scientists' discourse touches on a similar phenomenon. They show how scientists make use of two distinct repertoires to establish and justify their authority. The first repertoire is the empiricist repertoire. This repertoire is most common in the formal literature. It portrays scientific results or facts as objective, "as following unproblematically and inescapably from the empirical characteristics of an impersonal natural world" (Gilbert \& Mulkay, 1984, p. 56). The second repertoire is the contingent repertoire and is common in informal talk among scientists. This repertoire is in opposition to the empiricist repertoire because it emphasizes the importance of context, personal inclination, and judgement. While there is an obvious tension between these two repertoires, scientists are apparently able to draw upon both repertoires. Examining this tension as it takes place in auditing will result in a better understanding of the cultural norms - both formal and informal - that are embedded in auditing (Power, 1995).

Thus, what we see emerging here is a paradox of expertise: on one hand, experts need to follow strict rules and they need to be objective, while on the other hand, expertise is about mastering a craft, which involves subjective feeling and intuition. Furthermore, there are times when pure, objective knowledge either does not suffice, or is not possible. Objectivity and subjectivity must be aligned through expertise. Conceptualizing the presentation of the trapping of expertise, authority and objectivity, as performance allows us to make sense of this paradox. Goffman (1959) presented the concept of performance as a way to explain how and why people behave in certain, largely consistent, ways when confronted with repeated or habitual, self-contained events. According to Goffman, people play specific roles, which encompass all the little details that are expected when the proper situation is presented. These roles are self-contained and rigid since breaking character causes a failure in the performance. To ensure a successful performance, the actors must be aware of, and control the 'frontstage' and 'backstage' of a performance. As we will show, the frontstage is the formal and public part of the activity. Here objectivity is emphasized as in Gilbert and Mulkay's (1984) empiricist repertoire. While in the backstage, behind the scenes, all kinds of activities and interactions take place which make the frontstage performance possible, but which in themselves are not part of, and may even seem incompatible with, that performance. It is here that the contingent repertoire abounds. Hilgartner (2000) expanded Goffman's dramaturgical perspective to include documents and reports, revealing how documents can obscure backstage elements, in particular the messiness of 
scientific processes, and either implicitly or explicitly bring authority- granting elements, such as claimed domains of expertise and partnered organisations, to the frontstage performance. Applied to the paradox of expertise identified earlier, this suggests that the successful frontstage performance of objectivity depends on the intuitions and values that are part of the mastery of the craft that needs to be kept backstage.

How then is objectivity performed in auditing? We draw on Douglas (2004) to further explore the different meanings that are associated with the notion of objectivity. Douglas argues that objectivity can be interpreted in three interrelated ways, which she calls 'modes of objectivity'.

1. Object-oriented objectivity: how knowledge- creating actors "get at" objects in the world.

2. Value-oriented objectivity: values that are upheld by observers in order to know some- thing objectively, such as detachment, disinterestedness or neutrality.

3. Process-oriented objectivity: the methods and processes that are deemed necessary in order to produce objective knowledge.

We assert that each of these interrelated modes emphasizes the performative dimension of objectivity: in order to demonstrate objectivity, actors must show that they have the right values and have followed appropriate procedures, and they must convince outsiders that in doing so, the knowledge produced refers to the object, not to the subject.

In most uses of the term, subjectivity is the opposite of objectivity: if knowledge is subjective, it cannot be objective. According to Douglas (2004), the negative connotation of subjectivity is misplaced. The knowing subject cannot be erased, but forms a component of the process of producing knowledge and objectivity. We have also seen this in our earlier discussion of mastering the craft and of the importance of the backstage for the successful performance of objectivity.

As Porter (1995) has shown, objectivity is evoked mostly in fields that face outside scrutiny. This explains why it is important in auditing practices. Auditing itself is a form of outside scrutiny, and in order to be authoritative both towards those who are scrutinized and those who do the scrutinizing, it must be held to the highest standards. Keeping in mind the paradox of expertise - the fact that backstage processes of subjective interpretation are vital for the successful frontstage performance of objectivity - how are prospective auditors trained to perform objective audits and become masters of the craft of auditing? How do they learn to navigate the paradox of auditing and 'do' objectivity as well as interpretation? The element of training adds an important dimension to this because the auditor training is itself a performance in which the teachers must convince their pupils that they are experts in their field while at the same time they must teach initiates how they do auditing. To use a well-known expression: they must not only convince the students to eat the sausage, but also show them how it is made.

\subsubsection{Analysing FSC audit practices}

Our analysis is based on materials from two FSC auditor training courses, which took place in northern Europe in 2013 and 2014. Information was gathered via active participant observation by the first author who enrolled in the courses as a trainee. The participants were informed that the first author was there in an academic capacity and would be writing a paper based on the course contents and trainee actions and reactions, and they all consented verbally in the presence of the trainers. The trainings were held in a hotel conference room with a U-shaped arrangement of tables and chairs facing an open space that included a projector screen (it was the same location, setup, and content 
both years). The trainings were attended by an international group of 12 and 13 auditors-in-training. Over the course of the following days, the majority of the time was spent listening to and watching the trainers present slides, each reproduced faithfully in the training manual, while they responded to questions from the trainees. This was interrupted by exercises where the trainees were told to divide into smaller groups in order to practice the content that had been covered recently, or the entire group was asked to respond to items displayed on the projector. The courses culminated in a multiplechoice and open-response exam covering all the content. If successfully passed, the trainee received a certificate from the training organisation certifying successful completion of the course. The lead author of this article participated in all activities as well as in informal socialization during breaks and evenings.

During the training, the lead author's focus alternated between cataloguing and critiquing the substantive details of the training material, and observing the reactions, questions, and conversations of the trainers and trainees. Data was collected by means of note taking and audio recording when possible. The result was approximately 25 type-written pages of field notes per training course (divided into 'direct observations' and 'interpretations'), compiled daily and revised over the weeks following the courses. These notes included in-situ observations, as well as post-hoc interpretations of training manual contents (documents, PowerPoint slides, and images) and utterances during the training (both from notes and from transcribed audio recordings).

Analysing this data proved challenging due to its heterogeneous nature. Following Law's (2009b) approach to iterative interpretive analysis of mixed content, interpretive analysis of the content was performed during the training, at night following each training day, and 'out of the field' in the weeks and months following the course. By reading and re-reading the notes and training manual, it was possible to classify them according to emergent themes and patterns. Particular attention was paid to key buzzwords, including those referring to the modes of objectivity that were used, and the meanings associated with them. This was supported by considering the use of images that were paired with particular phrases, and the physical reactions of the trainers and trainees. Furthermore, due to the participative nature of data collection, I served as the primary tool of measurement, and so personal reactions to the course content served as an input to understanding the training.

The findings presented below are the result of the iterative process described in this section, as informed by the theoretical perspective above. The first part of the findings is structured on the basis of the modes of objectivity in order to highlight the multiplicity of ways in which objectivity is performed during the training. The second part of the analysis focuses on how the trainers perform for their students that they are masters and teach them how to become the same. We end by discussing how the tension between performing objectivity and performing mastery is mitigated in the performance itself through auditing/auditor values.

\subsubsection{The Forest Stewardship Council}

The basis for FSC's Forest Management certification system is its ten principles of responsible forest management. These are the same regard- less of the location or type of forest to which they are applied and are established and revised periodically by FSC. These principles define what FSC regards as responsible forest management practices and are operationalized by a set of criteria and indicators. The criteria serve as the first- order test if the principle has been met, and are generic, applicable to most locations. Indicators, on the other hand, are country-specific and represent the specific management elements that must be monitored in order to determine if the criteria, and therefore the principles, are fulfilled. 
The first year, and every fifth year thereafter, that a forest management entity wishes to be certified, a certification body (CB) is hired to perform an audit for all the principles, criteria, and indicators. In the interim years, surveillance audits focus on a selection of principles and criteria and associated indicators, purposefully limiting the scope of the audit. During the audit proceedings, auditors are expected to carefully examine the forest management procedures and processes to determine if they conform to the principles and criteria, or if they are non-conformant. In the case of non-conformance, the auditor determines if this is a major or a minor non-conformance and reports it as such. In the case of a major non-conformance, the managers have 6 months to respond satisfactorily to the findings, while a minor non-conformance has a year to respond. If the responses do not come, or if they are inadequate, the certificate is suspended.

Each audit results in a report, some of which is made available on the FSC International website, and some of which is not made public. The report details the nature of the management, what species are present, the history of the management, and the products produces (from round logs to finished goods to non-timber forest products), as well as a catalogue of non-conformance reports (NCRs).

Auditors are required to meet certain requirements before they can be accredited as FSC auditors. One such requirement is a minimum number of hours of training (FSC, 2016). The list of topics to be covered by training is extensive but not exhaustive, detailed while remaining vague. Individual auditing firms have their own training requirements that auditors must meet as well. To gain entry to the world of FSC auditors, one must be prepared to immerse oneself in training material.

\subsection{Performing Objectivity}

The trainers introduced the notion of objectivity early in the training. After an opening title slide featuring auditors talking to a man in a piece of forestry machinery, the trainers presented a slide titled "What is auditing?" in large, bold letters. Their definition, "Objective and independent evaluation of conformance to specified and agreed requirements", stood next to an image of an evenly-balanced golden scale. Verbally, the instructor added that it is important to remember that the audit is against something specific, not what the auditors think is right or wrong. A second definition of auditing was presented shortly after the first. It was the International Organization for Standards (ISO) definition of an audit, characterising it as a "systematic, independent and documented process for obtaining audit evidence and evaluating it objectively to determine the extent to which the audit criteria are... fulfilled". There was no discussion of what was meant by the elements of this definition, just nods and note-taking by the trainees.

The term objectivity appeared many times more during the first half of the training, being expressly named 13 times, but slowly disappeared as the training progressed. However, given its prominence in the opening definitions, it is of paramount importance to the role of an auditor. While it was never explicitly stated what is meant by 'objective', we can get a sense by noting the connotations associated with it. The image of a balanced scale connoted fairness, justice, and impartiality. It also suggests the removal of the human contextual element, replacing it with technology that has an expressly designed purpose of measuring accurately and precisely.

As its position is so important, many elements of the training explicitly or implicitly communicate how the role element of 'objectivity' should be performed. We examine the aspect of objectivity using Douglas' (2004) three-part frame of the term: Object-oriented objectivity, values-oriented objectivity, and procedurally-oriented objectivity. The details of the 'modes of objectivity' (Douglas, 2004) will be discussed in the following sections. 


\subsubsection{Object-oriented objectivity}

In order to "get at" the true, objective facts of the audit, the trainers put forward a model of action that, if followed, would lead auditors to be certain of what is observed. 'Triangulation' was named as the proper method for "gathering audit evidence". The trainees were told that if something is observed, an auditor must seek out "all" the evidence, either supporting or contrary, through documents and interviews. If pursuing a detail through multiple lines of inquiry leads to the same evidentiary result, the auditor can be sure this is the true, objective reality. Figure $\mathrm{G}$ reproduces how this principle was presented during the training.

\section{Documents}
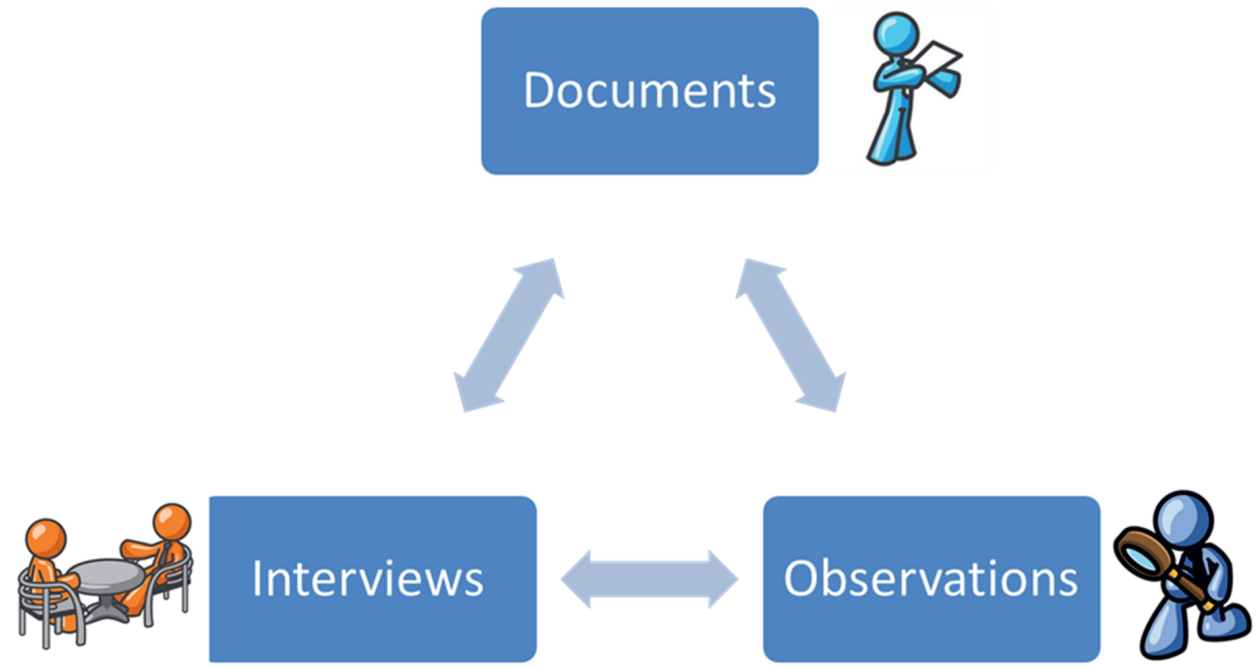

Figure G. Proving something as objectively true involves triangulation, as reproduced above.

The trainers went on to define "audit evidence" as "records, statements of fact, or other verifiable information". Therefore, in order for something to be considered evidence at all, it must be documented and possible to check it against something else. During the training, it was stated that it is preferable to check a possible piece of evidence against another type of evidence but checking against the same type of evidence is also acceptable if circumstances prevent cross- checking.

This form of objectivity served as the foundation for the whole training. Nothing could be stated without the express reference to multiple sources of evidence, or at least with the offhand comment that in a real audit, we auditors-to-be would look for something to support or refute our findings in other sources. The objects of the audit, therefore, are not necessarily the forests themselves, but rather the management artefacts around the forests. By ensuring multiple avenues of evidence, the foundational objectivity is supposedly ensured.

\subsubsection{Value-oriented objectivity}

The trainers dedicated an entire section of the training and its manual to explicitly laying out the aspects of proper auditor behaviour and attitude. This was led by the assertion that the purpose of an audit is "to find POSITIVE evidence of conformance" (emphasis theirs). This means that rather than focusing on finding evidence of what was going wrong, we were told to focus on evidence of what was 
going right. In order to get "the real" evidence, auditors need to maintain an "open" frame of mind. The term 'open' was the second most repeated buzzword of the training, and usually referenced how an auditor or audit process should be. Valuing 'openness' ensures an auditor is willing to investigate all sources of possible evidence to "get all the information" (according to the method of triangulation) before deciding about conformance or non- conformance. Adhering to the value of openness allows auditors to focus on what is observable rather than on what is valued by the auditees; this allows the auditor to not be blinded to unpleasant or unexpected findings.

The trainers underlined this by showing an overarching communication flowchart juxta- posing "openness" with "criticism". Figure $H$ shows how openness is inherently a virtue that leads to a positive outcome, while not being open inexorably leads down the path to withdrawal from communication. Thus, auditors should promote the value of openness because that ultimately leads to communication of information, which allows for triangulation regardless of the values influencing the situation.

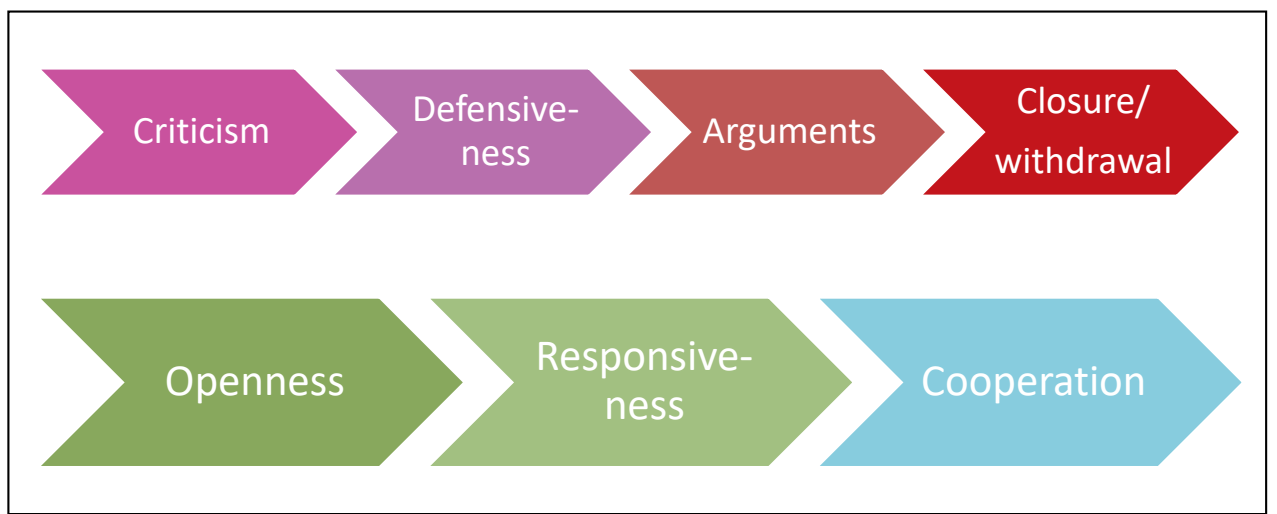

Figure H. The inevitable link between openness and cooperation, and criticism and closure, as presented in the training.

The topic was complicated, however, by the idea of 'neutrality' which the trainers introduced later in the training. The trainees were instructed to "view without prejudice" the situations during the audit, but to nevertheless come to understand why we see what we see. Therefore, the value- laden aspect of human-managed systems is given weight, but supposedly not allowed to influence the findings of the auditor. Auditors should have the "ability to understand the... situation," although there is no need to take sides on the values at stake. Thus, an auditor can transcend these values by remaining neutral and thereby maintain the objectivity of the findings.

\subsubsection{Process-oriented objectivity}

A large portion of the training was dedicated to the procedures of an audit; it focused on engaging the right processes to attain objectivity. These processes would ensure that, as summed up in an offhand comment by the trainer: "anybody would come to the same conclusion". In theory, if an audit were performed twice, and the same procedures followed, the same conclusions would be reached regardless of the auditors present. How- ever, in the same breath, this situation was problematized when the trainers introduce the idea of the "unforeseen situation". At this point in the training, the trainers were vague about what such a situation may be, but we experienced simulated "unforeseen situations" in the exercises discussed later. The addendum of the unforeseen suggests that each audit is unique, and following standardized procedures is an attempt to control a chaotic system in order to claim a form of objectivity. 
During the first day of the training, the trainers spent time describing the procedure of an audit, which included establishing the shared vocabulary of an audit. To someone unfamiliar with the audit process, terms like ' $C B$ ' would be meaningless, and indeed, most of the trainees seemed to know what it meant, as the lead author was the only one who felt the need to ask. Having, and effectively utilizing, a shared and codified vocabulary can serve two purposes: First, it identifies to others in the auditor role that you are also in the role of auditor, and it also eliminates imprecise, humanising language. Throughout the training, the trainers, and progressively the trainees, continued using terms like 'CB', 'surveillance audit', and 'NCR' (non-conformance report) consistently. By employing such codified, expert language, auditors can supposedly be more precise and can attempt to eliminate personal idiosyncrasies.

Due to the nature of the training, field observation procedures were not very well covered, as all material had to be presented to the trainees in a classroom setting. However, the topics of interviewing and communication had a well-defined set of recommendations, almost to the point of being a script. The value of openness identified earlier came strongly to the fore here. Specifically, it was considered important to avoid closed and aggressive forms of what they called "shoot and reload" communication. Rather, to promote open communication, the trainees were instructed to use "open questions" to promote "conversation" instead of "interrogation". This included a list of stock-phrases and questions to be used ("Tell me how...", "what is the procedure...", "why have you...").

Following this instruction, we performed an exercise to test our "interview skills". We were playing the role of auditors who had a short time to interview a health and safety officer and a chainsaw operator (played by the trainers). Based on the way the interview progressed, the trainers offered critique if we interrupted or did not ask sufficiently 'open' questions. The purpose of the exercise, it was explained, is to allow those being interviewed the chance to give you all the information so you can come the correct conclusion.

Alongside the information collecting, the trainers also addressed recording and reporting by introducing the NCRs. NCRs were described as the "mechanism for requiring the auditee to take action to meet the standard". It was previously established in the training that auditors should communicate non-conformities in an "objective and diplomatic way" and "be open for additional information". Therefore, even concluding that there is a non-conformance may change in the face of additional evidence. To present the NCR, the trainers showed an example NCR form with pre-determined fields for describing the non-conformance, "corrective action request" (or 'CAR'), and timeline for conformance among other fields. The result is an inflexible, but subjectively descriptive way to frame the observations made during the audit.

During the substantive teaching of the training, all three modes of objectivity emerged as being important to the success of an audit. No type of objectivity was given precedent over the others, as process-oriented objectivity mingled equally with statements on value- or object-oriented objectivity. Through this explicit or implicit discussion of objectivity, we can see how each type of objectivity is trained to be performed during an audit, and how they are co-supportive.

In the following section we examine how objectivity might be done in the chaos of the field. We discuss several exercises which served to simulate the chaos of a "real audit". While the application of procedures described previously was encouraged, in the end, the trainees needed to step away from the cold application of knowledge to make it practical. As we will describe in the following section, trainees were expected to interpret the situation using heretofore undefined or poorly defined criteria. 


\subsection{Performing interpretation}

During the training, objectivity was actively named and encouraged as something to promote and aspire to. In the previous section we discussed the most prominent ways in which objectivity was invoked. There emerged another aspect of being an auditor that did not follow the zealous application of objectivity, and was, mostly implicitly, termed interpretation.

"Interpretation" was mentioned explicitly only once during the training. In the section regarding auditor behaviour (discussed previously), interpretation appears in a communication model explaining how auditors should strive to understand what is truly meant by the auditee and understand that the auditee must do the same. Figure 3 reproduces this image. In this context, interpretation is something that is actively done to decode encoded statements. The trainers fully acknowledged that despite having technical know-how and information about the management, it is still possible to not get at the real "reality" of the situation. However, previously, the trainers had stated that there is "no one reality", and that it is an auditor's job to discern which reality presented by various actors is most valid, or the really real reality.

The trainers identified this as the "ability to understand... the situation" but were not able to characterise it beyond the methods, procedures, and facts described in the previous section. In order to actually "understand... the situation", we were told to pay attention to auditee tone of voice, body language, and what was not said as much as what was said. The idiosyncratic nature of these elements meant that the trainers were only able to speak in broad terms, and it was up to the trainee to determine when there was "enough information" to judge the situation. For example, the trainers explained that if a worker seems reluctant to speak, failing to make eye contact or speaking softly, it is a good idea to speak to them on their own later as they might be hiding something. We asked about how to consistently interpret these elements, but the trainers were not able to give meaningful answers. The term "interpretation" was clearly not acceptable for this type of analytical work. Nevertheless, we were being asked to observe and interpret the actions and utterances of the auditees.

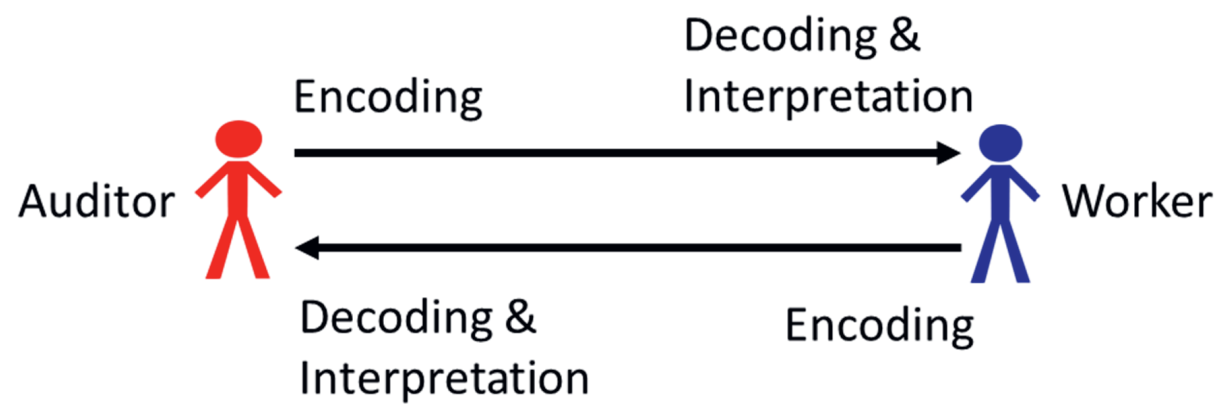

Figure I. The only official use of the term "interpretation", presented in the training in a highly simplified communication model.

One set of exercises where interpretation was practiced was roleplaying exercises. We had access to mock forest management plans and were expected to effectively and efficiently divide the work to assess conformity. However, they also included "unforeseen situations". For example, a gregarious manager who wanted to have a celebratory drink, and a business partner who was quiet when in the presence of the other partner, but talkative alone. If we, the auditors, were not sufficiently strict with 
the former or did not interpret the downcast eyes of the latter properly, the trainers would critique our interpretive skills.

The trainers acknowledged that these situations were artificial and contrived in nature, but they were meant to simulate the chaos of a real audit. If we did not follow the proper interviewing guidelines, or failed to utilise the approved language properly, our interpretations were considered fallacious. In particular, the role of properly distinguishing between friendliness and deception, properly understanding body language, and tone of voice were practiced. Each team (3-4 people) was able to watch the others perform their interviews and offer their own critiques. These exercises still relied on executing the 'audit procedures' properly but required the trainees to interpret and react on their feet without the benefit of conscious, rational deliberation.

This was continued with a photo identification exercise. In the evening of the second day, the trainers presented a series of slides containing various scenes around a forest management unit. We were asked to look at each picture for a few seconds at a time and determine if there were any nonconformances. If there was a problem, we were expected to identify which part of the FSC standard was being violated. The results were mixed. Some non-conformances were missed, but more often, non-conformances were identified when in fact there were not any. The lead author made at least 4 incorrect identifications of non-conformances when, in fact, there were no problems. Following the exercise, there was discussion where trainees were asked to reveal their judgement of the photos, and to justify their findings. While some were definitively ruled as correct or incorrect by the trainers, more than once the trainer conceded that there was missing information or room for classifying it either minor or major non-conformances. When put in a situation that needed snap-decisions, we were expected to rapidly interpret the situation and come to a conclusion utilising the details learned during the course.

One of the trainers brought up a clear example of interpretation in a situation where a snap- decision was required. To illustrate the point of knowing how to "split auditors appropriately", dividing the audit team to cover more ground in an efficient manner, the trainer told an anecdote wherein, on a "hunch", he thought there was a need to investigate a certain area of the forest. There he found evidence that the managers were hiding evidence of all the injured workers from the auditors. When pressed on how he knew to look for this, the trainer gave a small hand wave, and an answer along the lines of "I just knew" based on all the glances, winks, nods, utterances, and silences he witnessed during the audit.

During the training, it became increasingly clear that interpretation is demanded of auditors in almost all aspects of their work: in assessing management plans, in exploring situations, in understanding the behaviour and responses of auditees and in making judgements about conformance or nonconformance. It was also clear that, despite the emphasis that was put on procedures, there can be no procedure for interpretation; it can only be based on experience and intuition in the moment.

The front staging of interpretation during the training, like in the example of auditors acting on a hunch, triggered two simultaneous responses. On one hand, it was seen as evidence of the authority of the trainers. At the same time though, it posed a problem for the trainees because they did not know how, nor could they be taught to do this themselves and maintain objectivity. The trainer was unable to communicate the imponderable details that led up to this insight; he could not provide an answer that could help the trainees learn how to do this themselves. Nevertheless, through the gesture of the shrug, he showed that he recognized the problem but that it did not bother him. 
Forgoing deliberation helped reinforce the necessity of becoming an authority and satisfying the audience.

This situation was echoed in another manner during the training. Over the course of the training, approximately six times when a trainee would ask a question or pose a hypothetical situation that would address a tension between the seemingly straightforward procedures for auditing and the need for interpretation, there would be a moment of pause, after which the trainers responded in a similar way as described above. They would try and offer an explanation and while the answer was relayed, a hand would be waved through the air. This gesture specifically became attached to the phrase "we all know how it is" when it was repeated three times in short succession by two trainers and a trainee when describing hypothetical forest management practices.

As we will argue in the next section, these gestures are an important part of the trainers' performance. They are where objectivity and interpretation become entwined in the performance of mastery.

\subsection{Performing mastery}

Utilising Douglas' (2004) modes of objectivity, we have demonstrated how FSC auditors are taught to perform objectivity in audits by trying to get at the object, following the right procedures, and adhering to the right values. In agreement with her analysis, we find that most forms of objectivity are encouraged, though not necessarily equally, in most situations. We have also seen that the subjective, in the guise of "interpretation", and the objective overlap in many cases. In fact, interpretation is necessary for the successful performance of objective audits. Thus, subjectivity is not the antithesis of objectivity, but rather a vital support of it.

In the training, they often belonged to different settings. Objectivity was most prominent in the more substantive parts of the training where content was taught explicitly. Interpretation, on the other hand, could not be taught in the same way as the elements of objectivity. It was taught as something done in the mind of the auditors, or within a team of auditors based on the information gathered while employing the modes of objectivity. It was highlighted in stories of the trainers and it was practiced in exercises. Trainers also assessed and critiqued the performance of the trainees in both aspects. They assessed our level of knowledge (for example, identifying the correct part of the standard to use), but also less tangible skills (for example, spending too much time complimenting good management or not asking sufficiently open questions).

Objectivity and interpretation did not clash but smoothly alternated and aligned for the most part of the training. Generally, interpretation was implicitly recognized as important and non-threatening. One way in which this was done was by taking the FSC standards and criteria as the immutable starting point of interpretation. While it has been said that standards are not in fact stable or immutable (Eden, 2008), this is not how they were presented during the training. By initially referencing something that neither the auditors nor the auditees had any hand in creating, something that cannot be changed by the involved parties, the auditors are able to claim objectivity. Therefore, it is never the auditor who is saying if a management practice is (in)sufficient, it is the standard saying it. Although interpretation is seen as part of process, specifically when the findings of the audit are tested against the standards, this interpretative part quickly disappears from view when the findings become objective evidence of conformance or non-conformance.

However, in some instances, interpretation could not be hidden or denied. In the example of the "hunch" leading to discovering hidden injuries, the trainer revealed how he had to make a judgement on whether to follow his interpretation of the situation (his "hunch"). He decided to "go with his gut" 
and this led him to certain results that after proper documentation could be used as objective evidence of non-conformance. While the judgement of non-conformance could be justified by referring to the evidence and their testing against the standards, it does not meet the expected burden of object-oriented objectivity of auditing. It would be entirely possible for another auditor to not make this decision and miss the evidence. When asked during the training, the trainer was unable to explain what exactly made him suspicious. In this story, and in other similar anecdotes that were shared during the training, the tension between objectivity and interpretation manifests itself on stage. While in most cases, interpretation can be kept hidden in the backstage, in the context of the training where interpretation is taught and put on stage, the trainers must find a way to mitigate or transcend this tension. This was not just a matter of flexibly, manoeuvring between contrasting repertoires as Gilbert and Mulkay (1984) suggest. Instead, this transcendence was accomplished in bodily performance; in the shrugs, nods and handwaves. We suggest that these gestures, combined with phrase "we all know how it is" are central to the performance of mastery. This performance of mastery illustrates Dreyfus and Dreyfus' (2005, p. 787) argument that the "proficient performer" has a "repertoire of situational discriminations" that allows for "immediate intuitive situational response[s]." It fulfils several functions. First, it bypasses cumbersome explanation. Thus, the successful performance of mastery is characterised by not needing to justify or explain the interpretative process. Second, it recognizes the trainer's inability to explicitly explain or justify while at the same time dismissing it as insignificant, as unthreatening to the objectivity of auditing. Third, it creates a sense of community among trainers and trainees. By shrugging or handwaving and communicating "we all know how it is", and by employing the same, codified language, the trainer conveys what Goffman (1959) calls a role secret. It signifies that trainers and trainees are all member of the auditing community while still maintaining process- oriented objectivity (Douglas, 2004). Trainees could respond, and many did by nodding understandingly, confirming their membership of the community. Finally, it serves a didactic purpose: regardless of whether trainers or the trainees do in fact "know how it is", the trainees get a sense of what it might entail to perform mastery without having to fully come to terms with what is needed to be a master. The attention paid to interview and interviewee affectations, as well as the importance of auditor language and behaviours can lead an auditor in training to be a master at adopting the mannerisms of a master with the assurance that true mastery will come through practice.

This aligns very closely with the notion of interactional expertise. By progressing from strictly knowing the content of an audit as a function of promoting objectivity, to accepting the role of interpretation, to mastering the meta- aspects of an audit performance, the lead author was inducted into the ranks of FSC auditors. In the following section, we discuss some key points from the analysis and conclude with broader implications for the field of forest certification auditing.

\subsection{Conclusion}

Objectivity was considered fundamental to auditing during the trainings. Using Douglas' (2004) modes of objectivity, we highlighted how objectivity was promoted explicitly and implicitly during the training. According to the principles of the training, however, attempting to do objectivity in the field inevitably leads to a breakdown in objectivity. The knowing subject (the auditor or trainee) is forced to inject her/ himself into the situation in order to properly interpret what is going on. From an outsider's perspective, the resulting paradox could be seen as problematic, as interpretation seems to be anathema to objectivity. However, the trainees are taught that by properly performing the audit, it is possible to simultaneously perform objectivity - establishing and maintaining an object separate from the subject - and perform interpretation. In doing the audit or practicing the doing of an audit, objectivity and interpretation become co-supportive or co-constituent. In the performance of 
mastery, the paradox of auditing is mitigated or transcended almost completely without conflict. While the current analysis is based on auditor trainings, where interpretation cannot be left in the backstage but must be put on stage for teaching purposes, the same co-constitutive relation between objectivity and subjectivity is expected to take place in auditing practices (Eden, 2008). Thus, our analysis has implications for our understanding of auditing and other practices of the construction of evidence in natural resource management and policy more generally.

While we should not overstate the possibility of extrapolation based on only two training sessions, there are two important factors to consider. First, the training organization is considered a preeminent external trainer on the topic of FSC. This implies that they will be the trend-setters and their training will be the entry point for many auditors globally, who will then go on to train others. Second, the training itself espoused that fundamental auditor and auditing characteristics are universal and absolute. Therefore, the insights generated by analysing auditor training will also be relevant for FSC auditing.

Our research showed that the 'fluency' model, identified by Kotzee (2014) is very much alive and well in the world of FSC auditing. As noted, the trainers pointed out how the training cannot possibly replace real-world experience and that instinct and intuition is what often gets auditors through rather than deliberation. The result is that the leg-work of the audit is hidden in the end, making it look like a charlatan's magic trick (Fuller, 2006, cited in Kotzee, 2014). For example, the trainees were instructed to "find positive evidence of conformance". This suggests that it is not the goal or purpose of an audit and auditor to find what is wrong with the management of a forest. Furthermore, it is not considered sufficient to simply not find any evidence of wrongdoing. Auditors are expected to find evidence of right- doing, even though in the official reports there is no space for these findings. Thus, an activity with the goal to reveal and increase transparency may, in the end also conceal and increase opacity instead, as noted by Strathern (2000).

In this paper we focused on, and are critical of, the tension between objectivity and interpretation during the training course, but it is important to note how each aspect needs the other in order to function meaningfully. Eyal and Buchholz (2010) noted this in their literature review as the issue of 'interstitial domains', where technical and non-technical (or political and apolitical) collide outside of well-defined domains or disciplines. The job of these auditors is, ultimately to make a recommendation as to whether, in sum, the auditee does or does not meet the standards set by FSC. In the end, this cannot be done without the auditors making a judgement call, although they are averse to the very idea of 'judgement'. During the training, the notion of coming to a conclusion was predicated first upon having all the information, but later upon having enough information to pass a judgement. However, there is no clear point at which enough is enough, and obviously, it is unlikely that one can ever possess all information on a given topic. Thus, except in artificially simplified cases, eventually it comes down to the auditor and his team saying, 'in sum, I think they are/aren't in compliance'. This exemplifies how the process in which observations are tested against a set of criteria and standards and become evidence involves a creative and interpretative leap that cannot be justified completely with reference to the objectivity of the observations or the standards (Turnhout, et al., 2015).

Our analysis of learning to become an auditor has its foundations in the values present in the learning process. While the training itself goes to great lengths to characterise auditing and auditors as objective, and the trainers presented the values an auditor should possess to do auditing well, there was no attempt to identify them as actually value-laden, and therefore subject to the influence of the morals of the times. These values include the explicit, such as objectivity and assumed conformance, 
as well as the implicit, including both ontological relativism ("there is no one reality") and ontological realism (finding "the real" evidence). It seems that auditor trainings could become much more salient and instructive if the dilemmas associated with these values (how do you prove that something is positively true, how do you get to the truth while at the same time taking all representations of reality seriously) were openly discussed and deliberated, perhaps resulting in ultimately more effective audits and auditors. The more crucial point, however, is that none of these values are inherently bad or wrong, regardless of the implied or explicit position that is taught on the topic of personal values. In fact, they serve auditors in overcoming the paradox auditors face between objectivity and subjectivity. Along these lines, Collins and Evans (2007) argued that the study of experts and expertise had become too concerned with how expertise is attributed. Kotzee $(2014$, p. 176) expanded this critique to include the trainers of experts and experts themselves: the education of experts was concerned only with the appearance or procedures of being an expert, focusing only on their own interpretations, while avoiding "real and objective" abilities to accomplish their tasks. While we agree that such navel-gazing should be avoided, it seems this critique has little value. The training of FSC auditors seems to surpass the point entirely, as it included the performance of being an auditor (values and procedures), and the impact of being an auditor (monitoring and reporting). By examining the learned values of auditors, as suggested by Collins and Evans (2007), we can see that the tension between expertise as performance and expertise as reality does not exist in the field of forest management certification auditing.

This lies close to the heart of a larger issue. Rather than dismissing audits for being subjective, apparently failing to meet the standards of objectivity, we follow Bourdieu's suggestion as presented by Power (2003) that it is time to get passed this way of thinking altogether. Why does something so seemingly trivial, that the construction of evidence is a human endeavour, often become so problematic? The value of objectivity permeates decision making regarding environmental management, and yet if that were the sole goal of such activities, we would entrust this work to purely computational systems. Instead, context, skill and personal experience play a vital role and auditors are, inevitably, interpreting, thinking, reflecting subjects. Our criticism of objectivity does not, however, imply that we abandon objectivity as an unattainable ideal and celebrate subjectivity and interpretation (also see Cook et al., 2016). Rather we suggest that it is time to recognize that this is how objectivity is done: by interpreting subjects. Pointing to the role of subjectivity, values, and interpretation in audits in that way does not diminish audits' objectivity but gives important insight into objectivity's production in practice, as hinted at by Power's 1995 work. It follows that auditor trainings can be more open about the values to which auditing adheres to fulfil not only Kotzee's (2014) call to be more explicit in characterizing expertise types, but also Eyal and Buchholz's (2010) problem of 'interstitial domains'. As Douglas (2009) argues, being value free in the production of knowledge is not only impossible, it is also undesirable. Rather, objectivity can in fact entail the open reflection on what would constitute the right, ultimately subjective, values to guide the production of knowledge. On an even broader level, this supports the growing demand for information on environmental governance, and furthermore, information on the information about environmental governance (Mol, 2008). This is the opportunity for auditors to lead the charge on providing grounded information for environmental governance at a time when the call for such has never been greater. 
Two-thirds of the Earth's surface is covered in water. The other third is covered with auditors from headquarters.

-- Norman Ralph Augustine 


\title{
Chapter 4
}

\section{Performing an FSC Audit}

\begin{abstract}
Purpose - The Forest Stewardship Council (FSC) intends to promote responsible forestry through its certification scheme. The primary engine that drives this promotion is auditing. Audits serve a dual purpose: they make forest managers accountable for their claim of meeting the FSC standard, and they make the actions of auditors and auditee account-able, or able to be put into an account. The latter of these is rarely investigated, despite it being crucial to understanding how FSC audits are done.
\end{abstract}

Design/methodology/approach - This article examines FSC forest certification audits as practices where the FSC standards gain meaning. In-depth analysis of these practices enables insight into how different values related to forest certification and auditing are articulated and negotiated in practice, characterizing particular modes of auditing. In this paper, the authors examine the practices of FSC forest management auditors in multi- day audits in Africa and in Spain. Their materials were analyzed and coded using Goffman's elements of dramaturgy.

Findings - The authors' findings show that auditing practices entail a series of nested performances in which the auditors and auditees interact together and in which front stage and back stage performances constantly alternate as auditors and auditees perform for each other and simultaneously for an absent audience.

Originality/value - The authors' analysis demonstrates how in these performances, professional values related to following auditing rules and ensuring that audits are rendered account-able in a particular way take a prominent position. This risks overshadowing the accountability of the FSC system which is ultimately grounded in its ambition to improve forest conservation and management.

William Cook, Esther Turnhout, Séverine van Bommel

Published (online) in Journal of Organizational Ethnography in $2021^{2}$

DOI: 10.1108/JOE-10-2020-0039

\footnotetext{
${ }^{2}$ Minor typographical errors in the original text have been corrected in this thesis.
} 


\subsection{Introduction}

We were well and truly stuck. The Range Rover had sunk up to its axles in thick mud. It was not so much the heat as the, to me, oppressive humidity that dampened my spirits. As one of the auditees walked off in the distance back to the nearest village to hire some help, I thought to myself "the best laid plans of mice and men oft go awry!" No amount of training or preparation can ready an auditor for the chaos that is the field visit.

It was not the first time, nor would it be the last, that force majeure would cause a change in plans for the auditors, and this troubled them. As third-party auditors, they are the engine that drives the whole machine that is the Forest Stewardship Council (FSC) certification scheme. In the FSC system, third party audits are the way to ensure a fair, objective, and unbiased application of the FSC standards. It is the auditor's job to "get at" the reality of the situation in the field in order to make an informed judgement that is reflected in their reports. However, this is anything but self-evident considering the confounding complexity that assails auditors at every turn.

It is exactly this confounding complexity that demands a closer examination of forest auditing as it is done in the field. Cook et al. (2016) made an effort to characterise the major themes in the literature about environmental audits. The results show a preoccupation with the effects or outcomes of the audits: are hectares of forest being preserved?; is participation in decision making increased?; are companies making money?; is the environmental audit sufficiently objective? These are the types of questions posed by many studies on the subject. Relatively few focus on the goings-on of the audit and the activities of the auditors themselves. This is particularly troublesome given the central role auditors play in translating abstract standards to workable realities (Eden, 2008), the critical or routinized way an audit proceeds (Power, 1991), and the role audits play in legitimising environmental management methods (Taylor, et al., 2001). Therefore, it is not enough to merely examine what goes in and comes out of an audit. In order to understand how forest management certification works, the complexity of audit practices themselves must be addressed directly.

Thus, we propose to conceptualize auditing not as a representation of the reality of the forest, which can be measured, assessed and reported on, but as a performance where different players enact their parts in order to display how good they are at their roles and how well the audit was done. The term performance should not be taken to present it as somehow fake or trivialize the work done (Cook, et al., 2020). Rather, our point is that the performance is just as real as any facts an auditor may report, and its outcome no less real than the documents produced by it.

By examining audits as performance, we highlight how auditors successfully enact their roles. This contributes insights into how audits are done, audit results gain credibility and authority in practice, and how they ensure the accountability that auditing demands. Before we present our findings, we first outline the theoretical and conceptual approach we used to analyse how audits are performed.

\subsection{The problem of FSC auditing}

\subsubsection{FSC certification audits}

FSC is a global standard-setting organization for forest products. The organization was founded as an answer to "the need for a system that could credibly identify well-managed forests as the sources of responsibly produced wood products" (FSC UK, 2020). FSC aims to balance social, economic, and environmental needs through a set of principles and criteria that govern what does and does not meet the standard of "FSC Certified". 
Enterprises that use the FSC trademark, certificate holders $(\mathrm{CH})$, must periodically undergo an audit against the standard by an auditing firm, or "certification body" (CB). The first year the trademark is to be acquired, and every $5^{\text {th }}$ year thereafter, the enterprise must be audited for all the principles and criteria by an accredited CB. The interim yearly surveillance audits focus on specific principles and criteria, as well as on the following up of past problems.

These problems, called non-conformities, are those parts of the forest management that the auditors deem out of alignment with the standard. Non-conformities have two categories: major and minor. Minor non-conformities are classified as non-systematic errors in management and have a full year (until the next audit) to be rectified. Major non-conformities are systematic, egregious errors in management, and must be rectified within 3 months of the audit conclusion or the certificate will be suspended (or not issued if it is the first audit). A minor non-conformity may be upgraded to a major if it is not dealt with to the auditor's satisfaction. A third category of errors is called "observations". Observations indicate possible minor infractions that currently do not impinge the integrity of FSC but may in the future if they get worse. These can be upgraded to a minor or major non-conformity later, or they can stay as an observation.

At the end of the audit, the auditors submit their findings (both conformities and non-conformities) with a recommendation to their CB director. A report is then submitted to FSC's certification accreditation body (ASI). The auditor's recommendation can be to suspend the certificate, to issue the (re)certification subject to addressing the non-conformities within the time allotted, or to issue the certification without reservation. These details (non-conformities, positive findings, recommendation) are found in an audit report, which is stored in FSC's online database by the CB.

The audit report presents a streamlined account of the events of the audit, and each audit report format is idiosyncratic to the $C B$, although they must contain the same general information. Some information is not made publicly available online. For example, a list of consulted stakeholders and visited locations is often excluded from the public report. They are noted as existing but not being available. Although the day-to-day actions that take place during an audit are important in the construction of audit facts, they are not included in the audit report. In this article we open this black box by presenting an analysis of two FSC audits.

While the different actors in the FSC certification scheme - FSC, ASI, CBs, and CHs - are separate organizations with their own procedures and artefacts, they nevertheless form a larger social organization (Watson, 2012). The audit is the mechanism by which the organizations are connected and FSC can function as an organization.

\subsubsection{Audits, accountability, and account-ability}

In discussing our observations of FSC certification audits, we use the distinction between accountability and account-ability. Schrøder (2019) succinctly explains the difference between these two as "accountable" meaning being able to know who is responsible, and "account-able" meaning the interactions necessary to make things able to be put into an account. This distinction is best displayed by a broad consideration of FSC's purpose and functioning.

FSC was originally founded in response to a lack of governmental action on deforestation (FSC UK, 2020). The mechanism that is meant to ensure its success is to make certification profitable at every step along the supply chain. The idea is that consumers are compelled to buy a product over others 
when they see the FSC trademark or willing to pay more for it because they are assured it is better than other products. An informed consumer could even go online and check the requirements that an organisation needs to meet in order to use the FSC label. But this only works if the organization making the claim that it meets the FSC requirements can be held responsible for making that claim. It needs to be able to be held accountable. The method for ensuring this accountability is the audit report. In it, auditors detail how the organization did or did not make good on its claim of meeting the standard requirements. But the report typically only contains the final outcomes and does little to report on the deliberative processes and messy interactions that go on during the audit itself. These things, not valued by the principles that guide the FSC certification process, are smoothed over in the final report. In this way, what is observed in the audit is made account-able, but the way it is made account-able is often lost or ignored.

So, while FSC audits enable organizations and even individuals to demonstrate responsible forest management by means of administrative routines that are intended to render accountability, the formal routines do not reveal much about the way that the audit performance is made account-able in terms of making it communicable to other audiences. Scott (1995) associates the process of making something accountable as a mechanism of standardisation to create legibility, which subsequently facilitates control. This notion of creating legibility is similar to the process of creating account-ability, as a process of 'giving accounts' by actors in terms of telling or accounting (Garfinkel, 1967). Accountability and account-ability are often presented as a trade-off (Ezzamel, et al., 2007). In practice, in the FSC system, we see that in order to hold actors accountable in a regulatory way, considerable work goes into the audit performance in order for it to be made account-able in the audit report. This is precisely the area that this paper interrogates: how are audits performed and made account-able and with what consequences for the accountability of the FSC system?

\subsubsection{Values and modes of auditing}

FSC auditors highly value the idea of objectivity in an audit (Cook, et al., 2020), but auditing, even financial auditing that does not have to contend with social interactions, has been criticized for its inability to reach outcomes that are not influenced by who is doing the audit. According to Maltby (1995), the idiosyncrasies of individual auditors can lead to "decisive effects" on the audit process. Fischer et al. (2005) agreed, stating that "independent certification organizations may interpret and verify the same certification criteria very differently" (p. 17). These perceived weaknesses have triggered the increasing standardization of audit approaches, including "manual[s] and handbooks offer[ing] a step-by-step protocol" (Thompson \& Wilson, 1994). This push for increased proceduralization in pursuit of objectivity as something to be valued across auditing disciplines is part of an effort to ensure the mode of the audits is one of professionalism (Cook, et al., 2016). Professionalism attempts to minimize the discretionary space of auditors and by standardizing the way in which they interpret both the situation they encounter and the standards they apply to it.

However, according to Power $(1991 ; 1997)$, such professionalization of environmental auditing risks obscuring the original purpose of the audit. In the case of FSC certification, this original purpose was to ensure the legal or responsible source of wood, thereby responding to the protest of certain groups and individuals demanding a system to "identify well-managed forests as the sources of responsibly produced wood products" (FSC UK, 2020). This mode of auditing is one of protest and protest auditors aim to make the timber industry more accountable by making its practices more transparent and account-able. There is a stark contrast with professional modes of auditing where auditors do not protest or question established relations but rather follow "expert... procedural rationality" (Power, 1991, p. 31). 
FSC certification is an interesting case in terms of accountability and the different values underlying these two different modes of auditing. One of the purposes of FSC certification, as evidenced through its extensive consultation and reporting requirements, is to make the many steps of the audit process deliberate and explicit in detailed formal procedures. Yet, the enactment of these steps by professionals and experts will inevitably involve tacit dimensions not formalized in these procedures. They are likely to display mastery of the topic that includes more than the mere knowledge of the profession (Desmond, 2006; Yanow, 2015a). This is important in view of the different professional and protest values discussed earlier. These two sets of values are markedly different in how they conceive of a proper audit and of what auditors should do. Thus, a tension can be identified in environmental auditing. On one hand, the importance of auditing portraying itself as professional - adhering to welldefined procedures and offering credible assessments of agreed standards and verifiers, and, on the other hand, the equally important need of auditing to portray itself as a form of protest: critically scrutinizing and exposing business-as-usual, irresponsible, or unsustainable use of environmental resources (Elad, 2001).

In view of this tension, auditors must strive to balance the demands of professionalism - the use of a standardized approach - against the activism-inspired values that underlie and gave rise to the certification system. This is further compounded by the indeterminacy of the field in which auditing takes place, which means that the application of standards is inevitably a matter of practice and interpretation (Robertson, 2006; Eden, 2008; Turnhout, et al., 2015).

Thus, despite the effort to standardize and make explicit the steps of the audit, there inevitably remains a heavy reliance on the expertise and experience of the auditors to negotiate the tensions between the different auditing values and to align the ideal of objectivity with the reality of subjectivity and interpretation. Through auditors' expertise and mastery of the craft of auditing (Cook, et al., 2020), they provide legitimacy, efficacy, and expediency to the audit process (Power, 2003).

This article unpacks how auditors operate in this problematic setting, and how they balance and perform different professional and protest values for different audiences. This requires a detailed investigation of how certification standards are applied and how information is treated. While protestoriented values require auditors to disclose the reality of forest management and offer transparency, professional values dictate that only information pertaining to the standards is relevant to collect and disclose. In either case, making things visible simultaneously obscures other things (Strathern, 2000; Etzioni, 2010). Therefore, according to the values that characterize the mode of auditing being employed, certain information is also not collected or disclosed. Certain realities that may signal a non-conformance with a standard and should be revealed according to professional values might not be relevant from a protest-oriented perspective. Vice versa, specific realties that are relevant for the sustainability of forest management but are not directly addressed in the standards and verifiers do not require collection or disclosure from a professional perspective. You could say that when FSC auditors aim to be more professional, they necessarily move away from the burden of transparency towards the burden of objectivity and neutrality (Cook, et al., 2016).

Relating the modes of auditing to the topic of accountability and account-ability from section 2.2, one can start to see the contours of the dilemma being interrogated in this paper. A professional audit is an audit that is standardized, replicable, and easily understood. It is highly account-able. The audit practices are reported and recorded in a way that easily fits into an account. A protest-oriented audit is one which will focus on transparency, including procedural and analytical transparency, even at the 
cost of replicability and understandability. This perspective is more focused on accountability, ensuring that what is claimed is being fully explored so we can know the full extent of the responsibility of the auditee. FSC and FSC auditors seek to balance accountability and account-ability, and how this is done is not often explored in literature with very few exceptions (Elad, 2001; Eden, 2008).

\subsection{A dramaturgical approach}

In order to examine how audits are performed, we apply a dramaturgical approach. "All the world is not, of course, a stage, but the crucial ways in which it isn't are not easy to specify" (Goffman, 1959, p. 72). Irving Goffman wrote this phrase, appropriating the famous Shakespearean quotation, in order to highlight the performative nature of human interactions in daily life. Goffman's dramaturgical framework for analysing social interactions has proven useful in a wide range of fields from financial crisis to police relations analyses (Hilgartner, 2000; Boje, et al., 2004; O'Brien, et al., 2010; O'Neill, 2017). Dramaturgy highlights the day-to-day actions that make processes possible (McCormick, 2007; Nyqvist, 2015; Lundberg \& Syltevik, 2016). This aspect of dramaturgy makes it ideal for the study of auditing as FSC audits are routinized, ordinary, and day-to-day activities within the FSC system. Every auditee is audited once per year, and auditors perform multiple audits per month. It allows us to examine how an audit is done and how auditors make their actions account-able.

By viewing the world through the artifice of theatre, we can come to better understand how and why people behave as they do in a grounded manner. Dramaturgy has the benefit of being largely accessible and intuitive by relying on a metaphor and language many people are familiar with. However, we are taking Goffman's symbolic, metaphoric position a step further by blurring the line between artifice and sincerity. If one takes a performative approach, that which is "real" is made real through interactions and practices and has no fundamental reality outside these interactions and practices (Law \& Urry, 2004). Goffman hints at this when he says that "there is often no reason for claiming that the facts discrepant with the fostered impression are any more the real reality than the fostered reality they embarrass" (Goffman, 1959, p. 65). Accordingly, our approach is situated within the tradition of critical constructivism. When considering a performance, "the empirical reality of the social (and the natural for that matter) is inseparable from the way in which we [the actors and audience] interpret it" (Behagel, 2012, p. 29). That is to say that the actions done in a social interaction are inherently "sign vehicles", to use Goffman's chosen phrase, of the norms and values the actor carries. Therefore, the meanings of those norms and values are determined through these interactions. In summation, reality is constructed in the performance, and nowhere else.

In our analysis, we use four key dramaturgical concepts: teams, regions, impression management, and secrets. First is the notion of teams, the smallest unit of analysis. Team members are actors who "cooperate in staging a single routine" (Goffman, 1959, p. 85), having a shared goal of putting on a single performance. They are therefore identifiable to each other by knowing each other's secrets (routines, lines, blocking, etc.), and they seem to be striving to show the same thing to the audience. The audience for whom the teams are performing can be either immediately observing the action, or they can be an absent audience imagined by the teams.

The second element of concern is regions, which are areas, in the loosest sense, where perceptions are bounded by barriers. These are not hard-and-fast, as the degree of boundedness can vary. In the front region (frontstage) the audience can see what the teams are doing, and the functions of the team's roles are performed for the benefit of the audience. The back region (backstage) is characterised by its barrier to the audience's perception; the audience is not allowed to see what is happening. In the backstage, actions that contradict the frontstage performance may be taken, and 
out of character communication can take place. Each region can be adjusted to include or exclude audience members as the actors deem necessary.

The outcome of team interactions in the different regions is, from the perspective of the performers, impression management. This includes keeping role secrets from the audience, being well practiced enough to not be too caught up in the performance, dealing with unforeseen circumstances, and being aware of what is going on in other regions and of what the audience is privy to.

One of the most important dramaturgical elements is the secret, something that an actor keeps from the audience, but allows fellow actors to know or see. Related to auditing, secret keeping refers to the way in which certain information is disclosed to certain actors in the auditing performance but not to others. The different teams in the performance must continually enforce region control in order to maintain certain secrets while also disclosing certain information. In other words, the transparency about forest management that auditing purportedly contributes to is staged through these selective activities of information disclosure and secret keeping.

We will use this terminology and the elements of dramaturgy to describe our analysis of two FSC audits. This helps us to conceptualize auditing as made up of interactions between auditors and auditees who work together (often very explicitly) to establish and maintain roles, control regions, and manage impressions. This approach also provides a way to examine the unpredictable and the role of improvisation as well as the ways in which different performances can be related and nested within each other.

Within the broader conceptual topic of performativity, it should be clear that our analysis is limited to the performance of the audits, and the interactions between auditors and auditees that shape this performance. As such, we do not discuss how well FSC auditing performs in changing forest management practices or even how auditing changes how the actors perform being audited. Our use of performance focuses on "how... things constitute reality through actors' practices" (Gond, et al., 2016). Following Boedker (2010), we aim to show that interactions that make up auditing are fragile, unstable, and mutable. And yet, the things that are done during an FSC audit to make what is seen and said able to be accounted (account-able), are, in the end, able to be presented as robust, stable, and fixed. Using the lens of dramaturgy will allow us to analyze how this robustness and stability comes about; how auditors and auditees constitute themselves in relation to each other, how the reality of forest management comes to be presented, and how this affects the FSC system. The empirical focus of this article is on the actors' practices and interactions, with artefacts, such as the forest or the audit report, in a secondary role. In the concluding analysis, we consider how the values and modes of auditing are performed, and how that relates to the account-ability of the audit, and the accountability of the FSC system.

\subsection{Methods}

Framing our research with the terminology and concepts of dramaturgy, we relied on it being "grounded in the everyday-ness of work, not in a priori concept development and testing" (Yanow, 2012, p. 35). In 2015 and 2016, the first author observed two multi-day FSC forest management audits, one in Spain and one in Africa. The first author attended as an "official" observer, a status which meant agreeing to comply with a specific agreement between the first author and the certification body (CB). In both cases, the agreement included the express instruction to in no way hinder the auditors in their duties. This included not interrupting during the audit in order to ask a question, though the auditors 
themselves were at liberty to ask if the first author had questions, and they did so regularly in both cases.

Both audits had a team of two auditors. In the case of Spain (a three-day audit), the auditors were often in the same place together, but working on different topics with different people. They would occasionally separate, but only rarely. In the African case (a five-day audit), the auditors performed the first, second, and fifth days together, but were otherwise separated due to the geographic spread of the forests to cover. In both cases, the auditors assigned the first author to one of them (with input from the first author), so there was no doubt who was responsible for the observer.

The first author spent every hour of the audit itself (the time in which the auditor was in the presence of an auditee) with an auditor. This would usually be close to 8 hours per day. The first author also spent out-of-audit time with the auditors, including meals and break times. In Spain, breakfast time was spent discussing the previous day and preparing for the coming day. The first author was encouraged to listen in and ask questions about the previous and coming days. The first author was not able to be present for any evening-time discussions due to lodging constraints. In Africa, the first author was able to sit in on discussions in the evenings (review of the day) and in the mornings (closing issues from the previous day, preparing for the coming day). The auditors again encouraged the first author to ask questions.

Small, informal interviews occurred during these break times, and in the case of Spain, semi-structured interviews were carried out back in the auditors' main office several days after the audit was complete. These methods of observation limited the first author to specific locations (only where the auditors went), but did have the benefit of allowing verification or denial of what the first author thought had happened against what the auditors thought happened.

While observing the audit, field notes were taken, resulting in two notebooks full of notes. The notes were transcribed nightly into two categories: observation (what was said, done, shown) and thoughts (what was felt, interpreted, or reminded of). Upon returning from the field, the notes were analysed in light of the dramaturgical concepts over the weeks and months following the audit. The primary method of analysis was coding based on Goffman's elements of dramaturgy. The first author reviewed the notes, expanding descriptions or adding additional thoughts, and then marking groups of observations as they corresponded to Goffman's terminology (e.g. "Example of role secrets", "maintaining teams", "trying to control region", "this was backstage, is now frontstage", etc.). The first author also downloaded the publicly available audit reports from the FSC database to check what was finally reported. From these notes, and building upon past research concepts, the analysis below was developed.

\subsection{Findings}

FSC audits are complicated social interactions in which experts discuss topics that, to a non-expert, are mostly obscure. However, upon using dramaturgy as a lens for examining those interactions, we can see the different ways in which audit results are made account-able, and how they ensure accountability. The importance of teams and role secrets, region control, and impression management will be characterized through examples of actions during the audit.

\subsubsection{Teams and role secrets}

Over the course of the audits under study, there were many instances when it is made clear that there is a we and a they. They are the audience for which we -must perform by keeping our role secrets. 
These moments are implicit, explicit, protracted, brief, spoken, and enacted, but they all build to a clear separation of teams who are each treating the other as an audience.

Even before the audit properly started, this distinction was put in place. The morning before the audits started, before meeting the auditees for the first (official) time, the auditors met and discussed the coming day. They discussed exactly which standard clauses would be scrutinized first, and what kinds of evidence each auditor could be looking at for those cases (e.g. maps, invoices, hauling contracts). They also handed over their individual copies of the checklists used by their company for this purpose. The auditors highlighted particular items on the list for their focus during the day, or scratched out items that their partner was going to cover, or had been decided to not be included in the scope of this audit. On days following the official audit start, all these topics were discussed in addition to discussions of what the auditors observed, or thought they observed. During these discussions it was not uncommon for one of the auditors to say to the other, "No, no. That's not what they meant. I could see...", or "I thought that the last audit report said... so we need to follow up on that."

In one instance, due to a question from the main author, the auditors spent time debating the difference between an observation (a note to the certificate holder that future audits will keep an eye on something, but not enough to deny them the certificate if nothing changed), a minor nonconformance (something that would lose the certificate if not fixed before the next audit), and a major non-conformance (something that would lose the certificate if not fixed immediately). This started as a theoretical discussion between them, but before long resulted in the auditors trying to decide if some of the activities they had observed were severe enough to warrant a minor non-conformance, or only an observation.

These instances were not shared with the auditees, but they were necessary in order for the auditors to perform their role of "professional auditors". If these secrets were shown to the audience (the auditees), the auditors would not have appeared legitimate, and they would not have been perceived as responsible for their decisions. However, simply having the secrets is not enough. There needs to be the ability to prevent the audience from gaining access to them, or only accessing them when the team wants them to. This is implied in the previous description due to the examples all being while the teams are apart. We will make it explicit in the following section.

\subsubsection{Controlling the regions}

The previous examples demonstrate times at which the auditors were very strict about what they talked about in front of the audience (auditees), and what they talked about with only each other. They kept these latter discussions entirely in the backstage, away from the frontstage where the audience (the auditees) could see. But at some points, the auditors would need to bring (aspects of) the role secrets to the attention of the audience in order for the performance to continue. This meant bringing elements of activities discussed away from the auditees in the backstage to the frontstage or allowing the auditees to see the backstage. This meant exercising control over those regions beyond not being physically in each other's presence.

One such example comes from the African case, wherein the auditors had discussed in the evening about the auditees not being able to account for a stakeholder consultation they were supposed to have held before the audit started but had not. There was a short debate on whether this was necessary to follow up on, but in the end, they agreed that it was needed. They then speculated to each other on some legitimate reasons why the consultation had not taken place. 
The following day, the auditors met with the auditees and posed their question: Why had this consultation not been carried out? The auditees retreated for a short time to discuss the issue amongst themselves before returning and telling the auditors that the consultation had be postponed because of a major election, due to which few people would have the inclination to participate, followed shortly by the start of the rainy season, which prevented most people from traveling. They explained that while they could have held the consultation on schedule as planned, turnout would have been poor, and the consultation meaningless.

Another example of this region control was in the Spanish case wherein, during one of their morning discussions, one of the auditors noted with alarm that all their site visits were close to well-maintained access roads, but there were a number of possible sites not near good roads. Together they decided that during the audit that day, when visiting a particular pre-chosen site near the road, one of them would ask the auditee to take us on foot to a nearby site that was not on the well-maintained road. This happened as described during the audit, with no mention of the realization of the planning error.

These examples show instances where auditors brought issues discovered in backstage discussions onto the frontstage. Keeping control of the regions prevented the auditees from seeing the auditors' doubts, while figuring out a way to have those doubts confirmed or denied. This was required for the audit to proceed, and allowed the auditors to continue acting their role, and thereby maintaining their legitimacy and accountability. The combination of effectively building and maintaining a team while keeping role secrets, and flexibly manoeuvring between regions contributed to the successful performance of the audit.

\subsubsection{Impression management}

The sum of the auditors' circumspection (awareness of others' relationship to the performance), characterised by region control, and introspection (awareness of own relationship to the performance), characterised by roles and teams, is called impression management. Put simply, impression management is what is done to influence how one is perceived by others (Goffman, 1959). As shown by the preceding examples, auditor actions are often, intentionally or unintentionally, directed to influencing the audience (auditees) so that the auditors continued being seen as legitimate and accountable, as professional auditors. If this were not a concern, then sharing doubts and deliberations would have been a communal activity, including both auditors and auditees.

If the audit existed in a vacuum, managing this impression would be all that auditors would need to consider. They are accountable to the auditees, and the auditees accountable to them. However, this would only be the case if it were an internal audit, with the final audience being the auditees themselves. Instead, the final audience of all this activity is, in fact, the non-present audience of the auditors' superiors, Assurance Services International (ASI), the FSC audit watchdog and accreditation organization, and the public who have access to audit reports.

Therefore, it is also the responsibility of auditors to ensure that all of the messy discussions and observations are distilled into an account that is understandable to the final audience. They must make the audit account-able in another performance that it being prepared simultaneously with the audit itself. As we have shown, auditors engage both the immediate audience of auditees and the imagined audience of FSC/the public. Influencing how each audience perceives them, however, requires a difference in what information is allowed to each audience.

The impression management demonstrated by the auditors allows for what we refer to as nested performances. What we mean here is that the front stage of one performance is in fact the backstage 
of another. An FSC forest management audit is a nested performance in that all the activities that take place between auditors as actors and auditees as audience (the first-level performance) serves as the backstage of the larger performance with auditors and auditees as actors and FSC/the public as the audience (the second level performance).

\subsubsection{Nested performances}

Setting aside the immediate, individual performances of auditor/auditee, we must consider the overall routine of the audit itself. It is the goal of auditors to find positive proof of compliance (Cook, et al., 2020), and this aligns with the goal of the auditee also. Therefore, both auditors and auditees cooperate to stage the routine of the audit. What we see then is that the auditors and auditees are, when considering the audit as a whole, on the same team, not different teams. The audience of this performance is the absent audience of ASI and any member of the public, as they are the ones for whom the performance is a benefit. The audit report that is submitted at the end of the audit is the main frontstage actor for this higher-level performance in which the audit performance is nested.

This is best reflected in an episode during the African audit. The auditors were reviewing a past observation regarding a forest road crossing a river, possibly resulting in enhanced erosion and pollution. The only possible solution would be to "upgrade" the crossing; it would be necessary to either build a bridge or resurface the crossing in some way. The auditees explained that it was not realistic to think they could upgrade the crossing, and that the risk of pollution and degradation was not high. The auditors asked who owned the road, and therefore who was responsible for its upkeep. The auditees stated that it was a government road, and because of its rural location, it had very low priority for upkeep.

Furthermore, they explained that the number of crossings due to management activities (rather than other uses) was minimal over the course of a year. The auditors countered that it was still an identified risk that should be addressed lest it become a real problem in the future. The auditees once again stressed their inability to upgrade the crossing and their belief that the actual impact of forest management activities on the condition of the cross was low. The auditors took note of this in their publicly available report, which was downloaded from the FSC database, stating "... there is a need to consider some up-grading of the road or alternative route for log transport in the future". In so doing, the debate on the topic was minimised, and a streamlined narrative was included on the final report. The debate was effectively smoothed over in preference for showing the absent audience (ASI and the public) an efficient and effective audit. The discussion between auditor and auditee remains a secret from the audience, temporarily placing auditor and auditee on the same team rather than opposing teams.

The final audit report that is submitted to FSC both reveals and hides information, just as auditors both reveal information to and hide information from auditees. In the performance of the audit itself, auditors enact their role as independent judges sent to understand and come to a conclusion about forest management practices. The role includes certain secrets especially regarding uncertainty over how standards are interpreted. These secrets may only be revealed backstage to other fellow actors. The frontage is the space where auditors gather information from the auditee, and faithfully report it to FSC. But we saw numerous examples where auditors and auditees stopped working on the performance of being good auditors and auditees in order to work for the second-level performance.

In those moments, the role of the auditor changed from being concerned solely with faithful reporting to being about constructing reasonable explanations or interpretations with the help of the auditees. This collusion, in the strictest dramaturgical sense, could result in the performance collapsing. But this 
did not happen because both performances took place simultaneously. So, while the collusion may be destructive to the first-level performance, it is supportive of the second-level. Therefore, the conflict is transcended.

By necessity, the auditors abridge or do not report the details of this nesting of performances. This is where information is selectively revealed or concealed. For example, the auditors made notes in the audit reports that "the manager explained...", but they did not write "at first, I was certain they were wrong, but over three days they eventually convinced me that...". The end report is a sanitized account which presents a simplified version of the audit in the name of effectiveness. In so doing the auditors, together with the auditees, manage the impression of the audit being performed in the proper way, and make it possible to place the events in an understandable account.

\subsection{Discussion}

Utilising the dramaturgical approach espoused by Goffman $(1959 ; 1967)$, we have examined how role secrets and teams and region control combine in impression management to allow auditors and auditees to share in a performance for a non-present audience while simultaneously performing for each other. The result is an ongoing exercise in impression management on the part of the auditor. It also highlights the fact that auditor and auditee are simultaneously performing as part of the same team for an audience that is not present. When one considers the nested performance wherein the two teams "auditor" and "auditee" merge or become more fluid, then we see that an effort is made by a single team of "auditeurs" to perform a professional audit to the audience of ASI or the public. This is done through auditors and auditees coming to tacit agreements on what exactly should be performed, without ever intending on revealing this rehearsal to the audience. In so doing, the audit evidence can be presented in such a way that "anybody would come to the same conclusion", thereby ensuring it fits the mode of professionalism through being made account-able. The performance of different modes of auditing is needed for the audit to go from merely ensuring the actors are accountable (i.e. responsible for their roles) to ensuring the performance is account-able (i.e. able to be put into an account).

As such, choosing to examine FSC auditing through the lens of Goffman's dramaturgy allows us to consider that not just pockets of a performance might be the backstage for another performance (Nyqvist, 2015), but that whole performances might in fact be nested within a larger, unseen one. This means that by keeping back- and frontstage behaviours in mind while observing practices encourages the consideration of what is seen as the backstage for another performance. Considering the importance of absent audiences on the here-and-now in a broader organizational sense are easily forgotten, and this way of framing interactions brings it back to the analysis.

At this point, we will return to the values and modes of auditing and we will reflect on the implications of this for the FSC certification system. First of all, our findings show that auditors hold objectivity, with which they mean that anybody would come to the same conclusion, as their primary value (Cook, et al., 2020). This value typifies the professional mode of auditing (Cook, et al., 2016). The professional mode of auditing is also characterized by predictability and proceduralization, ways in which FSC's certification system has been characterized before (McDermott, 2012). To perform a good FSC audit, the outcome should be seen as procedurally predictable, and that anybody in the same situation would have come to the same conclusion. As the findings have demonstrated, the professional elements of the FSC audit are manifold: routines, forms, checklists, and guidance documents abound, and these constitute the primary way the auditing team can make the audit content account-able, and ensure their own accountability. The well-defined procedures and principles of auditing technologies 
including the auditors' forms, routine schedules, guidelines, and checklists provide a reliable reference point for future scrutiny. This allows things to go smoothly and gives auditing a business-like veneer. This dimension of auditing foregrounds process as crucial for replicability and verifiability (both key components of objectivity). Audits without any surprises can easily support the professional aspect of auditing.

But, our examples above highlight a problem with this mode of auditing. The mélange of team-building and maintenance, region control, and impression management seems too chaotic to be proceduralized or replicable. It seems entirely bespoke, based upon events that may not happen again in the same way. Thus, the path followed by the auditors to reach their conclusions may be shut for others. As our examples illustrate, auditors often face difficulties managing impressions. If one looks at the example of the safety equipment issue in Africa, for example, one can see how auditors need to qualify the requirements of the FSC standards with contextual information. In facing these challenges, we see that auditors draw on values embedded in a protest mode of auditing. Here, the focus is on content rather than process. Considering that FSC arose in protest to the business-as-usual approach to forest management globally, auditors focusing on ensuring improvements in forest management also results in acquired legitimacy. However, it can lead to an interesting burden on auditors: if they see something "bad" that is not covered by the requirements, protest values still encourage them to note it as something to monitor. Equally, when they see minor problems in the application of the standards, this same substantive focus can lead them to downplay these problems if they see continued improvement in forest management. Therefore, in a mode that espouses openness and transparency of information, these audits may conceal secrets, either through not showing the opacity of the process, including the various complexities, uncertainties and interpretations, or by showing only the straightforward and transparent parts. What is interesting is that these kinds of situations, though drawing on the protest-based history of FSC auditing, are smoothed over in the final report; they are presented as part of the overarching performance of "a good audit". In other words, the protest aspect of the audit ends up serving the professionalization of the audit performance through the auditors' region control.

Seen from this perspective, it could be argued that the form of auditing described in this paper has already strayed quite far in the direction of professionalism, or perhaps due to its conception and the fundamentals taken from financial auditing set it up to skew away from its protest-orientation, as Power (1991) warned might be the case. Numerous authors have pointed to the potential harmful consequences of this development (Smith, 1995; Power, 2000; Turnhout, et al., 2014; Turnhout, et al., 2015). Specifically, these authors warn against the way in which systems of (performance) measurement and auditing can result in an unhealthy focus on measurement and indicators, which not only overshadows but potentially hampers actual performance. This means that as forest management certification continues to be professionalized, a focus on box-ticking might arise, which can result in forest managers only getting better at being audited rather than improving forest management practices. Therefore, the assurance that certification auditing of forest management leads to continual improved management practices should be questioned.

This is not, however, to say that abandoning the characteristics of professional auditing is desirable. In the age where information and its availability dominate decision making, having reliable, robust, and replicable data is crucial for affecting any change in the world. If FSC's certification audits are to remain salient and meaningful, it is up to FSC auditors to balance the demands of their profession now against the protest-orientation of their profession's history. 
Indeed, balancing the protest and professional aspects of the auditor's role in the performance is important to ensure that the audit is seen as both credible and authoritative, thereby contributing to the accountability of the FSC system. In other words, auditors need to build the story of the audit (account-ability) in such a way that it is explanatory and justifiable (accountable). Without the professional, universalist aspects of the auditor's role being displayed, the audit would just be a rambling story told by some person with no qualification, but without the protest values, audits would be empty bureaucratic procedures without meaning, context, or purpose. Therefore, auditors need to strike the right balance between these sets of values when deciding how to manage their impression in the field and in the report and what is seen on stage and what is kept as secrets.

\subsection{Conclusion}

Moving away from the individual interactions of auditors and auditees to take a wider view of auditing in general forces us to reflect on the question of what the impact is of the dominance of professionalization on the FSC system. We suggest that part of the answer is the production of auditable forest management entities. The question though is whether this is sufficient. While it is perhaps unreasonable to expect FSC to single-handedly "turn the tide" of forest degradation (FSC, n.d.), current trends in deforestation, particularly in developing countries, do warrant further reflection about the contribution of FSC to halting deforestation and forest conservation, since this contribution is so central to the legitimacy of the FSC system as a whole. As our analysis has shown, the FSC system has increasingly adopted professional values in auditing to improve account-ability, but the question is whether this has sufficiently contributed to FSC's accountability. Indeed, continued deforestation - which signals an overall lack of effectiveness of the FSC system - provides a reason to put the protest dimension much more centrally. Ultimately, the broader FSC certification system may need to seize the protest-oriented aspects of their roots and thrust it into the frontstage for all to see, with auditors being key actors fulfilling this role. 
Change means movement. Movement means friction. Only in the frictionless vacuum of a nonexistent abstract world can movement or change occur without that abrasive friction of conflict.

-- Saul Alinsky 


\title{
Chapter 5
}

\section{How Do Policy Ideas Travel? Enactment, Friction and Alignment in Forest Stewardship Council Certification}

\begin{abstract}
This article addresses the question how policy ideas travel? We address this question by providing an analysis of the FSC certification scheme, using the concepts enactment, friction and alignment. We show that as FSC's standards travel through the FSC-network, they are confronted with existing practices and preferences, leading to friction between the standards and these practices and preferences. Such friction is not necessarily problematic: it may trigger creativity and pragmatism. The standards are renegotiated and reinterpreted according to different local needs: they are enacted in practice. However, these enactments also pose a risk. FSC has to guarantee that certified products comply to their standards and this is more difficult of enactments are seen to vary. Subsequently, alignment practices are needed to ensure that the standards' meanings are harmonized and that the boundaries of their interpretative flexibility are stabilized. Auditing plays a crucial role in these alignment practices; it connects the standards to their application on the ground. By introducing the concepts of enactment, friction, and alignment, this article has introduced a provisional vocabulary required to understand the processes and translations that allow policy ideas to travel.
\end{abstract}

Séverine van Bommel, William Cook, Esther Turnhout 


\subsection{Introduction}

How can the global impact on the local? This question has bothered anthropologists, political ecologists and policy scientists alike. The question can refer to the implementation (or lack thereof) of global agreements, the effects of development interventions, or the subjugation and destruction resulting from global capital. Scientific debates about this question often take the form of top-down versus bottom-up approaches or structuralist versus agency-based perspectives. This paper adopts an interpretative and practice-based perspective that aims to go beyond these dichotomies and unpacks the interactions that shape the relation between the global and the local. It uses the Forest Stewardship Council certification scheme to illustrate how FSC's global standards travel through the FSC network and how they are enacted in complex processes of interaction between standard setters, auditors, and local forest managers and their respective preferences, perspectives, and interpretations. In so doing, we draw attention to the entwinement both of the structuring and disciplining effects of global standards, and of the agency of actors in translating these to their local settings.

Drawing on insights from interpretive approach to policy analysis (Fischer \& Forester, 1993; Yanow, 1996; Yanow, 2000; Hajer \& Wagenaar, 2003; Fischer, et al., 2015), we conceptualise standards as policy ideas that are characterised by a certain understanding of what the problem is, how it should be solved, who is responsible for solving the problem, and what sort of consequences are acceptable. For a global policy idea such as forestry standards to impact the local, a shared understanding of that policy idea needs to formulated in one location and then it must be able to travel to another location where this shared understanding can be reproduced. Usually this is done by writing the policy idea down in a document and sharing this document with other actors, thereby making the policy idea available to those that were not present at the original interaction or meeting during which it was formulated (Freeman, 2008; Freeman \& Maybin, 2011). Those that read the document - in a different location or at a different moment in time - then need make sense of it, which will result in a new process of meaning making. Following a broader mobility turn in social science (Urry, 2007), academic literature has discussed this travel of policy ideas, including international standards and norms, in terms of policy transfer or policy diffusion (Dolowitz \& Marsh, 1996; Dolowitz \& Marsh, 2000; Evans, 2010), and policy translation or policy mobility (Lendvai \& Stubbs, 2007; Mukhtarov, 2014; Clarke, et al., 2015; Kortelainen \& Rytteri, 2017). Scholars from the policy transfer or policy diffusion tradition take a more structuralists approach and suggest that global policy ideas shape our conduct and influence our practices more than we would often like to admit (Peck \& Theodore, 2012). In contrast to this, scholars from the policy translation of policy mobility tradition take a more agency-based approach and argue that the implementation of global policy ideas is the consequence of local actors using their situated agency to appropriate global discourses in ways that resonate with their local practices (Mukhtarov, 2014). Instead of treating structure and agency as a dualism, we propose a practice-based perspective that recognizes structure and agency as dialectically related and mutually constitutive (Behagel, et al., 2019). Using this perspective also allows us to unpack the way in which power is part and parcel of negotiating, setting and interpreting FSC standards, while at the same time, the FSC standards also exert power themselves (Barnett \& Duvall, 2005). Thus, this perspective emphasizes not only the 'disciplining effect' of policy ideas but also the role of 'agency' in interpreting and using them. As such our approach enables a nuanced understanding of what policy ideas are, what they do, how they travel and how they involve control and power mechanisms.

Our article is structured as follows. In section 2 we introduce our conceptual approach to policy travel that unpack the notion of translation by introducing the concepts enactment, friction and alignment. 
In section 3 we use FSC certification as a case to illustrate our analytic arguments. In section 4, we discuss the implications of our findings for policy theory and practice.

\subsection{Policy travel as enactment, friction, and alignment}

Policy travel refers to the circulation processes that enable policies to move between the spaces, locations, and networks in which policies were developed and those in which they are taken up or implemented. Policy travel has been studied in political science and geography (Kortelainen \& Rytteri, 2017) leading to a range of studies, among others, in the field of transport (McCann, 2011), renewable energy (Kortelainen \& Rytteri, 2017), education (McKenzie, 2017), crime (Newburn, et al., 2017), water management (Mukhtarov, 2014) and gender mainstreaming (Engberg-Pedersen, 2018; Acosta, et al., 2019). These studies draw attention to policy translation as a "process of modification of policy ideas and creation of new meanings and designs in the process of the cross-jurisdictional travel of policy ideas" (Mukhtarov, 2014, p. 6). The universal and ambiguous nature of policy ideas means that each instance of enactment can involve multiple interpretations and translations of those ideas (Yanow \& Schwartz-Shea, 2006) As part of those interpretations, actors can appropriate, contest, ignore parts, or alter and re-negotiate the meaning of policy ideas in order to make them work in their local context (Clarke, et al., 2015; Draude, 2017). As all local contexts are different, translation processes necessarily produce new meanings ( $\mathrm{Gal}, 2015)$. As such, interpretation and meaning making are inseparable from the travel of policy ideas as local actors in various parts of the network have to 'make sense' of what the global policy ideas mean in relation to their own local circumstances. Instead of considering those diverse enactments of policy ideas from an evaluative perspective as implementation gaps or failures, we emphasize that they are vital for policies to work because they carry them forward. When such enactments would stop, the policy ideas would in fact cease to 'exist' (Gherardi \& Nicolini, 2000; Freeman, 2012). As such, the concept of enactment helps us to understand how policies change meaning as they circulate and are employed in practice (McKenzie, 2017). It recognizes that that policy ideas do not simply diffuse or spread to new geographical locations (Engberg-Pedersen, 2018) without "shifting, moving terms around, linking and changing them" (Law, 2009a, p. 144).

To understand the enactments through which policy ideas assume specific meanings, we propose to use the concepts of friction and alignment. In her book with the same title, Tsing (2005) introduces the term friction to illustrate how what she calls universals enter specific locations as a kind of confrontation that evokes tension and results in productive forms of irritation (Tsing, 2005, p. 58). According to Tsing $(2005$, p. 9), "friction gives purchase to universals, allowing them to spread as frameworks for the practice of power. But engaged universals are never fully successful in being everywhere the same because of this same friction." Thus, the term friction is helpful in understanding diverse enactments of policy ideas in ways that go beyond analyses cast in terms of implementation, smooth translation, or in terms of resistance. Friction draws our attention to the active readership of policy actors in various parts of the network who decide what meaning policy ideas have to them in their local context (Yanow, 1996; Lendvai \& Stubbs, 2007). As such, practices of friction protect policy actors from marginalisation and create heterogeneity and diversity of enactments.

Yet, when the diverse enactments that result from these frictional encounters travel back to the spaces from where the universal policy ideas spread, it is clear that diversity, while being key to make policies work, but also poses problems. There are limits to the kind and degree of diversity that can be allowed for an enactment to still count as an enactment of a policy idea. This is of crucial importance for sustainability standards and certification schemes like FSC. The forest management practices that receive an FSC certificate may vary, but still need to be seen as in accordance with the 
standards. To be able to analyse how this gets done in practice, we propose to use the concept of alignment. Alignment highlights how compliance and competence are accomplished in and through the different "forms of practical 'subversions' taken up in the name of getting the work ... done" (Suchman, 2000, p. 313). Using the example of building a bridge, Suchman (2000) underscores the important role of persuasive story telling in aligning the interests and needs of diverse stakeholders and engineers. Applied to global standards, those stories are then a way to ensure a degree of equivalence between the global and the local so that the local can be "predicted from the global model; that is the point of its globality. Local data may adjust the global model but never defy it." (Tsing, 2005, p. 102). Thus, alignment orders people and things to create legibility and facilitate control; it enables central authorities to not only 'read' and evaluate certain distant practices but also control them at a distance (Scott, 1998). It entails a form of power that renders local practices amenable to standardization (Miller \& O'Leary, 1987). Alignment results in the harmonization of meanings, in our case of the FSC standards and what it means to comply to them, without making them the same. This harmonization is a mutual process in the sense that it involves the simultaneous temporary renegotiation of the global standards and of the forest management practices that enact them, thereby creating a persuasive story about how forest management practices can be seen as instances of compliance or non-compliance with the FSC standards.

In this article, we will analyse the travel of the FSC standards using the concepts of enactment, friction and alignment. Fieldwork for this analysis was conducted as a multi sited ethnography (Marcus, 1995). This allows us to track the standards across spatial and temporal boundaries, as they travelled through the FSC network from the global to the local and vice versa. We collected our data by means of 1) participant observation of events; 2) semi structured interviews about the history of the FSC certification process; and 3) document analysis. More specifically, the sections on standard setting and operationalisation of the standards draw on participant observation of one of the authors who has been working with FSC international as policy officer for three years. The section on auditing compliance draws on participant observation and shadowing of the auditors during six audits (Africa, Asia, and Europe). The results in all three sections are further supported by 15 interviews with forest managers, auditors, and FSC representatives (both national and international level) as well as document such as historical accounts, memos, brochures, policy documents and research reports. Drawing on this material we discuss three main sites of enactment: the setting of standards at the global level, national and regional implementation and tailoring of the standards, and the auditing of forest management. For each of the sites we describe how the meaning of standards is translated, the role of frictional encounters, as well as the way in which diverse perspectives become aligned.

\subsection{The travel of FSC standards}

\subsubsection{The pathway of standard setting}

In the early 1990s, forest certification was born out of a mounting frustration with the failure of national and intergovernmental processes to halt deforestation and forest degradation. This led to the establishment of the FSC, the first international system of forest certification for responsible forest management in 1993 in Toronto, Canada (Tollefson, et al., 2008). FSC's self-described mission is to promote environmentally appropriate, socially beneficial, and economically viable management of the world's forests (FSC, 2021c). FSC has currently certified more than 220 million hectares of forest in 78 countries (FSC, 2021a).

One of the most striking aspects of FSC at the time of its creation was that it did not allow for government involvement in its development, nor in its governance structures, nor in the 
determination of forest certification standards and the auditing process. This decision was strategic, in that the FSC's proponents sought to bypass the government inaction and impasse that was evident at the 1992 UNCED Earth Summit in Rio de Janeiro, Brazil (Wood, 2009). This crucial decision involved introducing a three-chamber system, with environmental, social, and economic chambers, to make sure that each had equal decision-making power in FSC's governance. This was further geographically balanced, with equal power assigned to the Northern and Southern hemispheres (Tollefson, et al., 2008). This structure appealed to indigenous groups, NGOs, and other forest policy actors who were given more power than they had in conventional decision-making processes (Wood, 2009). However, the governance system made agreement between and within chambers very difficult.

FSC worked on establishing its framework in the form of rules, conventions and contracts. A so-called core group was established with the task of formulating the Principles and Criteria dealing with various aspects of forest management. The first version, formulated in July 1991, contained seven Principles to which sustainable forest management should adhere: 1) Management Objectives; 2) Management Plan; 3) Monitoring; 4) Silvicultural Aspects; 5) Legal-Political Factors; 6) Socio-Political Factors, and 7) Ecological Factors. In the following years, several drafts were produced and sent out to members in consultation. Finally, in 1994, a system of 10 Principles was put in place and operationalised through a total of 57 Criteria against which the Principles could be assessed. Box 1 presents the 10 FSC principles and specifies the different Criteria for Principle 1 as an example.

Revisions to the Principles and Criteria have continued since 1994, partly in response to problems experienced in cases where the Principles and Criteria were not able to accommodate emerging and unanticipated developments. A comprehensive review resulted in major revisions to the wording of the Principles and Criteria in 2012.

Over time, FSC elaborated their Principles and Criteria into accompanying policy documents, strategies and guidelines. These too are regularly revised on the basis of new experiences. For example, one important area of review was the policy on percentage-based claims. This refers to the question of how to deal with products that are partly derived from non-certified forest operations. In 1993, FSC required $100 \%$ of a product labelled with $\mathrm{FSC}^{\prime} \mathrm{s}$ logo to come from certified forests. Many representatives from industry (primarily pulp-related), protested this as they felt that it would be very difficult to produce profitable products from only material that was $100 \%$ certified. Segregating operations by either doing separate production runs or investing in whole new production lines would just not be profitable enough considering the amount of output that would be possible. In 1995, a discussion paper was drafted that proposed to revise the $100 \%$ rule, allowing some uncertified material to be mixed with certified material when it could not be avoided (up to a certain percentage). This resulted in friction, as some representatives felt that anything less than $100 \%$ would damage the credibility of FSC and therefore they strongly protested a more flexible position. Other representatives believed that this flexibility was necessary, but they did not agree to what extent uncertified raw materials should be allowed, how this percentage could be calculated, and how the information could be presented. In response, a working group, a stakeholder panel, and a technical committee were set up to determine a minimum percentage for certified material in a product. These groups published a report in 1999 detailing a proposal for percentage limits and technical specifications to implement these, in which they explain their position as follows:

We concluded that a highly restrictive policy would have advantages in the simplicity and credibility of the message, but would enormously weaken FSC's ability to achieve its mission of promoting good forest management through certification. If major industries decided that certification was not for them, because of this particular FSC policy, there would be fewer 
incentives on forest managers to improve their management and to seek certification. The board meeting in January 1997 noted that "FSC's mission is primarily to promote forest stewardship, not certification. If FSC insists on $100 \%$ certification, to the disadvantage of good forest stewardship, FSC is failing in its mission." (Synnott, 2005, p. 40).

\section{Principle 1.}

Compliance with all applicable laws and international treaties

1. Forest management shall respect all national and local laws and administrative requirements

2. All applicable and legally prescribed fees, royalties, taxes, and other charges shall be paid

3. In signatory countries, the provisions of all binding international agreements, such as CITES, ILO Conventions, ITTA, and Convention on Biological Diversity, shall be respected

4. Conflicts between laws, regulations, and the FSC Principles and Criteria shall be evaluated for the purposes of certification, on a case-by-case basis, by the certifiers and the involved or affected parties

5. Forest management areas should be protected from illegal harvesting, settlement, and other unauthorised activities

6. Forest managers shall demonstrate a long-term commitment to adhere to the FSC Principles and Criteria

\section{Principle 2.}

Demonstrated and uncontested, clearly defined, long-term land tenure and use rights

\section{Principle 3.}

Recognition and respect of indigenous peoples' rights

\section{Principle 4.}

Maintenance or enhancement of long-term social and economic well-being of forest workers and local communities and respect of workers' rights in compliance with International Labour

Organisation (ILO) conventions

\section{Principle 5.}

Equitable use and sharing of benefits derived from the forest

\section{Principle 6.}

Reduction of environmental impact of logging activities and maintenance of the ecological functions and integrity of the forest

\section{Principle 7.}

Appropriate and continuously updated management plan

\section{Principle 8.}

Appropriate monitoring and assessment activities to assess the condition of the forest, management activities, and their social and environmental impacts

\section{Principle 9.}

Maintenance of High Conservation Value Forests (HCVFs), defined as environmental and social values that are considered to be of outstanding significance or critical importance

\section{Principle 10.}

In addition to compliance with all of the above, plantations must contribute to reducing the pressures on, and promote the restoration and conservation of, natural forests 
The groups recommended changing the 100\% rule, and FSC's Board of Directors approved the committee's recommendations, eventually leading to the FSC MIX label. These changes gave representatives from previously excluded industries access to certification. This renegotiation and redefinition facilitated alignment by allowing the existing certification category to be enlarged, thereby accommodating more diversity. This stabilised the system and provisionally and temporarily restored order.

Although the friction appeared to have been overcome and order restored, within FSC there remained significant conflict over the mechanism and goal of allowing uncertified material to be mixed with certified. Some continue to see this as a purely economic or market solution. Allowing percentage claims means that it is easier for companies to use one of FSC's trademarks, improving market access in addition to improving the market penetration of the FSC brand. This is seen as positive ("any control is better than none") or negative ("FSC should only allow the best") depending on who is asked. Other groups see this as a way to promote full certification of forests. As FSC MIX products require the massbalance of material to be at least $70 \%$ fully certified, allowing mixing will in theory indirectly support the expansion of fully FSC-certified forests.

These issues are still being debated within FSC, highlighting the ongoing high-level friction on this issue. Even at time of writing, discussion is continuing regarding which of those goals were and should be the primary goal of mixing. Furthermore, there is discussion on the inner workings of percentage claims: should the $70-30 \%$ split be maintained, should it be a sliding scale slowly eliminating the uncertified material, should mixing be allowed at all in the long run? This debate is embodied by the so-called controlled wood strategy.

The controlled wood standards are the fundamental mechanism that allow certified and uncertified material to mix. In 2013, FSC's Board of Directors instructed the secretariat to design a process that would result in a long-term strategy for controlled wood (FSC, 2017a). Development of the controlled wood strategy began in 2016 with a series of scoping exercises by the secretariat followed by an international stakeholder meeting of about 30 participants representing all FSC regions and chambers. This was followed by a public consultation in 2017 on the resulting discussion paper. A second international meeting was held in 2018. Following a second consultation, an intense period of work between the FSC secretariat and an advisory group of FSC members resulted in the finalized document in April 2019.

The drawn-out nature of the development process of this document demonstrates just how much disagreement remained between actors about mixing certified and uncertified material. Furthermore, the text itself shows examples of friction that were hidden from sight. One such example is Core Objective 4 ("Communication"), which highlights the idea that some actors within FSC thought communication around controlled wood, the FSC MIX label, and its relationship to FSC $100 \%$ was misleading or insufficient. The document makes a point to say that environmental and social stakeholders within the process required truthful communication on this topic to continue accepting mixing certified and uncertified material in FSC labelled products (FSC, 2019b). This implies that without the changes promised by the development of this strategy, those members would have pursued actions that sought to undermine or remove mixing, a concept that allowed FSC to grow exponentially within the pulp industry.

The controlled wood strategy is already having direct impacts on FSC's normative requirements. Most notably, FSC announced that the text on the FSC MIX label will change in January 2022 (FSC, 2020c). The text has changed from "[Product] from responsible sources" to "[Product] | Supporting 
responsible forestry". Two facts highlight this as a significant moment where friction between FSC actors has been overcome: 1 ) The involved and lengthy process of the controlled wood strategy resulted in a direct call for "truth in labelling", and 2) The FSC MIX label text has not been fundamentally altered since 2010 (FSC, 2017d). When these facts are considered, this moment of alignment is shown to be significant indeed. Another impact is that starting in 2022, FSC license holders are allowed to communicate about controlled wood at all (FSC, 2020a). Prior to this, communicating about controlled wood was strictly forbidden. Together, these changes provide an example of how the internal friction of the fundamental underpinnings of one of FSC's major standards was, and still is, subject to intense friction as different actors vie for their own interpretation to become the dominant one. In the end, rather than collapsing under this friction, the normative elements of FSC changed, providing, alignment between actors, stabilizing the system.

This section has demonstrated how the setting of FSC standards included lobbying by powerful actors to get standards on the political agenda as well as working groups and assemblies further elaborating them. Originally formed to combat deforestation, forest certification is a fundamentally a consumerist tool. Even promoting "well-managed forests" and "supporting responsible forestry" (as the labels say) while using a tool that fundamentally incentivizes consumption (and thereby maximizing production above all else) represents a real conversation/tension among FSC members (still ongoing) about what is FSC for and how should FSC do it. When FSC members experienced such friction, as illustrated in the example of the percentage rule, processes of reinterpretation and renegotiation were initiated to accommodate these problems and realign the different views and interpretations. FSC's Principles and Criteria and the controlled wood strategy represent the negotiated meaning that the FSC members have given to 'responsible forest stewardship'. Together, they at least provisionally define what counts as responsible forest stewardship.

\subsubsection{The pathway of operationalisation}

The FSC Principles and Criteria were never meant to be the only certification guidelines. These were always meant to be translated into nationally and regionally appropriate standards, indicators, and verifiers. By 1997, there were already 20 groups (both national and regional) that were working on developing national or regional FSC standards (Tollefson, et al., 2008). A detailed description of the development of the regional standards for British Columbia Canada is given by Tollefson et al. (2008) and McDermott (McDermott, 2003; 2012). Their research shows how British Columbia's regional standards emerged out of a seven-year process of consultation and negotiation. Given the threechamber structure of FSC International, FSC-BC decided to adopt a four-chamber structure in which they added a Chamber for Indigenous People. Furthermore, an FSC-BC steering committee was formed that was ultimately responsible for approving the regional standards. To formulate a draft of the standards a technical committee was formed. Finally, multiple public hearings were organised to communicate FSC-BC activities (McDermott, 2003). Notably, both the negotiation process and the formulation of the standards involved significant conflict:

Large industry refused to sign on to the third draft (D3) because they viewed it as setting the bar too high, creating a "boutique standard" that would have little impact in the market. (Tollefson, et al., 2008, p. 318)

Comparable to the process during which the Global Principles and Criteria were formulated, FSC-BC's decision-making process reflected the huge differences in values between the various parties, making it very difficult to reach a consensus. After the failed third draft, it took three years of deliberation before all parties could be convinced to come back to the negotiating table and forge the final 
standards (McDermott, 2003). Despite their differences, all representatives had much to gain from its approval (Tollefson, et al., 2008). Finally, a compromise standard was brokered, and the FSC-BC standards were endorsed by FSC International in 2005 (McDermott, 2012). The FSC-BC standards are an elaboration of the Global Principles and Criteria in the form of indicators and verifiers which reflect the regional specificities of British Columbia. Because the generic principles and criteria were translated to the circumstances in many heterogeneous regions and were therefore context specific, the development of these regional standards helped to tailor FSC's international Principles and Criteria to the local context in British Columbia to which they were applied.

To further increase the salience of their certification initiative, FSC not only encouraged the development of tailor-made standards for specific countries or regions, but also actively developed tailor-made standards for specific groups of forest managers. This was important, because in the early 2000s FSC discovered that the impact of the standards on smallholders and community forests in developing countries was lower than desired. As the following quote explains, FSC International responded to this by initiating an initiative that is specifically tailor-made for small holders (Karmann \& Smith, 2009).

FSC's secretariat coordinated the initiative, and the process was designed to maximise the input and feedback from FSC members and stakeholders. In 2002, SLIMF came into force, further tailoring FSC Principles and Criteria to the local contexts of smallholders and communities. Besides the creation of new standards and criteria, the SLIMF process resulted in funding and direct field assistance to local small-scale forest enterprises by FSC-related or FSC-sympathetic development organisations. This assistance proved crucial for enrolling low intensity forest management systems of smallholder enterprises in the FSC certification process (Wiersum, et al., 2013).

NGOs and development organisations promoting and supporting forest certification not only supported forest managers in the certification process, but sometimes also added their own specific objectives to the mix. For example, NGOs in Nepal brought with them their own agenda and ideologies on community development, collective action, and gender balance in addition to FSC's standards. In 2002, the USAID Nepal programme provided US\$500,000 to the Asia Network for Sustainable Bio Resources (ANSAB) to pilot FSC certification (Bhattarai \& Dahal, 2005). The Federation of Community Forestry Users Nepal (FECOFUN) was responsible for helping communities attain certification. To do so, economic support was offered to communities by covering all field costs, including costs for auditing. Technical support included detailed forest inventories, surveys, and data analysis. FECOFUN also delivered the information and institutional support to get communities 'up to the standard' and allow them to be certifiable. Although the FSC standards do not consider gender issues, FECOFUN's programme also aimed to improve the social and economic circumstances of women in the participating communities. In the process of preparing communities for certification, FECOFUN required a gender balanced forest committees and subcommittees (at least $33 \%$ women) in villages. The community felt that they could not refuse these additional gender balance requirements and they tried to accommodate these additional social arrangements.

FSC also attempted to tailor their standard "Requirements for Sourcing FSC Controlled Wood" for use in specific countries. This standard requires the development of FSC-approved risk assessments that companies use to either avoid the risk or mitigate the risk of materials coming from unacceptable sources enter their supply chains. The thinking behind this was that if it was left up to the companies, the identified risks and actions taken to mitigate the risks would be too widely varied. This could result in companies within the same country, sourcing the same material from the same regions or suppliers, describing entirely different risks. since the certification bodies that audit the companies do not share 
this information in detail, this could result in a "race for the bottom" wherein companies try to describe as few risks as possible. Instead, by providing risk assessments for (some) countries, the conflict that arises between this situation and the claim that FSC label-bearing products are "from responsible sources" could be alleviated. FSC acknowledged that they would not be able to cover all possible countries, and so they laid out requirements for companies to develop their own risk assessments for areas that would not be covered by an FSC risk assessment (FSC, 2017c), but these are proprietary, and not subject to examination in this paper.

There are two types of FSC risk assessments. National risk assessments (NRAs) were developed by national FSC offices (network partners), supported by a national working group with representatives from all three of FSC's chambers. Centralized National Risk Assessments (CNRAs) were developed by FSC International, coordinated by FSC's secretariat and developed by hired consultants. In both cases, the risk assessments were subject to public consultations and extensive drafting processes. A recurrent issue during the creation of both types of FSC risk assessments was ensuring that they were actionable by most companies that would need to use them. This is best exemplified by the control measures (CMs) in the risk assessments that are intended to mitigate the risk of sourcing material from unacceptable sources. The CNRAs contain only "recommended" CMs, if any, which are general in nature. Companies are free to ignore these CMs without providing an explanation to their certification body during their audit. In doing this, FSC acknowledged that translating between their normative description of risk and the on-the-ground reality of a particular company's supply chain is not a small leap, and is probably best left in the hands of the company itself, to be verified by the auditors. FSC's distance from the field was seen as an almost insurmountable gap, and so they are asking the actors in the field to contextualise the CNRAs themselves. Without this tacit acknowledgement of the necessity of companies and certification bodies to translate between the national-level risk assessment to their situation, the CNRAs would likely be unusable, and would harm the credibility of FSC as a legitimate certification scheme.

NRAs, on the other hand, have both recommended CMs and mandatory CMs, which can only be replaced by the company if they can provide a control measure that better mitigates the identified risks, or demonstrates the risk is avoided altogether (FSC, 2017c). In doing this, FSC is restricting the contextualisation of the national-level normative document. This is not without rationale, however. FSC is relying on the principle that the document has already been contextualised when used by companies seeking certification, as the network partner and working group that developed the NRA are closer to the field than FSC International. Having mandatory control measures means that companies do not have to spend the effort to come up with their own, while it also means a higher burden of evidence if they wish to use other control measures. Ultimately, it was FSC's decision that the NRAs' contextualisation should lie primarily in the hands of the creators.

The formulation and implementation of National Standards, the SLIMF standards, and the FSC risk assessments illustrates another step in the contextualisation of the global standards. By travelling through the FSC landscape, FSC's normative documents connect international, national, regional, and local actors. During these travels, friction emerged when the global FSC standards did not meet the needs of national and regional actors, including local NGOs and forest managers. As the examples of the FSC-BC standards, the SLIMF initiative, and the FSC risk assessments illustrate, the documents had to be translated to align with the local contexts. The global normative requirements were translated into requirements for different regions as well as different sorts of stakeholder groups in order to be taken up. 


\subsubsection{The pathway of auditing compliance}

FSC accredits independent organisations - certification bodies - to assess whether forest management operations conform to its standards. Audits are carried out by one or more auditors who check whether the forest management practices are in compliance with the standards. During this process, auditors generate information by measuring and monitoring during field visits and then interpreting, evaluating, and reporting on their findings. This report can contain recommendations as well as specify corrective actions to be taken by a certain date. If the changes have been made in time, the forest operation can become or remain certified.

A forest audit typically starts outside the forest. At a meeting at the beginning of the audit, the auditor explains the specific Principles on which the audit will focus. Then the auditor tries to find as much evidence as possible to prove compliance. One source of evidence is the internal records kept by forest managers. These include the records of harvested forest products (both timber and non-timber), annual growth estimates, pesticide applications, contracts, minutes of stakeholder meetings, paid labour, boundary maintenance, and so forth.

Apart from reviewing documentation, auditors also make field visits. Typically, the auditor and the forest manager together discuss which parts of the forest will be visited during the field visit. The auditor selects a cross-section of sites in the forest that he/she wishes to visit based on a sampling strategy that includes the different types of forest, sites where specific problems have occurred, sites where specific management interventions have been carried out, and so on.

Field visits display numerous instances of friction and alignment, and auditors and forest managers spend significant time negotiating the meaning of the standards in their particular context. From the forest managers' perspective, the general standards do not always make sense. This can be illustrated by an audit of a community in Africa. FSC Principle 4 specifies that forest management should meet or exceed all applicable laws and/or regulations covering health and safety of employees and their families. This implies that forest workers must have access to clean and safe drinking water while they are working in the forest. According to the Western auditor, clean and safe water in Africa meant water had to be boiled and filtered. However, we found that in practice, local people do not like to drink boiled water because they feel that the process of boiling and filtering is burdensome, and water becomes tasteless. Furthermore, bottled water is not an option either because it is too expensive for them. An auditor explained:

There are subjects such as "Health and Safety" requirements (as covered under Principle 4, criterion 4.2 of the Standard) that are a bit trickier to evaluate in this case, mainly because this is not a notion that is generally widely recognised and applied in southern countries as compared to Europe for example. However, there are basic requirements that any FSC certificate holder has to comply with. FSC requires compliance with ILO Code of Practice "Safety and Health in Forestry Work" as a minimum and this is the code we use to evaluate those aspects [in this certificate holder].

The auditors and the forest managers discussed this issue and negotiated how the standard could be applied in this case. Finally, they agreed that, in this case, clean water constitutes water that comes from a trusted source and is put in clean bottles, but is not necessarily boiled.

The theme of health and safety emerged again in a later field visit of the same audit. Here, the auditors met with forest workers at their village headquarters. All the workers were in uniforms made of thick, canvass-like material, including hats, gloves, and boots. When asked by the forest manager, one 
forester stood with alacrity and enumerated his equipment: uniform, gloves, boots, helmet. The auditor asked whether his boots were steel-capped. There was some confusion among the workers, and they ended up explaining that these boots were new and safety-rated, but not steel-capped. The auditor asked why the forest workers did not have the steel-capped boots as expected. The manager explained that the village resource council could not afford the steel-capped boots until they had generated income from the sale of the FSC wood, but that they had already placed an order. As an interim safety measure, they obtained robust hiking or work boots. During the meeting among the auditors, this issue was raised for discussion. The second auditor, who had not been present earlier (but who had more local knowledge), said that work boots of any description were a major improvement. Formerly, these workers would likely have gone into the forest barefoot and in T-shirts. This continuous improvement and clear commitment to continue improving in the future resulted in the auditors not requiring immediate action on the issue, but flagged it for examination in the next audit.

An audit in the Netherlands provides a similar example of such field-level processes of friction and alignment. In this particular case, a small area of protected forest was observed to have been cleared. It was clear from the state of the stumps that this clearing had not taken place recently. The auditor made an unplanned stop to observe the site and asked the forester and the biologist participating in the audit questions about it. This triggered a discussion between these two experts about how clearings should be done. The forester explained that this clearing was an extraordinary case due to significant damage to the trees in that area. The biologist claimed that they should have left more fallen and standing trees and that they should have thinned the area to the south to allow sunlight in. The forester responded by explaining FSC's requirements and the forest management plan. At the conclusion of the conversation, the auditor stated that indeed such clearing is generally not considered appropriate but that the forest manager's explanation had convinced him that it was an isolated phenomenon and not a systemic problem. No further action was requested.

These examples that auditors are regularly faced with friction between global FSC standards and the particularities of the local context. In response, they improvise, as no preparation or checklist could cover these situations. The variability in enactment of FSC's standards in practice that thus occurs is compounded further by the fact that different certification bodies have their own procedures for certification and there is quite some variation among these. For example, some certifiers use predefined checklists whereas others work in a qualitative way (Cook, et al., 2021). Variability can also be observed between different auditors from the same company. It should be recognised that, in one sense, allowing for such improvisation and variability between contexts is what enables the FSC standard to travel and be a global standard. At the same time though, this variability poses a risk to the credibility of FSC certification. Indeed, FSC certificates are regularly challenged and accused of being inconsistent (Counsell \& Loraas, 2002; Dodge, 2006).

When friction arises during an audit, the resulting process may provide a conceptual bridge from the field back to the standard setting. Sometimes, when there is disagreement, confusion, or surprise about a normative requirement during an audit, a certification body auditor ${ }^{3}$ will send a request for interpretation to FSC including background information, a question, and the certification body's proposed response (FSC, 2019a, p. 10). The idea behind this is only to ensure that requirements that might be ambiguous in their wording are not interpreted in wildly different ways between certification

\footnotetext{
${ }^{3}$ Strictly speaking, FSC does not deal with auditors. Auditors are individuals. FSC deals with certification bodies, which are legal entities/organizations.
} 
bodies. If FSC agrees to issue the interpretation, it is published on FSC's Document Centre and announced on a mailing list including all accredited certification bodies.

The procedure for processing requests for interpretations specifies the timeline for responses, the requirement for consultation with certification bodies in general, and who is able to approve the interpretation (FSC, 2019a). It does not, however, detail the analytical process that the receiver should go through. In practice, this usually involves discussing the request with their immediate supervisor or colleagues. The person is also empowered to ask follow-up, clarifying questions of the certification body to obtain better situational context, and to reach out to network partners for feedback, suggestions, or clarifications of national context. Each of these interactions can involve discussions around how each actor perceives the problem, requiring realignment of the interpretation when new information is presented. This is especially true during the consultation phase when other certification bodies who may have experienced similar situations, but not raised a request for interpretation, provide their feedback on the proposed interpretation. After being published separately, those interpretations will be incorporated into the appropriate normative document during a normal revision process. These incorporations sometimes do result in additions or deletions to the normative requirements (FSC, 2021d), bridging between the audit and the standard-setting.

As this section has made clear, the practice of auditing provides many opportunities for friction and alignment. Many decisions are made about how to interpret and apply standards and what does or does not count as forest stewardship in a particular case. The examples have shown that these decisions are not always straightforward, and that the specificities of the local context are not easily captured in technical and measurable standards. However, at a certain point, when the final audit report or interpretation is produced, these messy interpretations disappear from view and, at least temporarily, certified activities are aligned with the standards.

\subsection{Discussion and conclusion}

We started this article by arguing that more insight is needed into the way in which policies and ideas travel to connect the local and the global. This paper has opened up the dynamics of translation in the travel of policy ideas based on the concepts of enactment, friction and alignment. Using the concepts enactment, friction and alignment to examine FSC's work to develop its normative requirements directs attention to the disciplining and structuring effect that standards have to shape these local forest management practices as well as the ability of actors to 'act otherwise' in interpreting and using the standards (Long \& van der Ploeg, 1989; Richards, 2005; Vellema, 2008). Our case of FSC certification illustrates that FSC standards do not have a pre-defined script that directly 'tells' decision makers, forest managers or auditors how to interpret them (Orlikowski, 2000) but instead offer scope for negotiation and interaction of what the standards mean. As such the standards can simultaneously be considered boundary objects (Star \& Griesemer, 1989; Turnhout, 2009; van Egmond \& Zeiss, 2010) which travel between and connect different social worlds as well as sites of boundary work (Gieryn, 1999) where actors demarcate what does and does not constitute sustainable resource management, negotiate the meanings of the standards, what it means to apply them, and what technical, professional and local knowledge is required to evaluate compliance. Thus, our approach allowed us to analyse the way in which the enactment of the standards occurs simultaneously with the enactment of the forest management processes these standards intervene in and control.

The case of FSC certification illustrates three pathways that enable the travel of policy ideas needed for an effective governance performance: 1) the pathway relating to setting the standard, 2) the 
pathway relating to operationalising the standard, and 3) the pathway relating to auditing compliance (see Figure $J$ ).

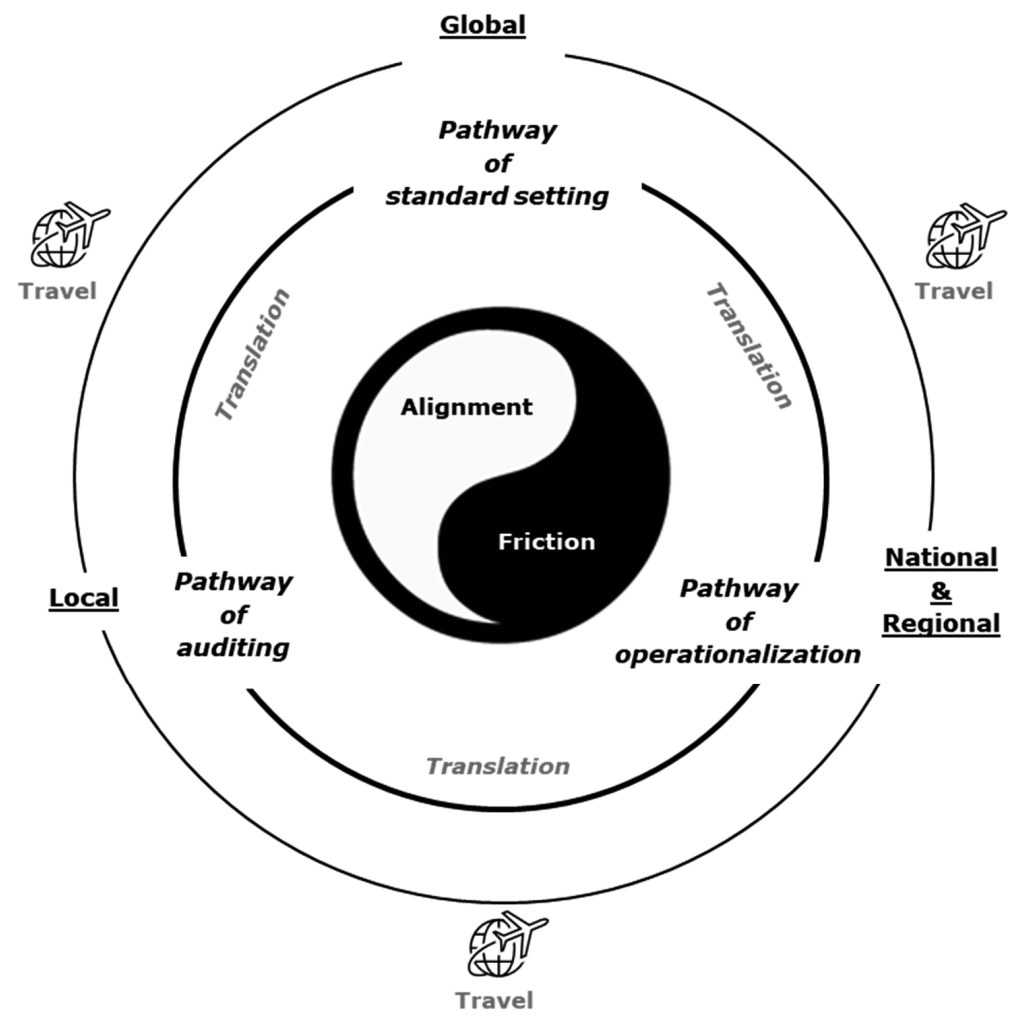

Figure J. The three pathways of the 'travelling' FSC standards.

First, the pathway relating to the setting of the standards facilitates control: they enable international FSC authorities to evaluate forest management practices and control them at a distance (Scott, 1998). Second, the pathway relating to the operationalisation of the standards connects standards and their application on the ground: friction triggers creativity and pragmatism that allows standards to be tailored to the needs of local forest managers, and this is a key step in making the standards 'fieldworthy' in different local settings (Eden, 2008). Third, the pathway relating to auditing facilitates the legibility of forest management practices (Scott, 1998). Auditing represents local forest realities according to the standards. In so doing, auditing manages the diversity of local interpretations and brings them into alignment with the standards, thereby maintaining the overall credibility of the standards (Gibbon \& Ponte, 2008). Taken together, these three different pathways illustrate how policy travel is arranged in the FSC network, how they are held together, and how in doing so they consolidate the 'globalness' of the FSC standards that makes environmental certification possible.

Our conceptual lens to analyse certification and auditing and unpack how policy ideas travel contributes to interpretive policy analysis in three ways. First, it provides a conceptual language to describe the phenomena that occur in the translation processes which form the basis for the travel of policy ideas and as such it responds to the call to develop analytical tools for studying the process of 
policy travel (Mukhtarov, 2014). Our conceptual lens adds a dialogical perspective (Wagenaar, 2011; Cook \& Wagenaar, 2012) on power to theories of policy travel. This dialogical perspective on powerwhich reconciles the disciplining effects of standards with agency - also means recognising the performative dimensions of policy travel. Although it remains important to analyse how the global standards impact on the local forest management practices and with what sort of consequences, it is also clear that such an analysis is not sufficient. Responsible forest management is not an a-priori given but it is constructed in interaction through the context specific dynamics of enactment, friction and alignment. This is consistent with contemporary ideas on dialogical meaning in interpretive policy analysis and the transformative potential of practices (Wagenaar, 2015).

Second, the methodological implication of our conceptual lens was a need for methods that could follow policy ideas across multiple sites (Kingfisher, 2013; Stubbs, 2014; Clarke, et al., 2015). As our study was not constrained to a specific geographical setting or a specific group of people, our 'unit of analysis' became the policy idea itself. As Yanow (2015b) observes, 'studying up' or 'studying down' is more common in interpretive policy analysis than 'studying across' (Shore, 2011) policy networks and this suggests that there is still a lot of scope for such a multi sited approach in interpretive policy analysis; However 'following the policy idea' and tracing sites of enactment, friction and alignment across space and time, also presented us with specific political and ethical dilemmas. Similar to Mukhtarov et al. (2017), we noticed that the usual challenges of interpretive policy research - such as the issue of power in researcher-research subject relationships in fieldwork and writing - became more complex; working with multiple sites in the FSC network increased the risk of 'flattening' our representation of the actors' experiences in those sites, their uniqueness and ultimately the actors' agency. We would welcome further discussion on the specific methodological challenges that interpretive practitioners face when studying the travel of policy ideas.

Third, the practical implication of this lens is that if connections are formed in processes of enactment, friction, and alignment, then instead of asking 'How can we improve the impact of global policy on local practices?' we should ask 'What sort of (partial) connections might enable the enactment of a certain policy idea?' (see also Shove et al. (2012)). The first question carries a fixed representation of what the problem is (Bacchi, 2009); one that assumes that it is self-evident what global policy is and that understands the relations between global and local in terms of effectiveness. This problem representation frames local people's behaviour as the appropriate site of intervention and therefore tends to propose solutions based on: 1) education to change people's attitudes and 2) removal of barriers to close people's intention - behaviour gap. The second question takes an interpretative perspective that avoids these problematic assumptions and thus also frames scope and role of intervention differently. Our lens makes it clear that standards travel through the social network, and, in doing so, they order people and things and allow certain kinds of connective action to emerge. This implies that questions such as who is included and who is excluded in the social network, of what responsible forest management is, cannot be determined or defined in advance; they are all a matters of interaction. It follows that if decision makers want to promote responsible forest management or any other policy idea, they need to go beyond trying to change the behaviour of local people. Instead of putting all the responsibility for responsible forest management with these local actors, decision makers are be better off by looking into the contours and the structure of the landscape of practices (Shove, 2010; Wenger-Trayner, et al., 2015). A focus on practice, which includes a sensitivity towards how behaviours are embedded in and structured by specific social-material contexts, are indispensable in the fostering of the kinds of productive connections that are needed for responsible forest management to emerge and equally in considering how to break connections that keep unsustainable governance performances in place. 
In conclusion, our approach and analysis not only contribute to the current body of literature on standards and certification, but also expands perspectives on interpretive policy analysis, specifically how travel of policy ideas links the local and the global. By introducing the concepts of enactment, friction, and alignment, this article has developed and explored some analytic resources and introduced a provisional vocabulary that enables understanding the processes involved in the translation processes that allow policies to travel. As we have suggested in this article, understanding the complex workings of policy travel and translation requires detailed investigations of practices of enactment friction, alignment: "universal claims do not actually make everything everywhere the same. [...] As soon as we let go of the universal as a self-fulfilling truth, we must become embroiled in specific situations. And thus, it is necessary to begin again, and again, in the middle of things" (Tsing, 2005, pp. 1-2). 
"Quis custodiet ipsos custodes? Your Grace."

"I know that one," said Vimes. "Who watches the watchmen? Me, Mr. Pessimal."

"Ah, but who watches you, Your Grace?" said the inspector with a brief little smile.

"I do that, too. All the time," said Vimes. "Believe me."

-- Terry Pratchett, Thud! 


\section{Chapter 6}

Conclusion and Discussion 


\section{Chapter 6. Conclusion and Discussion}

\subsection{Introduction}

This thesis set out to examine the nexus between global standards and local forest management practices. The first chapter generally characterizes the history of making claims about the origin or manufacturing processes of goods. This practice is ancient, and at in the past has sometimes been a life-or-death issue. In the modern era, a group of individuals sought to highlight deforestation as a global-level life-or-death concern, and so started their own scheme to label timber products that originated from forests managed to a set of standards of good practice that they themselves developed. Thus, the Forest Stewardship Council (FSC) certification scheme was born.

The crux of this certification scheme is the third-party audit, upon which the integrity of the system rests. The introductory chapter continues by describing how the audit really is the nexus between the global standard and the local management practices and begins to highlight the issues that the audit and auditors who undertake the audit must navigate. This highlights how examining the internal workings of FSC audits in a grounded fashion can illuminate fundamental aspects of the nexus between the local and global.

In pursuit of this goal, three research questions are proposed:

1. How is $3^{\text {rd }}$ party auditing of the environment conceptualized in literature?

2. How are auditing practices and values performed by auditors?

3. How does auditing connect global standards and local practices?

In this chapter, these questions will be answered directly. This is followed by a discussion of how the research presented in the thesis impacts elements of the theoretical framework presented in chapter 1. The focus of this discussion is on the concepts of Informational Governance, the practice of auditing, and the principles and dramaturgy. A reflection on the empirical research and analytical methods is then presented. The chapter concludes with a set of recommendations for future research and policy based on the synthesized themes arising from the thesis.

\subsection{Answering the research questions}

\subsubsection{Q1: How is $3^{\text {rd }}$ party auditing of the environment conceptualized in literature?}

This question is answered in chapter 2 of the thesis. Three trends in the literature are distinguishable. The first trend focuses on the outcomes of the audit. This includes examinations of whether or not the audits have the wished-for impact on management practices. In the context of FSC certification, this literature is preoccupied with answering the question of does FSC certification auditing result in better forest management practices, improved environmental conditions, or similar. This trend in literature is also associated with normative assessments of the audits themselves. In other words, this literature often asks, "are audits [neutral, objective, transparent]?" Thus, it positions audits as something that can inherently have or not have a certain quality.

The second trend in the literature is also concerned with the outcome of audits, as the previous group was, but instead of asking the normative question about what audits are, it frames the situation as the opposite. This group of literature starts from the supposition that auditing is not neutral, objective, transparent. Thus, these things should be strived for in the audit, but they represent platonic forms that can only be dimly mirrored in reality. 
The third trend in literature positions auditing as practices that constitute what comes to be seen as neutrality, objectivity, and transparency. This literature examines how these concepts are created in the process of auditing and certification. This perspective provides the primary basis of the other chapters of the thesis.

Thus, in chapter 2, we see the literature primarily frames auditing in terms of the effectivity of the audit (does the audit result in the desired outcome), and the characteristics of the audit (namely neutrality, objectivity, and transparency). A different conceptualization of auditing is offered by Power (1991) and Elad (2001) who suggest that auditing of the environment, due to its roots in both professional financial auditing and standardization, and transparency-seeking and protest over environmental degradation, can be seen to exist in a tension between protest and professionalism.

The chapter proposes a spectrum of modes of auditing, with protest on one pole, and professionalism on the other pole. We position the characteristics of auditing identified in the literature in relation to these poles to provide a comprehensive picture of how environmental auditing is conceptualized. The value of transparency is linked to the protest mode of auditing. This is due to the origin of environmental auditing as an act of rejecting traditional forms of accountability, questioning the status-quo, and bespoke tools for examining particular situations. The values of objectivity and neutrality are linked with the mode of professionalism. This is due to the necessity of professional audits needing to be seen as being not actively concerned with the outcome, and the importance of ready-made auditing tools that can work in any setting. The both modes of auditing are concerned with the effectiveness of the audits, and so it is positioned equidistantly between the poles. We also note that there exist definitions of auditing in the literature that better suit themselves to one mode or the other. The relationship between these concepts is visualized in Figure K.

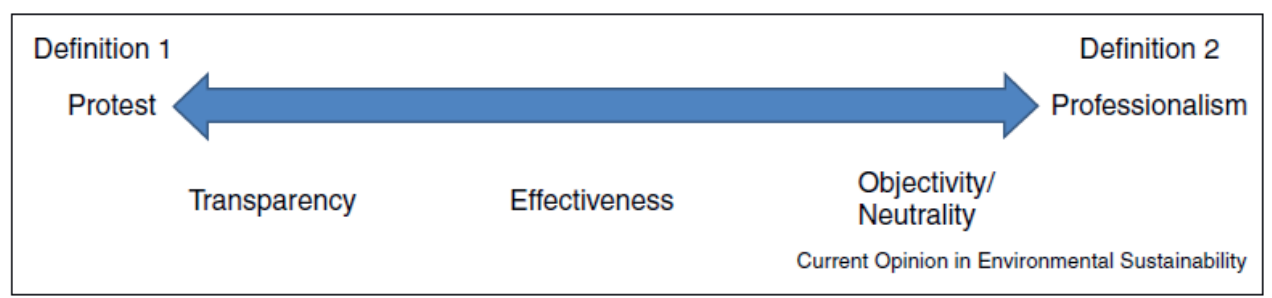

Figure K. How environmental auditing is conceptualized in literature.

The chapter posits that one would expect audits and auditors that focus on particular aspects, be it definitions of auditing or particular values, will likewise trend towards one or the other pole of the spectrum. Paying attention to these values gives hints to the mode of auditing that is being preferred, which then has additional, perhaps unnamed values. Considering the modes can add valuable context to understand that which is valued by the auditing system, rather than just focusing on the outcome of the audit or the plain actions of what is done. All this goes on to colour explanations of how and why auditing is done in a particular way.

\subsubsection{Q2: How are FSC auditing practices and values performed by auditors?}

This question is answered in chapters 3 and 4 . Chapter 3 provides an analysis of the values and practices that are taught to auditors-in-training. Chapter 4 examines how those values are brought to bear in the field during an audit.

Chapter 3 shows that objectivity is a key value in auditing This is demonstrated in the chapter by using Douglas' (2004) three-part frame for analysing what kind of objectivity is being discussed. While being 
trained, auditors are impressed to value and utilise all three types of objectivity: object-oriented, values-oriented, and procedurally oriented objectivity. The trainees were implicitly taught that objectivity is the right thing to value and subjectivity is the wrong thing to value, placing their conceptualization of auditing closer to the professionalism mode of auditing. This was framed in the training as "anybody would come to the same conclusion" as the auditor if presented the same information. This proved problematic, however, as the auditors also acknowledged that interactions unique to audit situations and auditor skills and dispositions impact what conclusion can be reached.

Rather than face the objectivity-subjectivity dichotomy head on, the auditors were instead taught to focus on the value (or skill) of interpretation. Through interpretation, auditors can bypass the problem of the subjective mind of the auditor and make the subjective be presented in an objective way, thereby propagating the most important value of an auditor. The implication is that if all auditors practiced their interpretive skills, then any other auditor would reach the same conclusion if they were properly trained and placed in the same situation. By entwining objectivity with interpretation, auditors are taught to perform mastery of their craft. By first referencing the stable, external requirements of the standards against which they will audit, auditors can lay claim to being objective. Then, even when a unique situation is presented, and the bespoke reaction of the auditor results in surprising outcomes that another auditor may not have gotten, the situation can be transformed to an objective interaction through proper documentation of the outcomes. The mastery of auditing being taught falls in line with Dreyfus and Dreyfus' $(2005$, p. 787) claim that a "proficient performer" has a "repertoire of situational discriminations [that allows for]... immediate intuitive situational responses," without which the whole performance of the audit would collapse.

Chapter 4 examines the performance of the audit itself, and how auditors bring the expertise and mastery of the craft to bear in the field. During the audit, auditors keep tight control of their role secrets and region access to manage the impression of being professional auditors. It is acceptable and good practice for one auditor to express doubt to another, and for them to come to a common interpretation of the situation divergent from either single auditors' judgement, but only when backstage, out of view of the auditees. However, auditors and auditees are not always on opposite teams. Yes, auditors must perform being a good auditor, but they must also cooperate with the auditee to perform a good audit. The result is that the audit itself form the backstage for the performance of the audit report, which goes on to perform for FSC's accreditation body (ASI), and the members of the public who read the reports. The existence of this nested performance proves to be crucially important to ensure that what is experienced during the audit is made able to be accounted for by the auditors. Without it, the experiences of the auditors cannot be condensed and translated into a form that is usable by the audience(s) that are not present for the audit itself.

Thus, auditors apply forms, checklists, and report templates, trappings of professionalised auditing, to the explosion of information that comes from fervently pursuing transparency, a primary indicator of protest-oriented auditing. Auditors therefore serve an important role in balancing the values that are part-and-parcel of the modes of auditing, which are themselves negotiated as part of the broader FSC certification system that exists between the abstract standards and the applications in the field.

\subsubsection{Q3: How does FSC auditing connect global standards and local practices?}

This question is answered in chapter 5 . The chapter connects the specifics of auditor training and the audit itself with the broader topic of the certification scheme. This is done by introducing the concepts of enactment, friction, and alignment as applied to how FSC certification and normative requirements 
travel between the spaces, locations and networks in which they were developed and those in which they are taken up or implemented.

The chapter provides several examples of instances within the FSC certification system of where universal normative requirements travel to local contexts, resulting in tension and creating heterogeneity and diversity in how the requirements are enacted in different contexts. It also highlights how this heterogeneity can still ultimately be considered meeting the normative requirements by demonstrating how actions in the local context travelled back to the standard-setters and resulted in alignment along the way. Alignment results in harmonization of meanings without making them exactly the same.

Specifically related to auditing, the chapter highlights how auditors and auditees may experience situations in which the normative requirements are not entirely clear, or where there is disagreement between auditor and auditee over how exactly a requirement should be applied or what it means. If this is the case, and the auditor and auditee cannot cooperate and the performance of the audit fails, the auditor can send a request to FSC International to provide clarification. The FSC International staff member that receives the request then engages in a series of conversations with other FSC International staff, FSC national staff, and the auditing firm representative (or particular auditor). These conversations are unique to the situation and may involve simple clarifying questions or deeper conversations on the principles of the requirement.

If the request for clarification is deemed valid and applicable to more than just the situation that birthed it, FSC International may issue an interpretation. These interpretations are explicitly not intended to change the requirements in any way. They are only meant to clarify the intention of the requirement to align expectations around implementation. These interpretations are binding and applicable to all audits of that requirement. Thus, outside the normal process of revising normative requirements every few years through highly structured working groups of experts and FSC members, the audit serves to connect local practices with the global requirements by stabilizing the meaning of the requirements.

\subsection{Discussion}

\subsubsection{Informational governance: A foundation from which to build}

As Mol (2008) has argued, the study of environmental governance is missing concepts that come along with the Information Age, chief amongst them being the concept of informational governance. This thesis helps fill that gap alongside other authors (Mol, 2009; Hoefnagel, et al., 2013; Prisupta, et al., 2016; Naus, 2017; Delina, 2019). The preceding chapters of the thesis support the foundational premise of informational governance. Indeed, "... information is becoming a crucial, causal and formative resource, but also a new battlefield..." (Mol, 2008, p. 19).

The entirety of the FSC certification system is oriented towards the production and dissemination of information. In fact, the very premise of on-product labelling is also information-oriented. In the context of FSC, one can piece together the flows of information from the preceding chapter. Information is produced in the form of normative requirements, which then flows to the auditors through training and practice in the field, the normative information is joined by information produced in the audit through the performance of auditors and auditees. The sum of that information is then curated and transcribed to a report which is then assessed by the CB. The report information is then transformed to permission to use FSC's label and placed on a product. The overall intent is to steer a 
buyers' behaviour, and at each step some of that information may make its way back to the standardsetters, beginning the cycle again.

The "information flow" (Mol, 2008) in FSC certification is quite clear in its direction on the macroscale, when considering the process as a whole. This is a fundamentally information-oriented machine, the standard setters provide the fuel, the audit is the engine that drives it, and the consumers ensure the machine goes somewhere. This analogy is quite apt, as the consumers may take the machine somewhere the standard-setters did not intend, and sometimes the engine breaks unexpectedly.

However, informational governance, as it currently exists, is not a concept that can be used to make sense of the interactions one sees in the field. It is instead oriented to understanding outcomes in broad strokes. It is, instead, a field or focus of research. In more specific terms, it appears to be a sociological perspective in the vein of epochal thinking or epochalism (du Gay, 2003; Savage, 2009), in that it is primarily defined in terms of contrasting or dichotomizing itself against some past state and establishing an "overarching societal designation" (Osborne, 1998, p. 17). While this kind of broad explanatory frame has value in certain circumstances (Gane, 2019), it has limitations if one is to actively engage in close description of actions, causes, effects, and implications are ultimately more explanatory (Savage, 2020). In short, informational governance is good at explaining the question of what happens at a large scale, but not very helpful for examining the why or how it happens.

This means that additional conceptual resources are needed to interrogate and analyse the specific actions, actors and processes that make up this kind of environmental governance. To this end, this thesis has engaged with critical transparency studies and critical accounting studies.

Literature in critical transparency studies has grown around the transparency turn in environmental governance (Gupta \& Mason, 2014) and the notion of 'governance by disclosure' (Gupta, 2008; Biermann \& Gupta, 2011). These concepts support the idea of governance structures being (re-) designed to facilitate information and they characterize how information production is meant to steer behaviour. This literature examines the mechanisms by which information not just informs but does governance. They also address the important question of what information is not produced or not made transparent or disclosed. As this thesis has shown, the production of transparency and opacity go hand in hand. In this sense, critical transparency studies provide a specific analytical lens from which to analyse and assess the nature and workings of informational governance, which deepen epochal sociological thinking (Savage, 2009).

This thesis has drawn on critical accounting studies that detail how information is produced at the most basic way in many governance systems. In many settings, some form of auditing serves as a powerful, or the primary way, of generating and disseminating information (Power, 1991; Power, 1996; Gray, 2000; Power, 2000; Watson \& Emery, 2004; Schrøder, 2019). Auditing has, as Power (1997) stated, exploded onto the scene in almost every field in one way or another and not in all cases with intended effects. Strathern (2000) highlights how certain ways of valuing and designing transparency can, in fact, be harmful to meaningful progress on the topic it is meant to benefit. Using the example of performance auditing practices in educational intuitions, the author shows how a highly professionalised, outcome-oriented, snapshot-based auditing system, in fact, hides the benefits the actors in the institutions bring about. Instead, the focus increasingly becomes not affecting the goals of the institution, but to become good at being audited, a concern that will be discussed later in this sub-section. These insights further refine the notion of informational governance, with a focus on the how and why informational governance comes about and on the often hidden and implicit values that guide the production and use of information. 
The role of values has been approached in this thesis by introducing of the spectrum of "modes of auditing" (Power, 1991; Elad, 2001). The formulation a mode of an activity being characterised by values or ways the activity is done is similar to the idea of "modes of governance" mentioned by Mol (2008) in the context of informational governance. In that work, the primary element that characterises a mode is the decision-making structure or way it is done; the ends of the general governance spectrum are "hierarchical" and "non-hierarchical" (NewGov, 2005). The secondary dimension for consideration is who is involved: public actors, private actors, or both. Thus, the focus is on the arrangement of actors and the relationship of power between them. Is one group of actors excluded, are they forced to participate? In this conceptualization the modes of governance are largely divorced from the assumed values of the governance modes, opting for a descriptive nature of how it is done.

The modes of auditing, on the other hand, focus very sharply on a particular type of governance through disclosure, that is auditing for certification. The modes of auditing also focus on values that are characteristic of auditing, rather than how the auditing as done. There is no reason to consider who can participate or way in which they can participate. This is a given under voluntary third-party certification. Appropriating the notion of modes, but for auditing, changes the focus from merely descriptive characterisation of to an interrogation of the principles that are advanced by auditors through their actions. This thesis takes this to mean that it is not terribly meaningful to judge or evaluate whether an audit or auditor is objective or transparent. Instead, research can analyse and demonstrate how these qualities come about, how they are maintained, and how their performance impacts what is done during an audit and why. The mode of the audit is made manifest in the practices of the auditors, but those practices are more fundamentally performing a value that the auditor has internalised.

Placing protest and professionalism at opposite ends of the spectrum of auditing modes highlights that decisions about which information is collected or generated and how it is generated necessarily impacts what that information can say and be used. Ultimately, the production and use of information for governance purposes has become so inextricably intertwined with each other as to render the value judgement of information questionable. The production and reporting of the information is inherently value-laden (Gupta \& Mason, 2014), and so the question of information being good or bad, high quality or low quality, biased or balanced can only be meaningfully engaged in terms of those values themselves. This is not a problem that can be solved, but rather a tension that must be accepted when studying governance processes in the context of informational governance.

To summarize, forest certification can certainly be considered a form of informational governance, but the existing literature on this topic primarily focuses on the outcomes of such processes, without interrogating how and why those outcomes are created in the field. This is also a weakness in the literature on informational governance. The theoretical perspective used in this research is innovative because it helps fill this gap by focusing on the processes of enactment involved in the use of standards and the constitutive role of information in governance. Applied to FSC certification, the approach is able to analyse the way in which auditing practices, and other normative processes, not merely generate information about local resource management in order to assess compliance with the standards, but simultaneously shape the standards as well as the management practices they audit.

The research contributes to the current state of the art on informational governance in three ways.

1. It addresses the role of information in practices of governance. 
2. It assesses the relation between information and the governance criteria of transparency and accountability.

3. It uses an innovative theoretical and methodological approach that focusses on the way in which informational governance materializes in practice. Applied to the topic of the research, the approach can investigate how, through information, practices of auditing both shape and are shaped by the standards as well as the resource management practices they audit.

Therefore, this thesis demonstrates that informational governance is an incomplete concept if one wishes to apply it in research. It is mostly preoccupied with an abstract description and diagnosis of what has happened and provides limited guidance in understanding the specifics of how and why things happen in informational governance. By complementing it with concepts from critical transparency and accounting studies, as this thesis has done, informational governance grows to become a more powerful concept that can then be applied to specific instances or types of tools that produce the information and the governance that is the subject of the concept itself.

This particular tool, certification auditing, itself requires careful consideration too. For, if the concept of informational governance needs to be further developed to examine auditing, then one also needs to have a clear idea of what auditing is all about.

\subsubsection{Whither auditing?}

FSC's certification is a particular type of informational governance, and the way it generates information is auditing. These audits are intended to be an exercise in transparency, or accountability and account-ability (Schrøder, 2019), for an audience, whether that is a select group of decisionmakers, such as the certification body when issuing or denying a certificate, or a broad group of consumers, such as customers in a stationary store deciding which paper to buy. This thesis demonstrates that how the information of an audit is generated is equally important as what information is generated.

This point has been highlighted in the past by Strathern (2000), who pointed out that certain auditing practices can overlook where the real action is. In this article, Strathern argues that the audit of academic output of university staff results in "outward indicator[s] pointing to otherwise invisible processes which contribute crucially to the operation of an organisation... simply get left out of the picture" (p. 134). In particular, the aspects that cannot be easily measured and accounted for, things such as contribution to ongoing work, knowledge transmission, and increased experience or skills, are simply not considered. This is despite the fact that those are all aspects that are explicitly stated as being valued by the institution. As a result, this information is never even brought to the attention of those who could use it. Likewise, the snapshot nature of auditing risks eliminating the dimension of time in the analysis of growth or change. Therefore, by demanding robust, replicable auditing procedures in the name of transparency can, in fact, obscure meaningful factors that might fall outside the scope of these procedures. The focus falls on producing outcomes that are able to be accounted for regardless of their actual impact (Schrøder, 2019). In other words, governing on the basis of information about performance indicators risks becoming self-defeating when the indicators come to stand for and replace the performance that the indicators were meant to value; a phenomenon also known as performance paradox or Goodhart's law.

Thus, the rigid use of standards, as prioritized in professional modes of auditing can pose problem. But we cannot be blind to the limitations of the opposite situation in which the auditor has free hand in interpreting the goal of the standard and what it means to comply. Gul, Wu, and Yang (2013) 
described 'significant variation in audit quality across individual auditors' (p. 2018) using statistical methods to analyse financial audit outcomes. Other authors have likewise examined how auditor judgement, a term that indicates the freedom an auditor to render judgements or follow lines of inquiry without following strict guidelines, can, in fact, be harmful to the objectivity or robustness of audit outcomes (Grout, et al., 1994; Smith, et al., 2001). These two examples speak to a deeper question about conformance auditing as a whole: What is it for? This varies depending on the type of organisation or field that is being audited.

Academia and medicine provide examples of the questionable value of using pre-determined performance indicators as measurements of success. In academia, professors often have a number of publications that are expected of them. As a result, many academics feel forced into a situation where the quantity of publications becomes the whole point, regardless of publication quality (de Rond \& Miller, 2005; McGrail, et al., 2006). In the field of medicine, with the goal usually focused on providing high-quality care and good patient outcomes, performance targets perversely result in a focus on high throughput, regardless of the quality of care (BMJ, 2018; Franco-Santos, 2018). The question to ask is, "why are we checking these performance indicators at all?" The reason often comes down to financial reasons (Butler, 2003; Eykens, et al., 2019; Mathies, et al., 2020) rather than concerns about quality. If academics do not publish prolifically, the money does not come in. If doctors do not maximize throughput, they are losing money. Therefore, it is in their interest to focus on the thing that rewards (or at least doesn't punish) them. There are tensions between performing well or performing to quantitative targets and this raises concerns about what the system actually values: improvement or just meeting the requirement. This is a fundamental tension between assessment and improvement.

In auditing, these concerns are well highlighted by the dichotomy of protest and professionalism presented by Power (1991) and further developed in the context of FSC by Elad (2001). FSC has its roots in protest, in that it was originally formed as a reaction to the milquetoast, business-as-usual approach to forest degradation in the 1990s. Therefore, its goals of disrupting and improving forest management practices is passed on in its auditing values. However, the extensive library of normative documents veers strongly in the direction of valuing procedure, replicability, and universalism.

FSC audits and auditors are therefore uncomfortably positioned between protest and professionalism, forced to reckon with both without giving either too much influence. They must decide which they would rather see: Increase box-ticking in order to minimize variation between auditors, or accept the production of variation through interpretation in the name of being salient or focusing on the things that make a real impact in the long run. Whichever choice is made impacts the way in which auditors perform their audit, and therefore necessarily impacts the information that is gathered and passed on to the decision-makers.

This thesis demonstrates that FSC forest management auditors are aware of this tension and seek to straddle the divide between protest and professionalism. They actively attempt to not just be boxtickers, to focus on what really matters, and to hold the protest values of FSC in their practices, even if this is not strictly the rules-as-written. However, auditors are impressed from the first instance of their training to ensure that their conclusions are objective, or that anybody else would reach the same conclusion. This is only possible if the system is completely routinized, eliminating individual auditor idiosyncrasies.

The empirical evidence in chapter 3 places FSC auditing practices closer to the 'professionalism' pole of the spectrum. Their preoccupation with all three types of objectivity (Douglas, 2004) demand that they have and follow procedures that can be replicated with some amount of reliability. This, by 
necessity, increases the likelihood of not challenging the status quo, even if it runs counter to the protest-oriented values of FSC. However, as demonstrated in chapter 4, demonstrates that auditors do still have the discretion to move away from professionalism to focus on activities that indicate improvement even if they do not necessarily fit the strictest reading of the standards.

The chapters 3,4 , and 5 all demonstrate how auditors serve as arbiters of what information is generated and passed on to decision makers. Very clearly, a preoccupation with transparency would result in an information dump, which might very well only serve to paralyze decision-making through too much information. In this way the professionalism value of FSC auditors serves to make the process more impactful by curating information for the audience. Even in the case of information not being included in the audit report, auditors may reach out to the standard-setters themselves who may then need to make subtle (and not so subtle) alterations to the normative requirements, which then echo back down to the field. This shows in its own way that whether or not this information is disclosed to the intended end-audience can be entirely beside the point. Some information circulates within the certification system itself and results in demonstrable outcomes.

This entire topic is couched in a very fundamental risk that is posed by dominance of valuing professionalism over protest in FSC auditing. This risk is often called Goodhart's Law, which is paraphrased by Hoskin (1996) as, "when a measure becomes a target, it ceases to be a good measure." The principle behind this premise is that when an indicator of a goal is turned into a target, then it will no longer be able to function in its original role as an indicator of the goal (Newton, 2011). In other words, it is inevitable that indicators of good performance become an end in themselves, rather than a mean to achieve the goal. When there is a benefit, or non-detriment, linked to a particular indicator of performance, the incentive is to become really good at showing that indicator, regardless of the actual impact the indicator has on the actual performance (Newton, 2011; Crawford, 2017; Fire \& Guestrin, 2019; Griesemer, 2020). To put this in terms of FSC certification, the goal is to ensure "that the forest is being managed in a way that preserves biological diversity and benefits the lives of local people and workers, while ensuring it sustains economic viability." (FSC, 2021b) One set of the indicators of this is (FSC, 2018):

2.3.1 Health and safety practices are developed and implemented that meet or exceed the ILO Code of Practice on Safety and Health in Forestry Work.

2.3.2 Workers have personal protective equipment appropriate to their assigned tasks.

2.3.3 Use of personal protective equipment is enforced.

But what happens when, as demonstrated by the audit described in chapters 4 and 5 , meeting these requirements threatens the economic viability of the auditees? Certainly, they can drop out of the certification scheme, but then how does this promote the preservation of biological diversity and social benefits? Is it better to game the system and equip only those who will be seen by the auditor, or is it better to justify the substandard safety equipment as a step to compliance? A strictly professional-oriented auditing system would strongly incentivize the former.

Ultimately, any auditing system will struggle against the outcome of its auditees just getting better at being audited, but a domination of professionalisation values can only hasten the process.

Taken as a whole, this research contributes to the academic treatment of auditing in general and FSC forest management certification auditing in specific in three ways: 
1. It positions auditing and auditors within the notion of informational governance, demonstrating its role in generating the information that goes on steer behaviour.

2. It contributes to the analytical toolbox of critical auditing studies by elaborating the use of the protest-professionalism spectrum of auditing, linking it to values implicitly and explicitly built into the normative framework that auditors exist within.

3. It adds to the body of literature examining auditing as a contextualised interaction between individuals, highlighting the risks and advantages inherent in such arrangements.

\subsubsection{Dramaturgy: Practicing performative performances}

Ethnographic examinations of environmental policy practices are not unheard-of, but they are relatively rare compared to other analytical frames that are not so directly rooted in the reality of the actors in the field. Such ethnographic studies have the benefit of focusing on the actions of individuals in the field, busy with the work of making environmental policies happen in the world (Eden, 2008; Henne, 2010; Lippert, 2018; Eastwood, 2021). Such studies provide grounded analyses which enable broader discussion and conclusions to be drawn from them, rather than starting with abstracted notions and from those notions filling in the gaps with observations. In the context of the social encounters of interest to this thesis, such deductive reasoning risks putting the cart before the horse, especially in the case where intentionality and values may play such an important role. Ethnographic accounts of the environment and environmental policy in action lead to situating the outcome of practices firmly in terms of those practices, rather than something disconnected from what is happening between actors.

In this thesis we have used dramaturgy to provide an ethnographic account of social encounters. As Goffman (1959, p. 246) explains, dramaturgy is a way to analyse "structure[s] of social encounters... The key factor of this structure [being] the maintenance of a single definition of the situation... in the face of a multitude of potential disruptions." The actors in the encounter actively construct a particular reality through their utterances and actions. The only meaningful way to consider the content of the actors' roles and the performance as a whole is through the actors' practices; their practices are performative in nature (Salih, 2007; Skutsch \& Turnhout, 2018). Thus, dramaturgy is a way to examine the practices that happen to ensure a particular representation of reality is put forward. Analysing these structures requires both an understanding of the perspective of the actors themselves, and an analytical frame independent from the actors' perspectives, a characteristic belonging to the broader classification of ethnography (Hammersley, 2006). Thus, dramaturgy in this thesis examines the performative practices of auditors within an ethnographic enquiry.

A dramaturgical perspective, as a particular way to frame ethnographic enquiry, brings its own benefits to examining FSC certification auditing, as a particular type of environmental policy. Goffman (1959) limited dramaturgical analyses to human interactions, with objects serving only as props to further the performance in the hands of the human actors. However, later scholars demonstrated that a dramaturgical analysis need not be limited to human beings, and can in fact include non-human actors that have roles that are pre-constructed by other performances (Hilgartner, 2000; Cho, et al., 2018; Ohi, et al., 2020). Therefore, it is equally valid to consider objects as having agency and influencing behaviour of others in dramaturgy. This was demonstrated by Hilgartner (2000), and is equally demonstrated in the empirical chapters of this thesis. The existence of audit reports, their construction as actors, and the way they must go on to perform something separate from the auditors and auditees that create them demonstrates exactly how the object-actor can be constituted. While this thesis did not focus on the role of the audit report as an actor, it was hinted at in Chapter 4, by 
alluding to the absent audience of the certification body decision-makers, ASI, and the public, resulting in nested performances. Ultimately, the audit report is what is actually seen by those entities. They must encounter it to establish the situation, and the report may, in fact, not perform its role convincingly, leading to the performance of the "good audit" collapsing. By not necessarily prioritizing human actors, dramaturgical analyses open a fruitful line of examination for any social interaction that produces artefacts, so common in modern environmental governance. This means that the possibility of following the influence of actors from one performance to another is in-built to the dramaturgical perspective. As a result, the analysis of a practice can itself be traced further back to other performances without the need to alter analytical frames.

Taking a dramaturgical perspective also brings with it an explicit focus on the interactional, purposeful, directed nature of social interactions. The elements of dramaturgical analysis demand a direct confrontation with the question of "for whose benefit is this performance intended?" Certainly, other ethnographic accounts engage with this (Pentland, 1993; Eden, 2008; Lippert, 2018), but dramaturgy demands an active examination of this topic. Chapter 4 of this thesis demonstrated that each actor can be putting on a performance for the other, while simultaneously cooperating in a performance for the benefit of another audience. The dramaturgical approach highlights the fact that the interactions between actors have directed purpose, even if the actors themselves are unintentionally enacting it. As a result, analysing interactions in this way quickly results in engaging with the topics of what reality is being presented, and for whom. This provides a conceptual edge for the dramaturgical perspective as an innovative way to get at and analyse informational (environmental) governance practices.

The final consideration of dramaturgy as demonstrated in this thesis is its benefit as a well-established conceptual framework. Many works covering disparate topics have utilised the conceptual elements of dramaturgy to examine their topics (Haas \& Shaffir, 1982; Zurcher, 1982; Boje, et al., 2004; Salter, 2008; O'Neill, 2017; Reybold \& Halx, 2018; Visram, et al., 2020). Explicitly dramaturgical analyses of environmental topics, however, remain relatively rare (Hajer, 2005; Lippert, 2013; Suharjito, 2018), and environmental certification like FSC vanishingly rare. Therefore, environmental governance, and certification auditing in particularly, has largely not been examined using this perspective. The wellestablished nature of the conceptual framework makes analysis comparatively simpler, and the intuitive nature of the metaphor of theatre benefits the clarity of analysis, in addition to the theoretical benefits mentioned previously.

Due to these benefits, to bring the discussion full circle, employing the dramaturgical perspective in the field of environmental governance goes some distance to filling the gap left in informational governance as a usable concept. Dramaturgy focuses directly on the how and why informational governance is done, regardless of the practice being examined. It does this while not losing the contextualised practices and values that inform them, resulting in a descriptive but still explanatory analysis of a particular type of informational governance.

Furthermore, it shows in very concrete terms how a performance in front of you can simultaneously involve two interacting teams with their own goals (get certified vs. be professional auditors) and secrets, and a single team with a common goal (produce a good audit report). This thesis, and particularly chapter 4, demonstrates that, in large part, an audit is auditors and auditees performing a particular vision of the world for an unseen audience. This means that audits do not so much represent but constitute forest management realities. Thus, audits are "performative in the sense that they produce effects that cannot be understood with reference to their representational accuracy." (Skutsch \& Turnhout, 2018, p. 3). That is, from the outside, one cannot distinguish between the facts 
and the represented intentions or values of the actors. The "good audit" is constructed by the auditor and the auditee, and the audience that does not get to observe the audit itself is never able to judge how good (or bad) it really was. Dramaturgy examines the practices of individuals, what they do, but also is concerned with the values that inform what is done (Goffman, 1959). Therefore, taking a dramaturgical approach to examining audit practices serves as a way to render the performative nature of the audit explicit, and to bridge to institutional aspect of auditing, such as normative requirements and values taught to auditors, and the messy, chaotic practices of individuals.

Positioning the performative practices squarely in the frame of performance, while done in other fields as mentioned previously, is a novel approach for considering environmental governance in general and auditing in particular. This thesis demonstrates that these fields would benefit from taking a dramaturgical perspective more often for several reasons. First, auditing studies do benefit from the rich description and analysis that is necessary for dramaturgical analysis. This was demonstrated by Pentland (1993), who started examining the ritual auditors go through to "get comfortable with the numbers". As in this thesis, it demonstrates how individual interactions and higher-level activities interact with each other for an audit to be successfully concluded. Using the dramaturgical frame has the benefit of focusing in on what elements go in to "getting comfortable" and allows analysis to disentangle the performative elements of what is said and done from the practice of the audit itself. It grounds the description of the action while allowing for an active engagement with what the actions are trying to perform.

This research contributes to the body of dramaturgical analysis in two distinct ways:

1. It applies the concept of dramaturgy and its associated elements to a field that has rarely been included in dramaturgical analysis, once again demonstrating its utility.

2. It demonstrates how dramaturgy offers insights into information governance processes. Using dramaturgy takes informational governance out of epochalism, allowing effective examination of the practices of how information governs. This forces a change in perspective away from naivety, forcing confrontation with the messiness of everyday life.

\subsection{Reflection on data collection and analytical approaches}

\subsubsection{Data collection}

Very early in the development of this thesis, it was decided that a multi-sited ethnographic/participant observer approach would be necessary to obtain the depth of source data needed to examine auditing. Only by being present in the field during an audit would allow the thesis to "get at" the topic of auditing. We intended to follow the auditors across spatial and temporal boundaries to gain better insight into the practices of auditing. Interviews and focus groups would likely not reveal the actual actions and utterances of the actors, as they would likely filter their responses. However, this decision resulted in the main methodological difficulty of the thesis: gaining access to the field.

First came the difficulty of finding audits in a timeframe that was possible for me to mobilize. The publicly available list of FSC audits was, and still is, limited to a 2-week time horizon. Likewise, contacting the organization that maintained the list (ASI) revealed that they were not at liberty to divulge any audits planned further in the future due to their procedures for public announcement of planned audits. This meant that the only audits that could be reasonably observed had to be within a short airplane ride, and not require any special documentation from an embassy or similar. In fact, this meant that the list was nearly useless for planning research without directly contacting 
certification bodies and asking if they would be willing to share their plans for audits later in the year. In some cases, the certification bodies said they did not plan very far in advance, and in other cases they were not willing to share their plans with a stranger.

Second came the difficulty of auditee discretion on the topic of observers. In the FSC system, anyone may request to observe an audit, but only the accreditation-issuing body (ASI) cannot be refused. If anyone else asks to observe the audit, the auditee can reject the request based on "substantiated concerns" about the observer. Therefore, even if the auditor found the presence of the observer acceptable, the forest manager could refuse. And even if auditees did not express "substantiated" concerns, the auditee being unhappy or uncomfortable with the presences of an observer is a strong disincentive for a researcher who is interested in observing interactions as they would happen even if the observer was absent. A reluctant auditee would be unlikely to act as they normally would in the presence of an observer compared to an auditee that had no reservations about observers.

The final methodological difficulty related to my language limitation. Even if an audit was identified within a reasonable geographical area, and all parties agreed to the presence of an observer, asking for an interpreter to accompany the observer was beyond the pale in most cases. Observers of FSC audits are obliged to "not interfere with the audit/ assessment in any way," and the presence of another person who would need to be speaking at the same time as the auditor/auditee was unacceptable in some cases.

As such, the research quickly became mainly limited to audits planned reasonably far in the future, in a location with a primary language I could understand or where the auditors themselves would need an interpreter to a language I understood, and with auditees that did not have concerns about my role as a researcher. This narrowed the pool of possible audit observations considerably. In practical terms, these limitations due to the methodology resulted in research that was generally difficult to plan, limited to specific locations, and limited in sample size. Analytically, these limitations highlight the fact that, while FSC's audits are an exercise in transparency, FSC's transparency is highly focused. The primary point of view for outsiders is meant to be through the publicly published audit report. It is not a minor effort to be in a position to observe the construction this transparency from the inside.

As a result of these difficulties, I decided to use a different strategy for gaining access to the field. In order to build relationships with auditors and to become "one of them" (which would make it easier to join an audit), I decided to follow an auditor training and become an auditor himself. Being an auditor would make it far less sensitive to join audits. Analytically this proved to be a valuable addition to the body of research in terms of both content and practicality. Content-wise, the training provided insight into the values imbued in FSC's audits and auditors. Also, since there are currently only 11 accredited training providers in the world, it is reasonable to conclude that each trainer reaches many auditors. Therefore, conclusions derived from the training are more likely to be broadly applicable than conclusions drawn from only a small selection of audit observations.

Practically, starting with the training instead of the audit introduced me to many individual auditors and certification bodies in general. Furthermore, it gave me legitimacy by having the certificate that the course had been completed successfully. Instead of being an outsider, I could in some small way be considered one of us, an FSC initiate. This seems to be the case because after struggling to find audits to attend for more than a year, after attending the course and receiving the credentials, which could then be included in my CV, I was able to use this experience as a door-opener to start the conversation of joining audits as an observer. The impacts of this concession early in the research process continued past the expected period of research. While it would be difficult to prove, it seems 
likely that involvement in the training course, and having attended multiple audits, played a role in my obtaining a position within FSC, which later provided further insight reflected in chapter 5 of this thesis. Ultimately, a constraint derived from methodological choices resulted in a more robust and meaningful research experience.

These experiences highlight another insight when considering access to the field in general, not just in this research. By altering the characteristics of the researcher, the relationship between researcher and subject, called positionality, changes (Chacko, 2004; Cross, 2012; Schiffer, 2020). Even relatively extrinsic, transitory qualities of the researcher can have a disproportionate impact on the direction of the research. This is particularly important when being seen as an insider can grant you faster, easier, or more in-depth access to the field (Chavez, 2008). Indeed, in cases where this is the case, it would be best for the researcher to actively consider their positionality and how it can be strategically adjusted to gain access to the field and also how that may impact what data is gathered once in the field (Reyes, 2020). This consideration may very well have a disproportionate impact on the final analysis, even if it is not the subject of that analysis.

\subsubsection{Analytical approach}

The analytical approach of this thesis presented its own challenges. The primary challenge of the thesis was the application of analytical categories to observations. As discussed by Naus (2017), categorizing practices is a touchy or challenging topic, particularly when there is no template to follow. In the empirical chapters of the thesis, several existing categorical frameworks were applied. Two such frameworks were the typology of objectivity (Douglas, 2004) and the dramaturgical framework (Goffman, 1959). Neither of these frameworks have been applied to auditing, and so categorization proved a challenge. As a result, the outcomes, while solidly analysed in their own context, are open to being challenged with the introduction of new contexts, even from within the world of FSC certification auditing studies.

A slightly different challenge applied to the use of modes of auditing framework and distinction between protest and professionalisation. These concepts had already been named in the context of auditing (Power, 1991), and had later been appropriated to discuss FSC's normative processes, but these processes were unrelated to its auditing methods (Elad, 2001). Thus, the challenge came in two forms. The first was to develop a way to better characterise what "protest" and "professionalism" actually mean in the context of environmental auditing. There was a need to characterise them more fully to ensure they could be identified later based on observations of audit practices. In order to do this, it was necessary to sort through existing literature on environmental auditing and determine which characteristics or values were shared, and which were the focus of different groups. As a result, the spectrum of auditing modes and their associated values can only be considered a tentative tool for classifying audits and auditors. Furthermore, it only characterizes the extreme poles of the spectrum with stereotypical values. The observations in chapters 3 and 4 do, however, support the idea that FSC auditing is very much oriented towards objectivity, which sometimes comes at the expense of absolute transparency in that not everything gets recorded in the reports. This framework, then should be further refined in the future.

The second challenge was the weaving of concepts from different disciplines. Constructing a coherent conceptual analytical framework was a complex and messy business, leading to unlikely analytical bedfellows. Analysing the institutional aspects such as normative requirements, structural relationships between actors, and the rules of interaction is usually managed quite differently than individual actions such as the audit activities themselves. Thus, there was a need to find an 
intermediary analytical concept to bridge that gap. The audit and auditor values proved to be a highly useful tool to do just this. It served to connect abstract, institutional aspects of FSC certification to the contextual, individual actions during the audits. This was eased somewhat by focusing strongly on auditors and audits and not attempting a full-system description of FSC.

\subsubsection{Which came first: The research methodology or the analytical approach?}

To return to the overarching iterative nature of gathering and analysing data abductively as summarized in chapter 1 , and especially in Figure $C$, it is instructive to consider the impact it had on the outcomes of this thesis. Throughout the research, I would go into the field with a loose set of concepts to guide and focus their attention. During the auditor training courses analysed in Chapter 3 , these included concepts like "flows of information" and "auditor judgement". The first audit observed, but not featured heavily in Chapter 4, began with internalised notions of "fieldworthiness" and "dramaturgy", both notions gleaned from literature.

However, during the research itself, the focus of note taking would shift as analysis inexorably crept into the observations. In case of the training courses, the idea of watching flows of information was abandoned almost immediately when I noticed the stressed importance and repetition of certain words, phrases, and behaviours among the trainers and trainees. This caused the data collection to begin focusing on those words, phrases, and behaviours beyond even the normal qualitative research approach to note-taking. This then had the effect of directing the analysis of the observations outside the field when I was back from the training. The modification to the original observational conceptual guidance, based on what was observed while the observations were ongoing, impacted the analysis of those observations. This is what gave rise to the importance of "objectivity" in the context of FSC auditors. This, in turn, directed me to engage with different literature seeking extant useful concepts to help explain their observations that were completely unrelated to the original concepts.

To further complicate the matter, these observations and analyses were ongoing while I was drafting the content of chapter 2. The appearance of "objectivity" in that chapter is a direct result of the activities intended for an entirely different chapter.

Similar observations can be made about the audit observations in chapter 4. While "dramaturgy" was certainly present in my mind during the first audit observation, the recording of observations was not hyper-focused on this. By the time the second audit observation came around, however, the analysis of the preceding notes had already taken place, and I had judged that certain parts of the first research excursion, namely interviews outside the audit, did not yield important insights. It was far more valuable to focus on making detailed notes of what was said and what was done in the audit, and to focus particularly on instances during the audit that correlated with elements of Goffman's (1959) dramaturgical framework. Attention would be paid to what things were only said to other auditors, what actions were taken to maintain the distinction between auditor and auditee, and similar. And then, in the middle of the observation, I had the revelation that they were actually witnessing two performances: one of the auditors and auditees performing "good auditor" and "good auditee" for each other, and the collaboration between auditors and auditees to stage the performance of "good audit" for the certification body decision-makers, ASI, and ultimately the general public. This demonstrably had an impact on the analysis of the research notes when I returned to the Netherlands.

These examples demonstrate the highly iterative and intertwined nature of pre-existing knowledge of literature, observation, and analysis in interpretive-qualitative research (Schwartz-Shea \& Yanow, 2011). While this is discussed in even introductory methodological texts (Bryman \& Burgess, 1994; Merriam, 2002; Whiteley \& Whiteley, 2005), the particular way it manifested in the development in 
this thesis is helpful in understanding the way the chapters came together to form a more or less coherent whole. It was not through a highly structured, rigid, one might even say professionalised, process, but rather through a process that sought out meaning and intention with the goal of producing contextually meaningful results, even in protest to the theoretical groundwork that had already taken place.

\subsection{Recommendations for Policy and Research}

\subsubsection{Recommendations for policy}

1. Invest in certification auditors and the audit itself. Carefully consider the values imbued, make those values explicit, and understand the trade-off between them.

Audits and the auditors drive the FSC certification system. Without them, FSC cannot move at all. They fill a key position in fulfilling and making visible the claims and goals that FSC promotes. Therefore, it makes the best sense to ensure that the audit is well supported, and the auditors are well equipped. The values that are taught to auditors and propagated through expectations of behaviour and reporting very strongly impact which information is generated and how it is generated. As a result, those values directly impact what is made visible to the outside. Furthermore, different values are in many ways incompatible. Therefore, promoting audit and auditor values that are not in alignment with the values of the organization will inevitably cause confusion over the purpose and worth of the audits themselves, thereby undermining this key activity.

2. Do not become over-reliant on "professional" characteristics of certification auditing, as they often obscure as much information as they reveal.

There seems to be a trend in FSC certification auditing towards the "professional" with the corresponding shift away from "protest". While replicability and predictability are valuable to ensure the robustness of the auditing system, there comes a point when routinization becomes a detriment. The heterogeneous nature of the information they are faced with means that auditors may not be able to fit everything into pre-defined boxes. The flexibility to seek out situations and issues that are not fully covered by existing regulations and procedures in the name of the progress and good management that FSC promotes is critical to ensuring that these issues are not ignored until it is too late. Likewise, focus on professional characteristics runs the risk of auditors missing auditee starting to simply perform to the targets, instead of aiming to have the impact intended by the target. This consideration should be part of the focus even at the earliest stages of training and would likely help auditors retain focus on the wider objectives and goals of FSC.

3. Take advantage of the information that is present in audit reports. Leverage this to become more impactful in the field of environmental governance.

Audit reports are often static, flat objects. They are PDFs, document files, and spreadsheets. But hidden in those files is an incredible depth of information. FSC has been making efforts recently to make their available data more accessible and dynamic in the form of dashboards about their certificate and risk assessment data, but the audit reports themselves seem relatively ignored. By cracking into the data currently locked inside those reports, a wealth of information about how and why FSC can adapt to changing times could be leveraged. This would serve to provide a data-driven basis for FSC's political decision-making processes as well as putting to use the countless hours of auditor work outside the narrow application of issuing or denying a certificate. 


\subsubsection{Recommendations for research}

1. Compare audit and auditor values across certification schemes.

This thesis has only superficially characterized the values of one certification scheme's audits and auditors. Given how important those values are in what happens during an audit, and how important the audit is for such schemes, it would be valuable to both broaden and deepen their analyses. By examining the audit and auditor values of FSC and other schemes in more depth, a more complete typology of auditing can be developed, which itself can serve as a guide for future research. Comparing between certification scheme audit and auditor values can also serve to highlight further areas of investigation to determine the manifest differences in impact rendered by those differences in values. Thus, examining audit and auditor values within schemes and comparing between them can serve as a jumping off point for research that has direct meaning and impact for the certification schemes themselves.

\section{Assess the impact of environmental certification to see if it is living up to its promises.}

While not a new field of research, the impact of environmental certification considering the scheme's proposed goals should be continually assessed. This thesis has demonstrated that it is possible for there to be a disconnect between the inner workings that drive a scheme and the goals of the scheme itself. Therefore, it is important to regularly assess if the scheme is achieving its intended goals, or instead creating perverse incentives.

4. Examine how, or if, FSC changes in the face of more information and more ways to access and process it.

FSC's area of certified forests and number of chains of custody continues to grow year by year. This is necessarily accompanied by a continual growth in the number of audit reports and more information to cover within the reports themselves. Simultaneously, the hunger for information by decision makers and the public continues to grow. Until now, FSC has only slightly engaged with the vast demand for the information they might have access to and the equally vast source of information they have at their disposal. Changing this engagement might very well result in fundamental changes to FSC as a certification scheme, its governance systems, and its position in the arena of environmental governance. Monitoring and analysing any such changes may prove a fruitful line of enquiry for future research. 


\section{List of References}

Acosta, M. et al., 2019. Discursive translations of gender mainstreaming norms: The case of agricultural and climate change policies in Uganda. Women's Studies International Forum, Volume 74, pp. 9-19.

Arts, B., Behagel, J., Turnhout, E. \& Koning, D., 2014. A practice based approach to forest governance. Forest Policy and Economics, Volume 49, pp. 4-11.

Arts, B., Behagel, J., van Bommel, S. \& Turnhout, E., 2012. Prelude to Practice: Introducing a Practice Based Approach to Forest and Nature Governance. In: B. Arts, et al. eds. Forest and Nature Governance: A Practice Based Approach. Dordrecht: Springer.

Arts, B. \& Buizer, M., 2009. Forests, discourses, institutions: A discursive-institutional analysis of gloabl forest governance. Forest Policy Economics, 11(5-6), pp. 340-347.

Asdal, K., 2008. Enacting things through numbers: Taking nature into account/ing. Geoforum, Volume 39, pp. 123-132.

ASI, 2017. Accreditation Services International. [Online]

Available at: http://www. accreditation-services.com/archives/standards/fsc

[Accessed 01 September 2017].

Auld, G., 2010. Assessing Certification as Governance: Effects and Broader Consequences for Coffee. The Journal of Environment and Development, Volume 19, pp. 215-241.

Auld, G., 2014. Constructing Private Governance. The rise and evolution of forest, coffee, and fisheries certification. New Haven and London: Yale University Press.

Auld, G., Bulbrandson, L. \& McDermott, C., 2008. Certification Schemes and the Impacts on Forests and Forestry. Annual Review of Environment and Resources, Volume 33, pp. 187-211.

Auld, G. \& Bull, G., 2003. The institutional design of forest certification standards initiatives and its influence on the rol of science: the case of forest genetic resources. Journal of Environmental Management, 69(1), pp. 47-62.

Bacchi, C., 2009. Analysing policy. AU: Peason Higher Education.

Bal, R., Bijker, W. \& Hendricks, R., 2002. Paradox van wetenschappelijk gezag. Over de maatschappelijke invloed van adviezen van de Gezondheidsraad.

Barnett, M. \& Duvall, R., 2005. Power in international politics. International organization, 59(1), pp. 39-75.

Bass, S., 1997. Introducing forest certification - A report prepared by the Forest Certification Advisory Group (FCAG) for DGVIII of the European Commission, London, UK: IIED.

Behagel, J., 2012. The politics of democratic governance : the implementation of the Water Framework Directive in the Netherlands. Wageningen: Wageningen University.

Behagel, J., Arts, B. \& Turnhout, E., 2019. Beyond argumentation: a pracite-based approach to environmental policy. Journal of Environmental Policy \& Planning, 21(5), pp. 479-491.

Bhattarai, B. \& Dahal, N., 2005. Forest certification campaign in Nepal, Kathmandu, Nepal: Forest Action. 
Biermann, F. \& Gupta, A., 2011. Accountability and legitimacy in earth system governance: A research framework. Ecological Economies, 70(11), pp. 1856-1864.

BMJ, 2018. Changing how we think about healthcare improvement. The BMJ, p. 361:k2014.

Boedker, C., 2010. Ostensive versus performative approached for theorising accounting-strategy research. Accounting, Auditing \& Accountability Journal, 23(5), pp. 595-625.

Boje, D., Rosile, G. \& Durant, R., 2004. Enron Spectacles: A Critical Dramaturgical Analysis.

Organizational suties, 25(5), pp. 751-774.

Bryman, A. \& Burgess, R., 1994. Reflections on qualitative data analysis. In: A. Bryman \& R. G. Burgess, eds. Analyzing Qualitative Data. New York: Routledge, pp. 216-226.

Butler, L., 2003. Explaining Australia's increased share of ISI publications-the effects of a funding formula based on publication counts. Research Policy, Volume 32, pp. 143-155.

Chacko, E., 2004. Positionality and Praxis: Fieldwork experiences in rural India. Singapore Journal of Tropical Geography, 25(1), pp. 51-63.

Chavez, C., 2008. Conceptualizing from the Inside: Advantages, Complications, and Demands on Insider Positionality. The Qualitative Report, 13(3), pp. 474-494.

Cho, C., Laine, M., Roberts, R. \& Rodrigue, M., 2018. The Frontstage and Backstage of Corporate Sustainability Reporting: Evidence from the Arctic National Wildlife Refuge Bill. Journal of Business Ethics, Volume 152, pp. 865-886.

Chowdhury, M., 2014. Interpretivism in Aiding Our Understanding of the Contemporary Social World. Open Journal of Philosophy, Volume 4, pp. 432-438.

Clarke, J., Bainton, D., Lendavi, N. \& Stubbs, P., 2015. Making policy move: Towards a politics of translation and assemblage. Bristol: Policy Press.

Collins, H. \& Evans, R., 2007. Rethinking Expertise. Chicago: The University of Chicago Press.

Cook, S. \& Wagenaar, H., 2012. Navigating the eternally unfolding present: toward an epistemology of practice. The American Review of Public Administration, 42(1), pp. 3-38.

Cook, W., Turnhout, E. \& van Bommel, S., 2020. Learning to Become an FSC Auditor: Objectivity, Interpretation, and Mastery. Science \& Technology Studies, 33(2), pp. 32-48.

Cook, W., Turnhout, E. \& van Bommel, S., 2021. Performing an FSC audit. Journal of Organizational Ethnography, (Ahead-of-print).

Cook, W., van Bommel, S. \& Turnhout, E., 2016. Inside environmental auditing: effectiveness, objectivity, and transparency. Current Opinion in Environmental Sustainability, Volume 18, pp. 33-39.

Cooper, K. \& White, R., 2012. Qualitative Research in the Post-Modern Era: Contexts of Qualitative Research. 1st ed. New York: Springer.

Counsell, S. \& Loraas, K., 2002. Trading in credibility: The myth and reality of the Forest Stewardship Council, Oslo: The Rainforest Foundation.

Craig, R., Amernic, J. \& Tourish, D., 2014. Perverse Audit Culture and Accountability of the Modern Public University. Financial Accountability \& Management, 30(1), pp. 1-24. 
Crawford, S., 2017. Goodhart's law: When waiting times became a target, they stopped being a good measure. British Medical Journal, Volume 359 :j5425.

Cross, V., 2012. Relational positionality: Conceptualizing research, power, and the everyday politics of neoliberalization in Mexico City. ACME: An International E-Journal for Critical Geographies, 11(1), pp. 110-132.

Dando, N. \& Swift, T., 2003. Transparency and Assurance: Minding the credibility gap. Journal of Business Ethics, Volume 44, pp. 195-200.

de Rond, M. \& Miller, A., 2005. Publish or Perish: Bane or boon of academic life?. Journal of Management Inquiry, 14(4), pp. 321-329.

Delina, L., 2019. ICTs for delivering climate-development strategies: an informational governance framework for local climate-development organizations. Climate and Development.

Desmond, M., 2006. Becoming a firefighter. Ethnography, 7(2), p. 387-421.

Diamantis, D., 1999. The Importance of Environmental Auditing and Environmental Indicators in Islands. Eco-Management and Auditing, Volume 6, pp. 18-25.

Dodge, G., 2006. Final report of the standards review process for the Forest Stewardship Counsil of the United States, Washington DC: FSC US.

Dolowitz, D. \& Marsh, D., 1996. Who learns what from whom: a review of the policy transfer literature. Political Studies, 44(2), pp. 343-357.

Dolowitz, D. \& Marsh, D., 2000. Learning from abroad: The role of policy transfer in contemporary policy-making. Governance, 13(1), pp. 5-23.

Domingues, J., Sampaio, P. \& Arezes, P., 2011. Beyond "audit" definition : a framework proposal for integrated management systems. Reno, Nevada, USA, s.n.

Douglas, H., 2004. The Irreducable Complexity of Objectivity. Synthese, 138(3), pp. 453-473.

Douglas, H., 2009. Science, Policy, and the Value-Free Ideal. Pittsburgh: University of Pittsburgh Press.

Draude, A., 2017. The agency of the governed in transfer and diffusion studies. Third World Thematics: A TWQ Journal, 2(5), pp. 577-587.

Dreyfus, H. \& Dreyfus, S., 2005. Peripheral Vision: Expertise in Real World Contexts. Organizational Studies, 26(5), pp. 779-792.

du Gay, P., 2003. The Tyranny of the Epochal: Change, epochalism and organizational reform. Organization, 10(4), pp. 663-684.

Eastwood, L., 2021. Using Institutional Ethnography to Investigate Intergovernmental Environmental Policy-Making. In: P. Luken \& V. S., eds. The Palgrave Handbook of Institutional Ethnography. s.l.:Palgrave Macmillan, Cham, pp. 193-211.

Ebeling, J. \& Yasué, M., 2008. The effectiveness of market-based conservation in the tropics: Forest certification in Ecuador and Bolivia. Journal of Environmental Management, pp. 1-9. 
Eden, S., 2008. Being Fieldworthy: Environmental Knowledge Practices and the Space of the Field in Forest Certification. Environmental and Planning D: Society and Space, 26(6), pp. 1018-1035.

Elad, C., 2001. Auditing and Governance of the Forestry Industry: Between Protest and Professionalism. Critical Perspectives on Accounting, Volume 12, pp. 647-671.

Ellis, C., Adams, T. \& Bochner, A., 2011. Autoethnography: an overview. Historical Social Research, 36(4), pp. 273-290.

Engberg-Pedersen, L., 2018. Do norms travel? The case of gender in Danish development cooperation. Progress in Development Studies, 18(3), pp. 153-171.

EPA, U. S., 2020. Recommendations of Specifications, Standards, and Ecolabels for Federal Purchasing. [Online]

Available at: https://www.epa.gov/greenerproducts/recommendations-specifications-standardsand-ecolabels-federal-purchasing

[Accessed 17 January 2021].

Epstein, S., 1998. Craft Guilds, Apprenticeship, and Technological Change in Preindustrial Europe. The Journal of Economic History, 58(3), pp. 684-713.

Etzioni, A., 2010. Is Transparency the Best Disinfectant?. The Journal of Political Philosophy, 18(4), pp. 389-404.

Evans, M., 2010. New directions in the study of policy transfer. Oxfordshire: Routledge.

Eyal, G. \& Buchholz, L., 2010. From the Sociology of Intellectuals to the Sociology of Interventions. Annual Review of Sociology, Volume 36, pp. 117-137.

Eykens, J., Guns, R., Rahman, A. \& Engels, T., 2019. Identifying publications in questionable journals in the context of performance-based research funding. PLOS ONE, 14(11).

Ezzamel, M., Robson, K., Stapleton, P. \& McLean, C., 2007. Discourse and institutional change:

'Giving accounts' and accountability. Management Accounting Research, Volume 18, pp. 150-171.

Fairtrade, 2020. The Core Fairtrade Mark. [Online]

Available at: https://www.fairtrade.org.uk/What-is-Fairtrade/Using-the-FAIRTRADE-

Mark\#: :text=The\%20FAIRTRADE\%20Mark\%20is\%20a, people\%20to\%20buy\%20Fairtrade\%20produc ts.

[Accessed 21 June 2020].

Fire, M. \& Guestrin, C., 2019. Over-optimization of academic publishing metrics: Observing Goodhart's Law in action. GigaScience, Volume 8, pp. 1-20.

Fischer, C., Aguilar, F., Jawahar, P. \& Sedjo, R., 2005. Forest Certification: Toward Common Standards?, Washington, D.C.: Resources for the Future.

Fischer, F. \& Forester, J., 1993. The argumentative turn in policy analysis and planning. Durham, NC: Duke University Press.

Fischer, F., Torgerson, D., Durnová, A. \& Orsini, M. eds., 2015. Handbook of critical policy studies. Cheltenham, UK: Edward Elgar Publishing. 
Fischer, H., 1998. Response to disaster: Fact versus fiction \& its perpetuation: The sociology of disaster. Lanham, MD: University Press of America.

Florini, A., 2008. Making transparency work. Global Environmental Politics, 8(2), pp. 14-16.

Florini, A., 2010. The national context for transparency-based global environment governance. Global Environmental Politics, 10(3), pp. 120-131.

Fox, J., 2007. The uncertain relationship between transparency and accountability. Development in Practice, 17(4-5), pp. 663-671.

Franco-Santos, M., 2018. Reviewing and theorizing the unintended consequences of perofrmance managemement systems. International Journal of Management Reviews, 20(3), pp. 696-730.

Freeman, R., 2008. Learning by meeting. Critical Policy Analysis, 2(1), pp. 1-24.

Freeman, R., 2012. Reverb: policy making in wave form. Environment and Planning A, 44(1), pp. 1320.

Freeman, R. \& Maybin, J., 2011. Documents, practices and policy. Evidence and Policy, 7(2), pp. 155170.

FSC AC, 2009a. Forest management evaluations. [Online]

Available at: https://fsc.org/en/document-centre/documents/resource/279

[Accessed 21 June 2020].

FSC AC, 2009b. Forest management evaluations addendum - Forest certification public summary reports. [Online]

Available at: https://fsc.org/en/document-centre/documents/resource/253

[Accessed 21 June 2020].

FSC UK, 2020. Our history. [Online]

Available at: https://www.fsc-uk.org/en-uk/about-fsc/who-is-fsc/our-history

[Accessed 22 August 2020].

FSC, 2015. FSC-STD-01-001 FSC Principles and Criteria for Forest Stewarship. [Online]

Available at: https://fsc.org/en/document-centre/documents/resource/392

[Accessed 04 July 2021].

FSC, 2016. FSC Procedures. [Online]

Available at: https://ic.fsc.org/preview.fsc-pro-20-004-v1-2-en-general-requirements-for-an-fsctraining-programme.a-5679.pdf

[Accessed 14 September 2016].

FSC, 2017a. FSC controlled wood strategy process discussion paper. [Online]

Available at: https://ua.fsc.org/preview.fsc-controlled-wood-strategy-process-discussion-paper-

eng.a-59.pdf

[Accessed 12 June 2021].

FSC, 2017b. FSC IC. [Online]

Available at: https://ic.fsc.org/en/facts-and-figures

[Accessed 01 September 2017]. 
FSC, 2017c. FSC-STD-40-005 V3-1 Requirements for Sourcing FSC Controlled Wood. [Online] Available at: https://fsc.org/en/document-centre/documents/retrieve/3f838e51-be01-46a2-91dc3ea8b1ddcaa4

[Accessed 12 June 2021].

FSC, 2017d. FSC-STD-50-001 V2-0 Requirements for use of the FSC trademarks by certificate holders. [Online]

Available at: https://fsc.org/en/document-centre/documents/retrieve/f5ef795a-2afa-4e62-bd64a048b95525a1

[Accessed 12 June 2021].

FSC, 2018. International Generic Indicators (FSC-STD-60-004 V2-0 EN). [Online]

Available at: https://fsc.org/en/document-centre/documents/resource/262

[Accessed 03 July 2021].

FSC, 2019a. PSU-PRO-10-201 Enquiry Procedure. [Online]

Available at: https://fsc.org/en/document-centre/documents/retrieve/f51bb4cf-7690-4d15-bea0dd0ea62243e8

[Accessed 28 February 2021].

FSC, 2019b. Strategy for FSC Mix products and controlled wood. [Online]

Available at: https://fsc.org/sites/default/files/2019-12/2019-04-

29 Strategy\%20for\%20FSC\%20Mix\%20products\%20and\%20controlled\%20wood\%20\%28EN\%29.pdf

FSC, 2020a. Consultation report: The new MIX label text and the controlled wood statements.

[Online]

Available at: https://fsc.org/sites/default/files/2020-11/Consultation\%20report\%20-

\%20MIX\%20label\%20text\%20and\%20CW\%20statements.pdf

[Accessed 28 February 2021].

FSC, 2020b. FSC Annual Report 2019. [Online]

Available at: https://fsc.org/sites/default/files/2020-

11/FSC\%20ANNUAL\%20REPORT\%202019\%20ENGLISH\%20web.pdf

[Accessed 03 July 2021].

FSC, 2020c. FSC changes MIX label text. [Online]

Available at: https://fsc.org/en/newsfeed/fsc-changes-mix-label-text

[Accessed 28 February 2021].

FSC, 2020d. Looking back on 25 years of FSC. [Online]

Available at: https://fsc.org/en/about-us/25-years-of-fsc

[Accessed 21 June 2020].

FSC, 2021a. Facts \& Figures. [Online]

Available at: https://fsc.org/en/facts-figures

[Accessed 17 January 2021].

FSC, 2021b. Forest management certification. [Online]

Available at: https://fsc.org/en/forest-management-certification

[Accessed 25 April 2021]. 
FSC, 2021c. Forest Stewardship Council Global Strategy 2021-2026. [Online]

Available at: https:/fsc.org/sites/default/files/2020-12/FSC\%20GLOBAL\%20STRATEGY\%2020212026\%20\%28English\%20version\%29\%20\%282\%29.pdf

[Accessed 17 April 2021].

FSC, 2021d. Version comparison: Incorporation of the FSC core labour requirements within the Chain of Custody Normative Framework and Changes to Chain of Custody Requirements. [Online]

Available at: https://fsc.org/sites/default/files/2021-

02/FSC\%20core\%20labour\%20requirements\%20synopsis FINAL.pdf

[Accessed 28 February 2021].

FSC, n.d.. Forest Stewardship Council Global Strategic Plan 2015-2020. [Online]

Available at: https://ic.fsc.org/preview.global-strategic-plan-2015-2020-english.a-5093.pdf

[Accessed 27 June 2021].

Gal, S., 2015. Politics of translation. Annual Review of Anthropology, Volume 44, pp. 225-240.

Gane, N., 2019. Against a descriptive turn. The British Journal of Sociology, 71(1), pp. 4-18.

Garfinkel, H., 1967. Studies in Ethnomethodology. Cambridge: Polity Press.

Gherardi, S. \& Nicolini, D., 2000. To transfer is to transform: The circulation of safety knowledge.

Organization, 7(2), pp. 329-348.

Gibbon, P. \& Ponte, S., 2008. Global value chains: from governance to governmentality?. Economy and Society, 37(3), pp. 365-392.

Gieryn, T., 1999. Cultural boundaries of science, credibility on the line. Chicago: University of Chicago Press.

Gilbert, N. \& Mulkay, M., 1984. Opening Pandora's Box: A sociological analysis of scientist's discourse. Cambridge, UK: Cambridge University Press.

Glaser, B. \& Strauss, A., 1967. The Discovery of Grounded Theory: Strategies for Qualitative Research. Chicago: Aldine.

Goffman, E., 1959. The Presentation of Self in Everyday Life. New ed. Garden City, N.Y.: Doubleday \& Company.

Goffman, E., 1967. Interaction Ritual: Essays on Face-To-Face Behavior. New York, NY: Anchor Books.

Gomart, E. \& Hajer, M., 2003. Is That Politics?. In: B. Joerges \& H. Nowotny, eds. Social Studies of Science and Technology: Looking Back, Ahead. Sociology of the Sciences. Dordrecht: Springer, pp. 3361.

Gond, J., Cabantous, L., Harding, N. \& Learmouth, M., 2016. What do we mean by performativity in organizational and management theory? The uses and abuses of performativity. International Journal of Management Reviews, 18(4), pp. 440-463.

Goodall, H., 2000. Writing the New Ethnography. Walnut Creek: AltaMira Press.

Gray, R., 2000. Current developments and trends in social and environmental auditing, reporting and attestation: A review and comment. International Journal of Auditing, Volume 4, pp. 247-268. 
Griesemer, J., 2020. Taking Goodhart's Law Meta: Gaming, meta-gaming, and hacking academic performance metrics. In: M. Biagioli \& A. Lippman, eds. Gaming the metrics : misconduct and manipulation in academic research. Cambridge, Massachusetts: MIT Press, pp. 77-87.

Grout, P. et al., 1994. 'Auditor Professional Judgement': Implications for Regulations and the Law. Economic Policy, 9(19), pp. 307-351.

Gul, F., Wu, D. \& Yang, Z., 2013. Do Individual Auditors Affect Audit Quality? Evidence from Archival Data. American Accounting Association, 88(6), pp. 1993-2023.

Gupta, A., 2008. Transparency Under Scrutiny: Information disclosure in global environmental governance. Global Environmental Politics, 8(2), pp. 1-7.

Gupta, A. \& Mason, M., 2014. A Transparency Turn in Global Environmental Governance. In: A. Gupta \& M. Mason, eds. Transparency in Global Environmental Governance: Critical Perspectives. s.I.:MIT Press, pp. 3-38.

Gupta, A., Vijge, M., Turnhout, E. \& Pistorius, T., 2014. Making REDD+ Transparent. In: A. Gupta \& M. Mason, eds. Transparency in Global Environmental Governance: Critical Perspectives. Cabridge, MA: MIT Press, pp. 181-201.

Haas, J. \& Shaffir, W., 1982. Taking the Role of Doctor: A dramaturgical analysis of professionalization. Symbolic Interaction, 5(2), pp. 187-203.

Hajer, M. A., 2005. Setting the Stage. A Dramaturgy of Policy Deliberation. Administration \& Society, 36(6), pp. 624-647.

Hajer, M. \& Wagenaar, H., 2003. Deliberative policy analysis. New York: Cambridge University Press. Hammersley, M., 2006. Ethnography: problems and prospects. Ethnography and Education, 1(1), pp. 3-14.

Hansen, E., Fletcher, R., Cashore, B. \& McDermott, C., 2006. Forest Certification in North America, s.l.: Oregon State University Extension Service.

Henne, A., 2010. Green lungs: good firewood, healthy air, and embodied politics. Environment and Planning A, Volume 42, pp. 2078-2092.

Herbohn, K., 2005. A full cost environmental accounting experiment. Accounting, Organizations and Society, Volume 30, pp. 519-536.

Hess, D., 2008. The Three Pillars of Corporate Social Reporting as New Governance Regulation: Disclosure, Dialogue, and Development. Business Ethics Quarterly, 18(4), pp. 447-482.

Hilgartner, S., 2000. Science on stage: expert advice as public drama. Stanford, CA: Stanford University Press.

Hoefnagel, E., de Vos, B. \& Buisman, E., 2013. Marine informational governance, a conceptual framework. Marine Policy, Volume 42, pp. 150-156.

Hoskin, K., 1996. The 'awful idea of accountability': inscribing people into the measurement of objects. In: R. Munro \& J. Mouritsen, eds. Accountability: power, ethos and the technologies of managing. London: International Thomson Business Press, pp. 265-282. 
INAO, 2020. Les signes de qualité et d'origine. [Online]

Available at: https://www.inao.gouv.fr/Les-signes-officiels-de-la-qualite-et-de-l-origine-

SIQO/Appellation-d-origine-protegee-controlee-AOP-AOC

[Accessed 04 September 2020].

Islam, R., 2006. Does more transparency go along with better governance?. Economics \& Politics, 18(2), pp. 121-167.

ISO, 2020. Certification. [Online]

Available at: https://www.iso.org/certification.html

[Accessed 06 July 2020].

ISO, 2020. Forest Certification: In more depth. [Online]

Available at: http://www.fao.org/sustainable-forest-management/toolbox/modules/forest-

certification/in-more-depth/en/

[Accessed 04 September 2020].

Karmann, M. \& Smith, A., 2009. FSC reflected in scientific and professional literature. Literature study on the outcomes and impacts of FSC certification, Bonn: FSC International.

Kingfisher, C., 2013. A policy travelogue: Tracing welfare reform in Aotearoa/New Zealand and Canada. New York, USA and Oxford, UK: Berghahn Press.

Klooster, D., 2000. Institutional Choice, Community, and Struggle: A Case Study of Forest CoManagement in Mexico. World Development, 28(1), pp. 1-20.

Konefal, J. \& Hatanaka, M., 2011. Enacting third-party certification: A case study of science and politics. Journal of Rural Studies, 27(2), pp. 125-133.

Kortelainen, J. \& Rytteri, T., 2017. EU policy on the move-mobility and domestic translation of the European Union's renewable energy policy. Journal of Environmental Policy \& Planning, 19(4), pp. 360-373.

Kosack, S. \& Fung, A., 2014. Does transparency improve governance?. Annual Review of Political Science, Volume 17, pp. 65-87.

Kotzee, B., 2014. Expertise, fluency and social realism about professional knowledge. Journal of Education and Work, 27(2), pp. 161-178.

Kuit, M. \& Waarts, Y., 2014. Small-scale farmers, certification schemes and private standards: Costs and benefits of certification and verification systems for small-scale producers in cocoa, coffee, cotton, fruit and vegetable sectors, Wageningen: Technical Centre for Agriculture and Rural Cooperation.

Lamberton, G., 2005. Sustainability Accounting - a brief history and conceptual framework. Accounting Forum, Volume 29, pp. 7-26.

Latour, B. \& Wollgar, S., 1979. Laboratory life: the social construction of scientific facts. Beverly Hills: Sage.

Law, J., 2009a. Actor Network Theory and Material Semiotics. In: B. Turner, ed. The New Blackwell Companion to Social Theory. Oxford: Wiley-Blackwell, pp. 141-158. 
Law, J., 2009b. Heterogeneitiesdotnet John Law's STS Web Page. [Online] Available at: http://www.heterogeneities.net/publications/Law2009CollateralRealities.pdf [Accessed 5 December 2013].

Law, J. \& Urry, J., 2004. Enacting the social. Economy and Society, 41(4), pp. 390-410.

Lemeilleur, S. \& Alliare, G., 2016. Standardisation and guarantee systems: what can participatory certification offer?, Working Paper: UMR MOISA.

Lendvai, N. \& Stubbs, P., 2007. Policies as translation: situating transnational social policies. In: S. Hodgson \& Z. Irving, eds. Policy reconsidered: Meanings, politics and practices. Bristol: Policy Press, pp. 173-190.

Ling, T., 2010. Performance Audit: Contributing to accountability in democratic government. Prague, European Evaluation Society.

Lippert, I., 2013. Enacting Environments: An ethnography of the digitisation and naturalisation of emissions. Ausburg: University of Ausburg.

Lippert, I., 2018. On Not Muddling Lunches and Flights: Narrating a number, qualculation, and ontologising troubles. Science \& Technology Studies, 31(4), pp. 52-74.

Li, T., 2007. The Will to Improve: Governmentality, Development, and the Practice of Politics. Durham: Duke University Press.

Long, N. \& van der Ploeg, J., 1989. Demythologizing planned intervention: an actor perspective. Sociologia Ruralis, 29(3-4), pp. 226-249.

Lundberg, K. \& Syltevik, L., 2016. Everyday interaction at the front-line: The case of the Norwegian all-in-one bureaucracy. Journal of Organizational Ethnography, 5(2), pp. 152-166.

Maletz, O. \& Tysiachniouk, M., 2009. The effect of expertise on the quality of forest standards implementation: The case of FSC forest certification in Russia. Forest Policy and Economics, Volume 11, pp. 422-428.

Maltby, J., 1995. Environmental audit: theory and practices. Managerial Auditing Journal, 10(8), pp. 15-26.

Marcus, G., 1995. Ethnography in/of the World System: The Emergence of Multi-Sited Ethnography. Annual Review of Anthropology, Volume 24, pp. 95-117.

Markopoulos, M., 1998. The Impacts of Certification on Community Forest Enterprises: A Case Study of the Lomerío Community Forest Management Project, Bolivia, London: Department for International Development.

Marx, A. \& Cuypers, D., 2010. Forest certification as a global environmental governance tool: What is the macro-effectiveness of the Forest Stewarship Council?. Regulation \& Governance, Volume 4, pp. 408-434.

Mason, M., 2008. Transparency for whom? Information disclosure and power in global environmental governance. Global Environmental Politics, 8(2), pp. 8-13.

Mathies, C., Kivistö, J. \& Birnbaum, M., 2020. Following the money? Performance-based funding and the changing publication patterns of Finnish academics.. High Education, Volume 79, p. 21/37. 
McCann, E., 2011. Urban policy mobilities and global circuits of knowledge: Toward a research agenda. Annals of the Association of American Geographers, 101(1), pp. 107-130.

McCormick, D., 2007. Dramaturgical analysis of organizational change and conflict. Journal of Organizational Change Management, 20(5), pp. 685-699.

McDermott, C., 2003. Personal trust and trust in abstract systems: A study of Forest Stewardship Council-accredited certification in British Columbia, Department of Forest Resources Management: University of British Columbia.

McDermott, C., 2012. Trust, Legitimacy and Power in Forest Certification: A case study of the FSC in British Columbia. Geoforum, Volume 43, pp. 634-644.

McGrail, M., Rickard, C. \& Jones, R., 2006. Publish or Perish: A systematic review of interventions to increase academic publication rates. Higher Edutation Research \& Development, 25(1), pp. 19-35.

McKenzie, M., 2017. Affect theory and policy mobility: challenges and possibilities for critical policy research. Critical Studies in Education, 58(2), pp. 187-204.

Mechel, F., Meyer-Ohlendorf, N. \& Sprang, T. R., 2006. Public Procurement and Forest Certification: Assessing the implications for policy, law and international trade, Berlin: Ecologic Institute.

Merriam, S., 2002. Introduction to qualitative research. In: S. Merriam, ed. Qualitative Research in Practice: Examples for discussion and analysis. San Francisco, USA: Jossey Bass, pp. 3-17.

Millard, A., 2005. Makers' marks, owners' names and individual identity. In: C. Suter \& C. Uehlinger, eds. Crafts and Images in Contact: Studies on Eastern Mediterranean art of the first millennium BCE. Fribourg, Switzerland / Göttinen, Germany: Academic Press / Vandenhoeck Ruprecht, pp. 1-22.

Miller, P. \& O'Leary, T., 1987. Accounting and the construction of the governable person. Accounting, organizations and society, 12(3), pp. 235-265.

Mol, A., 2008. Environmental Reform in the Information Age. The Contours of Informational Governance. New York: Cambridge University Press.

Mol, A., 2009. Environmental governance through information: China and Vietnam. Singapore Journal of Tropical Geography, 30(1), pp. 114-129.

Moore, S. E., Cubbage, F. \& Eicheldinger, C., 2012. Impacts of Forest Stewardship Council (FSC) and Sustainable Forest Initiative (SFI) Forest Certification in North America. Journal of Forestry, 110(2), pp. 79-88.

Mukhtarov, F., 2014. Rethinking the travel of ideas: policy translation in the water sector. Policy \& Politics, 42(1), pp. 71-88.

Mukhtarov, F., de Jong, M. \& Pierce, R., 2017. Political and ethical aspects in the ethnography of policy translation: Research experiences from Turkey and China. Environment and Planning A, 49(3), pp. 612-630.

Naus, J., 2017. The social dynamics of smart grids: On households, information flows \& sustainable energy transitions. Wageningen: Wageningen University.

Newburn, T., Jones, T. \& Blaustein, J., 2017. Policy mobilities and comparative penality. Theoretical Criminology, 22(4), pp. 563-581. 
NewGov, 2005. NEWGOV: New modes of governance, Berlin: Free University of Berlin.

Newton, A., 2011. Implications of Goodhart's Law for monitoring global biodiversity loss. Conservation Letters, Volume 4, pp. 264-268.

Neyland, D., 2007. Acheiving Transparency: The Visible, Invisible and Divisible in Academic Accountability Networks. Organization, 14(4), pp. 499-516.

Nicolini, 2012. Introduction. In: Practice Theory, Work, and Organization: An introduction. Oxford: Oxford University Press, pp. 1-19.

Nitkin, D. \& Brooks, L., 1998. Sustainability Auditing and Reporting: The Canadian Experience. Journal of Business Ethics, Volume 17, pp. 1499-1507.

Nsekyiere, E. \& Simula, M., 2000. Comparative Study on the Auditing Systems of Sustainable Forest Management, s.l.: International Tropical Timber Organization.

Nyqvist, A., 2015. The corporation performed: minutes from the rituals of annual general meetings. Journal of Organizational Ethnography, 4(3), pp. 341-355.

O’Brien, T., Payne, S., Nolan, M. \& Ingleton, C., 2010. Unpacking the politics of evaluation: a dramaturgical analysis. Evaluation, 16(4), pp. 431-444.

Ohi, F., Schoch, L. \& Fincoeur, B., 2020. The toxic data of "clean sport" and IOC's and WADA's quest for credibility. International Review for the Sociology of Sport.

O'Neill, M., 2017. Police community support officers in England: a dramaturgical analysis. Policing and Society, 27(1), pp. 21-39.

Orlikowski, 2000. Using technology and constituting structures: A practice lens for studying technology in organizations. Organization Science, 11(4), pp. 404-428.

Osborne, T., 1998. Aspects of Enlightenment. London: UCL Press.

Peck, J. \& Theodore, N., 2012. Follow the policy: A distended case approach. Environment and Planning A, 44(1), pp. 21-30.

Pentland, B., 1993. Getting comfortable with the numbers : Auditing and the micro-production of macro-order. Accounting Organisations and Society, 18(7/8), pp. 605-620.

Porter, T., 1995. Trust in Numbers: The Pursuit of Objectivity in Science and Public Life. Princeton, NJ: Princeton University Press.

Power, M., 1991. Auditing and Environmental Expertise: Between protest and professionalisation. Accounting, Auditing \& Accountability Journal, 4(3), pp. 30-41.

Power, M., 1995. Auditing, expertise and the sociology of technique. Critical Perspectives on Auditing, Volume 6, pp. 317-339.

Power, M., 1996. Making things auditable. Accounting, Organizations and Society, 21(2-3), pp. 289315.

Power, M., 1997. The Audit Society: Rituals of Verification. New York: Oxford University Press. 
Power, M., 2000. The Audit Society - Second thoughts. International Journal of Auditing, Volume 4, pp. 111-119.

Power, M., 2003. Auditing and the production of legitimacy. Accounting, Organizations and Society, 28(4), pp. 379-394.

Prior, J., 2007. Makers and Their Marks: The Ancient Function and Modern Usefulness of Stamps on Glass and Ceramics. Victoria, Australia: University of Victoria.

Prisupta, A., Lamers, M. \& Amelung, B., 2016. Private informational governance in Post-Soviet waters: Implications of the marine Stewardship Council verification in the Russian Barents Sea region. Fisheries Research, Volume 182, pp. 128-135.

Rametsteiner, E. \& Simula, M., 2003. Forest Certification - an instrument to promote sustainable forest management?. Journal of Environmental Management, Volume 67, pp. 87-98.

Rau, S. \& Moser, D., 1999. Does Performing Other Audit Tasks Affect Going-Concern Judgments?. The Accounting Review, 74(4), pp. 493-508.

Reybold, L. \& Halx, M., 2018. Staging Professional Ethics in Higher Education: a Dramaturgical Analysis of "Doing the Right Thing" in Student Affairs. Innovative Higher Education, Volume 43, pp. 273-287.

Reyes, V., 2020. Ethnographic toolkit: Strategic positionality and researchers' visible and invisible tools in field research. Ethnography, 21(2), pp. 220-240.

Richardson, G., 2001. A Tale of Two Theories: Monopolies and Craft Guilds in Medieval England and Modern Imagination. Journal of the History of Economic Thought, 23(2), pp. 217-242.

Richardson, G., 2008. Brand Names Before the Industrial Revolution. Cambridge, MA: National Bureau of Economic Research.

Richards, P., 2005. Plant biotechnology and the rights of the poor: a technographic approach. In: M. Leach, I. Scoones \& B. Wynne, eds. Science and citizens, globalization and the challenged of engagement. London, New York: Zed Books, pp. 199-212.

Robertson, M. M., 2006. The nature that capital can see: science, state, and market in the commodification of ecosystem services. Environment and Planning D: Societ and Space, Volume 24, pp. 367-387.

Rogers, E., 1910. Some Historical Matter concerning Trade-Marks. Michigan Law Review, 9(1), pp. 29-43.

Rose, N. \& Miller, P., 1992. Political Power beyond the State: Problematics of Government. The British Journal of Sociology, 43(2), pp. 173-205.

Salih, S., 2007. On Judith Butler and Performativity. In: K. Lovaas \& M. Jenkins, eds. Sexualities and Communication in Everyday Life: A Reader. Thousand Oaks, CA: Sage Publications, pp. 55-68.

Salter, M., 2008. Securitization and desecuritization: a dramaturgical analysis of the Canadian Air Transport Security Authority. Journal of International Relations and Development, Volume 11, pp. 321-349. 
Savage, M., 2009. Against Ephocalism: An analysis of the conceptions of change in British society. Cultural Sociology, 3(2), pp. 217-238.

Savage, M., 2020. What makes for a successful sociology? A response to "Against a descriptive turn". British Journal of Sociology, 21(1), pp. 19-27.

Schiffer, A., 2020. Issues of Power and Representation: Adapting positionality and reflexivity in community-based design. The International Journal of Art \& Design Education, 39(2), p. 39.2.

Schrøder, I., 2019. Making Professional Decisions Account-able. Journal of Organizational Ethnography, 9(1), pp. 110-124.

Schwartz-Shea, P. \& Yanow, D., 2011. Interpretive Research Design. 1st ed. New York: Routledge.

Scott, J., 1998. Seeing Like a State: How Certain Schemes to Improve the Human Condition Have Failed. New Haven: Yale University Press.

Scott, R., 1995. Institutions and Organizations. London: Sage Publications.

Shapiro, S., 1987. The Social Control of Impersonal Trust. American Journal of Sociology, 93(3), pp. 623-658.

Shore, C., 2011. Espionage, policy and the art of government: The British Secret Services and the War on Iraq. Policy Worlds: Anthropology and the analysis of contemporary power, Volume 14, p. 169.

Shove, E., 2010. Beyond the ABC: climate change policy and theories of social change. Environment and planning $A, 42(6)$, pp. 1273-1285.

Shove, E., Pantzar, M. \& Watson, M., 2012. The dynamics of social practice: Everyday life and how it changes. Thousand Oaks, CA: Sage.

Skutsch, M. \& Turnhout, E., 2018. How Redd+ is Performing Communities. Forests, 9(10), p. 638.

Smith, M., Fielder, B., Brown, B. \& Kestel, J., 2001. Structure versus judgement in the audit process: a test of Kinney's classification. Managerial Auditing Journal, 16(1), pp. 40-49.

Smith, P., 1995. On the unintended consequences of publishing performance data in the public sector. International Journal of Public Administration, 18(2-3), pp. 277-310.

Star, L. \& Griesemer, J., 1989. Institutional ecology, 'translations' and boundary objects: amateurs and professionals in Gerkeley's museum of vertebrate zoology, 1907-39. Social Studies of Science, 19(3), pp. 387-420.

Strathern, M., 2000. The Tyranny of Transparency. British Educational Research Journal, 26(3), pp. 309-321.

Stubbs, P., 2014. Ethnographies of aid and development. Suomen Antropologi: Journal of the Finnish Anthropological Society, 39(3), pp. 14-23.

Suchman, L., 2000. Organizing Aligment: A case of bridge-building. Organization, 7(2), pp. 311-327.

Sugiura, K., Yoshioka, T. \& Inoue, K., 2012. Effects of acquiring FSC forest management certification for Japanese enterprises using Smartwood Audits. Journal of Forestry Research, 23(1), pp. 165-172. 
Suharjito, D., 2018. Dramaturgy of agrarian reform in forestry sector in java Indonesia. IOP Conf. Ser.: Earth Environ. Sci., 196 (012046).

Swanson, H., 1988. The Illusion of Economic Structure: Craft Guilds in Late Medival English Towns. Past \& Present, Nov 1988(121), pp. 29-48.

Synnott, T., 2005. Some notes on the early years of FSC. [Online]

Available at: http://www.fsc.org/fileadmin/web-

data/public/document_center/publications/Notes_on_the_early_years_of_FSC_by_Tim_Synnott.pd $\underline{f}$

[Accessed 6 July 2011].

Taylor, D., Sulaiman, M. \& Sheahan, M., 2001. Auditing of environmental management systems: alegitimacy theory perspective. Managerial Auditing Journal, 16(7), pp. 411-422.

Thompson, D. \& Wilson, M., 1994. Environmental auditing: theory and applications. Environmental Management, Volume 18, pp. 605-615.

Tikina, A. \& Innes, J., 2008. A framework for assessing the effectiveness of forest certification. Canadian Journal for Forest Research, 38(6), pp. 1357-1365.

Tollefson, C., Gale, F. \& Haley, D., 2008. Setting the standard-Certification, governance, and the Forest Stewardship Council. Vancouver, BC, Canada: UCB Press.

Tomlinson, P. \& Atkinson, S., 1987. Environmental Audits: Proposed terminology. Environmental Monitoring and Assessment, Volume 8, pp. 187-198.

Tsing, A., 2005. Friction: an ethnography of global connection. Princeton, NJ: Princeton University Press.

Turner, S., 2010. Normal Accidents of Expertise. Minerva, 48(3), pp. 239-258.

Turnhout, E., 2009. The effectiveness of boundary objects: the case of ecological indicators. Science and Public Policy, 36(5), pp. 403-412.

Turnhout, E., Neves, K. \& de Lijster, E., 2014. 'Measurementality' in biodiversity governance: Knowledge, transparency, and the Intergovernmental Science-Policy Platform on Biodiversity and Ecosystem Servcies (IPBES). Environment and Planning A, Volume 46, pp. 581-597.

Turnhout, E., Skutsch, M. \& De Koning, J., 2015. Carbon accounting. In: K. Bäckstrand \& E. Lövbrand, eds. Research Handbook on Climate Governance. Cheltenham: Edward Elgar Publishing Limited, pp. 366-376.

Ungureanu, M., 2012. Role of Environmental Audit in the Modern Enterprise. Annals. Economics Science Series, Issue XVII, pp. 88-95.

Urry, J., 2007. Mobilities. Cambridge: Polity Press.

UTZ, 2020. The UTZ standard. [Online]

Available at: https://utz.org/what-we-offer/certification/the-standard/

[Accessed 21 June 2020]. 
van Bommel, S. \& van der Zouwen, M., 2012. Creating Scientific Narratives: Experiences in Constructing and Interweaving Empirical and Theoretical Plots. In: B. Arts, et al. eds. Forest and Nature Governance. Dordrecht: Springer.

van Egmond, S. \& Zeiss, R., 2010. Modelling for policy, science-based models as performative boundary objects for Dutch policy making. Science Studies, 23(1), pp. 58-78.

Vellema, S., 2008. Postharvest innovation in developing societies: The institutional dimensions of technological change. Stewart Postharvest Review, 4(5), pp. 1-8.

Visram, S. et al., 2020. Health and wellbeing boards as theatres of accountability: a dramaturgical analysis. Local Government Studies.

Wagenaar, H., 2011. Meaning in Action: Interpretation and Dialogue in Policy Analysis. Armonk, NY: ME Sharpe.

Wagenaar, H., 2015. Transforming perspectives: the critical functions of interpretive policy analysis. In: F. Fischer, D. Torgerson, A. Durnová \& M. Orsini, eds. Handbook of Critical Policy Studies. Cheltenham, UK and Northampton, USA: Edward Elgar Publishing Limited, pp. 422-440.

Watson, M. \& Emery, A., 2004. Environmental management and auditing systems: The reality of environmental self-regulation. Managerial Auditing Journal, 19(7), pp. 916-928.

Watson, T., 2012. Making organisational ethnography. Journal of Organizational Ethnography, 1(1), pp. 15-22.

Wenger-Trayner, E. et al., 2015. Learning in landscapes of practice. Boundaries, identity, and knowledgeability in practice-based learning. London: Routledge.

Whiteley, A. \& Whiteley, J., 2005. The Familiarization Study in Qualitative Research: From theory to practice, Perth: Curtin University of Technology, Graduate School of Business.

Wiersum, F., Humphries, S. \& van Bommel, S., 2013. Certification of community forestry enterprises: Experiences with incorporating community forestry in a global system for forest governance. Smallscale Forestry, 12(1), pp. 15-31.

Wood, P., 2009. Public forests, private governance: The role of provincial governments in FSC forest certification. Toronto, ON, Canada: University of Toronto.

Yakhou, M. \& Dorweiler, V., 2004. Environmental Accounting: An Essential Component of Business Strategy. Business Strategy and the Environment, Volume 13, pp. 65-77.

Yanow, D., 1996. How does a policy mean? Interpreting policy and organizational actions. Washington, DC: Georgetown University Press.

Yanow, D., 2000. Conducting interpretive policy analysis. Newbury Park, CA: Sage.

Yanow, D., 2012. Organizational ethnography between toolbox and world-making. Journal of Organizational Ethnography, 1(1), pp. 31-42.

Yanow, D., 2015a. After mastery: insights from practice theorizing. In: R. Garud, B. Simpson, A. Langley \& H. Tsoukas, eds. The Emergence of Novelty in Organizations,. Oxford: Oxford University Press, pp. 273-323. 
Yanow, D., 2015b. Thinking Interpretively: Philosophical Presuppositions and the Human Sciences. In: D. Yanow \& P. Schwartz-Shea, eds. Interpretation and Method: Empirical Research Methods and the Interpretive Turn. Oxon and New York: Routledge, pp. 5-26.

Yanow, D. \& Schwartz-Shea, P., 2006. Interpretation and Method. Empirical Research Methods and the Interpretive Turn. New York: Routledge.

Zurcher, L., 1982. The Staging of Emotion: A dramaturgical analysis. Symbolic Interaction, 5(1), pp. 122. 


\section{Summary of Thesis in English}

Certification of environmental products and management processes is ubiquitous. It has become an important tool in many sectors for improving their practices and gaining access to valuable markets. While some are generally out of the eye of the general public (such as ISO 14001, Green Mark, or IEMA), others are expressly focused on resulting in on-product labels that consumers will see and, theoretically, prefer over non-certified or differently certified products. These kinds of products can be seen in nearly any store: UTZ certified chocolate, MSC certified fish, Fairtrade certified bananas, or FSC certified paper and wood products. All these systems, whether consumer-facing or not, are making claims about the nature of their products and how they were produced. In the field of environmental certification, the claim is usually related to the environmental, social, and economic benefit of the certification over non-certified products. They indicate to the consumer that the product was produced following a set of standards that are better than the conventional production process without the standards. But how can consumers be sure that the goods they are buying were actually produced following those standards?

This is where the compliance audit comes in. In the audit, auditors assess the practices of the producer and either judge the producer to be in compliance with the standards or not. These auditors, accredited authorities on the certification scheme's normative requirements they audit against, serve to bridge the gap between the abstract standards and the highly contextual practices of the producers trying to implement them. They are the watchmen of the system, ensuring the practices on the ground match the requirements. As a result of this process, auditors generate information that is passed on to those who need it in the form of audit reports, which serve to demonstrate that the audit was performed properly. The producer can then use the label, as their claim to compliance has been verified. This system is the primary check which lends credibility to a certification scheme. Auditors and audits are, therefore, the engine that drives these certification processes. Despite their importance, auditing practices are not often the subject of scrutiny and we do not know much about how auditors and audits work in practice.

This thesis examines the Forest Stewardship Council (FSC), one of the most well-known types of consumer-facing certification of forest products. In particular, the thesis focuses on the certification of forests themselves, rather than on the certification of the products' chain of custody. Commonly referred to within FSC as forest management (FM) certification, this part of the FSC certification scheme focuses on certifying practices of forest managers against the 10 Principles and Criteria of FSC. These guiding principles and criteria represent the highest goals of FSC. Material from forests that are verified as being managed in compliance with the principles and criteria can be sold alone or in combination with material from other FM certified forests bearing the FSC label. In some regions of the world (particularly Europe and Asia), it is difficult to find forest-based products like paper that do not have a FSC label. The thesis provides an examination of how the standards as well as the forest management practices that these standards intervene in are enacted in practice and what values are reflected in those enactments.

Following an interpretive-qualitative approach, the thesis primarily presents first-hand, ethnographic and auto-ethnographic accounts of the FSC certification system, particularly paying attention to the role of auditing. The data presented in the thesis are qualitative in nature, relying on descriptions of what was heard or seen in particular situations. In such an approach, the researcher is the primary tool for data collection and analysis, and as such is inherently part of the data itself. This leads to an abductive perspective on data gathering and analysis in which the topic of research typically departs from a surprize or puzzle caused by a mismatch between the literature and experience of the 
researcher rather than from a well-defined hypothesis that can be tested. It also means that the exploration of the case is iterative in nature, as the experience of the researcher builds upon, and is built upon by, existing literature on the topic.

The thesis attempts to answer three research questions:

1. How is 3rd party auditing of the environment conceptualized in literature?

2. How are FSC auditing practices and values performed by auditors?

3. How does FSC auditing connect global standards and local practices?

The research questions are addressed by connecting a constellation of theoretical concepts. The first is informational governance (IG). IG can be conceptualized as institutions and practices that aim to steer peoples' behaviours through information that are themselves organized around and governed by the use of, production of, and control over, information. This description clearly echoes the description of certification schemes and auditing. Certification fundamentally relies on information about compliance which is produced in auditing. Therefore, the thesis focuses on the actual practices of auditing and the ancillary practices around them. Conceptualizing audits as a set of practices in this way means that the meanings of standards are not self-evident and that the standards that are used in the audit should not be considered as external yardsticks that fully determine outcomes. Instead, the standards acquire meaning and are only understandable through the meaning that is constructed in interaction during the audit itself. This is the second theoretical concept of the thesis.

Auditing in FSC and other fields has been subject to scrutiny in both abstract and concrete ways in the past. The thesis draws on the theories developed in the field of critical transparency studies and auditing studies. These fields help conceptualize auditing in two ways. First is the notion that that which reveals can also conceal. Auditors cannot reasonably record and report on every interaction they have to the fullest extent. There is room for discretion exercised by auditors in what information to reveal and which information not to and how and this discretion is informed by values, which is the third key concept of the thesis.

With this in mind, the practices of auditing become acts of performing these values. To examine these practices in this light, the thesis draws on dramaturgy, the fourth key concept. Both using the notion of everyday interactions being performative and a performance and the specific analytical elements of dramaturgical analysis provides a framework for examining the specific actions of auditors and auditees. This does not in any imply that the interactions observed are in some way less real than anything else, but instead provides insight into the nested nature of reality. There is not really a frontstage and a back-stage. It is front-stages all the way down for the purposes of this thesis.

The fifth and final conceptual focus of the thesis aims to, describe how the FSC standards travel between and connect global and local levels. The thesis uses friction to analyse the process by which disagreements between actors' values destabilize the meaning of FSC's normative requirements and turn them into contested object the meaning of which needs to be negotiated between actors. Alignment between actors then allows the system to stabilize and continue functioning. This friction and alignment happens on multiple spatial and temporal scales from standard development processes lasting in the order of months and years to audit interactions lasting days.

Chapter 2 is a review of literature about environmental certification auditing in general. It explores the way in which literature characterises such auditing. The result is three primary characteristics of concern: 1) objectivity/neutrality of the audit and auditor, 2) effectiveness of the audit and the 
certification scheme in attaining its goals, and 3) the transparency of the audit and certification scheme. The chapter goes on to link these characteristics with a concept called the "modes of auditing". At one end of the spectrum is protest-oriented auditing, which is primarily concerned with values of transparency and the aim to reveal as much as possible about the system being audited. At the other end of the spectrum is professionalism-oriented auditing which is primarily characterized by values of objectivity/neutrality and ensuring the audit is replicable and predictable. Somewhere in the middle, or characteristic of both ends of the spectrum, is the characteristic of effectiveness. The result of this conceptual linkage is a nomenclature to discuss audits in terms of their primary values. This will return later in the thesis.

Chapter 3 is an ethnographic account of an auditor training course the author attended twice. It reveals the preoccupation FSC auditors have with objectivity. It demonstrates that FSC auditors are interested in all three types of objectivity: Object-oriented, value-oriented, and process-oriented. Despite the emphasis on objectivity, the chapter also demonstrates awareness that interpretation is indispensable in auditing. In the training, interpretation involved a process by which the auditors make meaning out of what they observe with the aim to ensure any other auditor would reach the same outcome. The combined enactment of objectivity and interpretation is a sign that an auditor has mastered the craft of auditing.

Chapter 4 provides a dramaturgical analysis of FSC FM audits in Africa and Spain, examining how auditors enact the values taught to them in their trainings and the values inherent to the FSC certification requirements. The chapter uses a dramaturgical approach to analyse the interactions between auditors and auditees. The chapter concludes by showing that FSC auditor practices skew towards the professional end of the spectrum of the "modes of auditing", but they are nevertheless keenly aware of the protest-orientation that is needed for the underlying values of FSC to be put forward. Valuing this mode of auditing (ensuring high account-ability) poses a risk to the overall goal of FSC certification (ensuring accountability for forest degradation). Moving away from professionalism is, of course, not without its dangers, but moving entirely away from protestorientation would be a betrayal of FSC's roots.

Chapter 5 examines how the FSC standards travel between and connect global certification systems and local forest management practices. The chapter presents examples of friction the scale of setting standards, operationalising those standards, and friction during the audit and it also shows how alignment is brought about to prevent the scheme from collapsing. While the downward impact of friction and alignment is obvious, the friction in the field during an audit also influences the alignment on the standard-setters, making the situation bi-directional. Furthermore, there is a friction that resides outside the normative framework of FSC: how an inherently consumption-based certification scheme aligns with the goal of good forestry practices, and the original goal of FSC to counter or "turn the tide" on forest degradation and deforestation. Ultimately, this cycle of friction and alignment is in fact necessary for the continued operation of such certification schemes.

By way of answering the research questions, the findings demonstrate how audits are conceptualized in literature as falling somewhere on the protest-professionalism spectrum of auditing modes. These modes have particular values associated with them which can characterize the mode that is preferred or valued. FSC auditors are taught to value characteristics of the professionalism mode of auditing. The audit itself is a space in which auditors need to strike a balance between the modes in order to make the audit contents possible to be accounted for. The actions in an audit resonate not just in the here-and-now but serve to stabilize the overall system. The frictions during an audit are necessary to align and ensure the continuation of the FSC certification system. To allow one mode to override the 
other completely would disconnect the global from the local, leading to a break-down of FSC certification as a meaningful tool for environmental governance (e.g. standards that mean nothing in the field, or entirely bespoke audits and audit reports that have no value to a larger audience).

The concluding chapter of the thesis critiques informational governance as an example of "epochal thinking" and highlights how considering themes of governance by disclosure and the tyranny of transparency ground the discussion in how and why informational governance happens as it does. It argues for the value of using dramaturgy to examine ethnographic studies of the environment due to its versatility and practice-based nature. Finally, it goes on to point out that the mode of auditing employed by auditors inherently contains certain values, and those values impact which information is made available to which audience, and that those values are in no way natural or inevitable. They are chosen and perpetuated in practice. Having a mode of auditing with values that do not match the values of the certification scheme may very well lead to perverse outcomes. Ultimately, the outcomes of certification are dependent on the values that implicitly and explicitly contribute to the mode of auditing that results. These values are of critical importance and should be carefully considered as certification schema continue to develop. 
William Clark Cook

Wageningen School of Social Sciences (WASS)

Completed Training and Supervision Plan

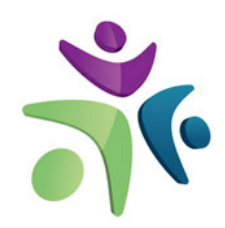

Wageningen School

of Social Sciences

\begin{tabular}{llll}
\hline Name of the learning activity $\quad$ Department/Institute & Year & ECTS* \\
\hline
\end{tabular}

A) Project related competences

Writing proposal

WUR

2012-2013

2

Political ecology

University of Copenhagen \& FNP

2013

8

FSC auditor training

NEPCon

2013

3

Putting meaning into action: Engaging with participants in the field

Interpretive Policy Analysis

2013

(methodology workshop)

'Scripts of Transparency: A

Conference, Vienna, Austria

Spaces of Evidence Conference,

2014

1

dramaturgical analysis of an FSC

auditor training course'

'Performing an FSC Audit'

Brighton, UK

Disclosing Sustainability

2016

Conference, Wageningen, the

Netherlands

\section{B) General research related competences}

\begin{tabular}{llll}
$\begin{array}{l}\text { Research Methodology I: From topic } \\
\text { to proposal }\end{array}$ & WASS & 2012 & 4 \\
$\begin{array}{l}\text { Political Theory, ENP 35306 } \\
\text { WASS Introduction Course }\end{array}$ & WUR & 2012 & 6 \\
$\begin{array}{l}\text { Interpretive methods and } \\
\text { methodologies }\end{array}$ & WASS & 2013 & 1 \\
$\begin{array}{l}\text { Qualitative Data Analysis with Atlas.ti: } \\
\text { a hands-on practical }\end{array}$ & WASS & 2013 & 4 \\
$\begin{array}{l}\text { C) Career related competences/personal development } \\
\text { WASS PhD Council Membership }\end{array}$ & WASS & 2016 & 1 \\
$\begin{array}{l}\text { Guest lecturer and assistant in } \\
\text { 'Strategic Planning in Forest and }\end{array}$ & FNP, WUR & & 4 \\
$\begin{array}{l}\text { Nature Conservation' (FNP-35306) } \\
\text { Supervising } 1 \text { BSc thesis }\end{array}$ & FNP, WUR & $2012-2014$ \\
$\begin{array}{l}\text { Spanish Language Course (B1) } \\
\text { Total }\end{array}$ & Radboud in'to Languages & $2014-2015$ & 3 \\
\hline
\end{tabular}

*One credit according to ECTS is on average equivalent to 28 hours of study load 
The research described in this thesis was financially supported by Wageningen University strategic IP/OP research theme "Informational Governance".

Financial support from Wageningen University for printing this thesis is gratefully acknowledged.

Cover design by ProefschriftMaken

Printed by ProefschriftMaken on FSC-certified paper 
